\title{
Review
}

\section{Neuroprotective Effects of Coffee Bioactive Compounds: A Review}

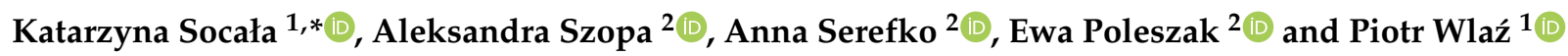 \\ 1 Department of Animal Physiology and Pharmacology, Institute of Biological Sciences, \\ Maria Curie-Skłodowska University, Akademicka 19, 20-033 Lublin, Poland; \\ piotr.wlaz@poczta.umcs.lublin.pl \\ 2 Laboratory of Preclinical Testing, Chair and Department of Applied and Social Pharmacy, \\ Medical University of Lublin, Chodźki 1, 20-093 Lublin, Poland; aleksandra.szopa@umlub.pl (A.S.); \\ anna.serefko@umlub.pl (A.S.); ewa.poleszak@umlub.pl (E.P.) \\ * Correspondence: k.socala@poczta.umcs.lublin.pl
}

Citation: Socała, K.; Szopa, A.; Serefko, A.; Poleszak, E.; Wlaź, P. Neuroprotective Effects of Coffee Bioactive Compounds: A Review. Int. J. Mol. Sci. 2021, 22, 107. https://dx.doi. org/10.3390/ijms22010107

Received: 10 November 2020

Accepted: 22 December 2020

Published: 24 December 2020

Publisher's Note: MDPI stays neutral with regard to jurisdictional claims in published maps and institutional affiliations.

Copyright: () 2020 by the authors. Licensee MDPI, Basel, Switzerland. This article is an open access article distributed under the terms and conditions of the Creative Commons Attribution (CC BY) license (https: / / creativecommons.org / licenses/by/4.0/).

\begin{abstract}
Coffee is one of the most widely consumed beverages worldwide. It is usually identified as a stimulant because of a high content of caffeine. However, caffeine is not the only coffee bioactive component. The coffee beverage is in fact a mixture of a number of bioactive compounds such as polyphenols, especially chlorogenic acids (in green beans) and caffeic acid (in roasted coffee beans), alkaloids (caffeine and trigonelline), and the diterpenes (cafestol and kahweol). Extensive research shows that coffee consumption appears to have beneficial effects on human health. Regular coffee intake may protect from many chronic disorders, including cardiovascular disease, type 2 diabetes, obesity, and some types of cancer. Importantly, coffee consumption seems to be also correlated with a decreased risk of developing some neurodegenerative conditions such as Alzheimer's disease, Parkinson's disease, and dementia. Regular coffee intake may also reduce the risk of stroke. The mechanism underlying these effects is, however, still poorly understood. This review summarizes the current knowledge on the neuroprotective potential of the main bioactive coffee components, i.e., caffeine, chlorogenic acid, caffeic acid, trigonelline, kahweol, and cafestol. Data from both in vitro and in vivo preclinical experiments, including their potential therapeutic applications, are reviewed and discussed. Epidemiological studies and clinical reports on this matter are also described. Moreover, potential molecular mechanism(s) by which coffee bioactive components may provide neuroprotection are reviewed.
\end{abstract}

Keywords: coffee consumption; caffeine; chlorogenic acid; caffeic acid; trigonelline; neuroprotection; Alzheimer's disease; Parkinson's disease; stroke

\section{Introduction}

The genus Coffea L. (family: Rubiaceae, subfamily: Ixoroideae, tribe: Coffeeae) includes at least 125 species which naturally occur in Tropical and East Africa, Tropical Asia, and Australia and also in the Comoros, Madagascar, and the Mascarenes [1]. Only three of these species are used in the commercial coffee production, i.e., Coffea arabica L. (Arabica coffee), Coffea canephora Pierre ex A. Froehner (Robusta coffee), and Coffea liberica Hiern (Excelsa coffee) [2-6].

Coffee beans are obtained from the tart red fruit of the evergreen coffee tree. They are used primarily in the food industry but also in cosmetology and medicine. Nowadays, coffee is considered to be one of the most highly popular and widely consumed pharmacologically active universal beverages $[7,8]$, and its drinking has become a regular part of daily life [9]. It is estimated that in 2019/2020 world coffee consumption amounted to about 10.1 million $\mathrm{kg}$ [10]. Most of all coffee is used due to its psychostimulating effect, taste and aroma as well as health-promoting properties [11].

The health effects of coffee consumption have been investigated in numerous research [12-19]. The outcomes from many of these studies showed the positive impact of 
coffee intake on various aspects of health, e.g., coffee possesses anti-oxidant (especially the medium-roasted coffee) [20] and anti-inflammatory properties [15] and limits the overall risk of stroke and coronary heart disease [21-23], cancer [22,24,25], mortality associated with cardiovascular disease [22,26], Parkinson's [22,27,28] and Alzheimer's disease and other neurodegenerative disorders [29,30], depression and suicide [31,32], liver damage particularly in patients at high risk for liver disease, such as cirrhosis, hepatocellular carcinoma and hepatic injury [22,23,33], and developing type 2 diabetes [7,19,22,23]. However, excessive coffee drinkers also experience negative effects of its use, e.g., caffeine raises concentration of total cholesterol and lowers high density lipoprotein in serum [34] and causes cardiovascular problems, including increased blood pressure, tachycardia, and arrhythmia [21,23,24].

Such multidirectional effects of coffee on the human health and body are due to the fact that it is a complex mixture of bioactive ingredients and both nutrients and non-nutrients which act together [35]. The composition of these elements in coffee beans differs and depends on (1) species of coffee; (2) conditions of roasting of the coffee beans, including temperature, time, and speed of this process; (3) coffee brewing conditions, i.e., the brewing method, coffee/water ratio, temperature of water, size of coffee grind, and duration of this process [35-37]. The most important bioactive compounds in coffee that might serve as physiologically effective agents include caffeine, chlorogenic acids, cafestol and kahweol, trigonelline (Figure 1), and melanoidins (Figure 2) [17,38,39]. The detailed chemical composition and content of active, nutritional, and mineral substances in green and roasted coffee beans and coffee beverage or brew are given in Tables 1 and 2, respectively.

(A)<smiles>CCn1c2c(c(=O)n(C)c1=O)N(C)CC2</smiles><smiles>C[n+]1cccc(C(=O)O)c1</smiles>
trigonelline

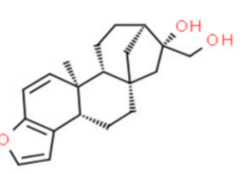

kahweol

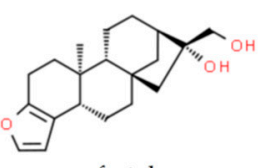

cafestol
(B)
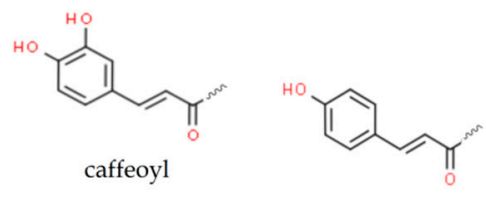

p-coumaroyl
(C)

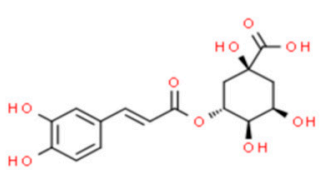

3-O-caffeoylquinic acid

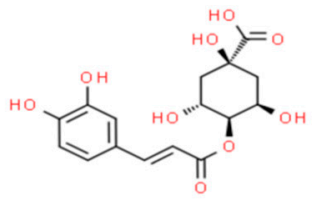

4-O-caffeoylquinic acid

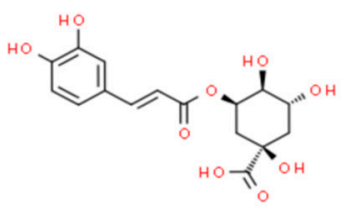

5-O-caffeoylquinic acid

3,4,5-trimethoxycinnamoyl

Figure 1. Structures of the most important bioactive compounds in coffee. (A) structures of key compounds not belonging to chlorogenic acids, (B) general structure of chlorogenic acids and the most important groups found in chlorogenic acids from coffee beans, (C) structures of caffeoylquinic acids found in coffee beans. 

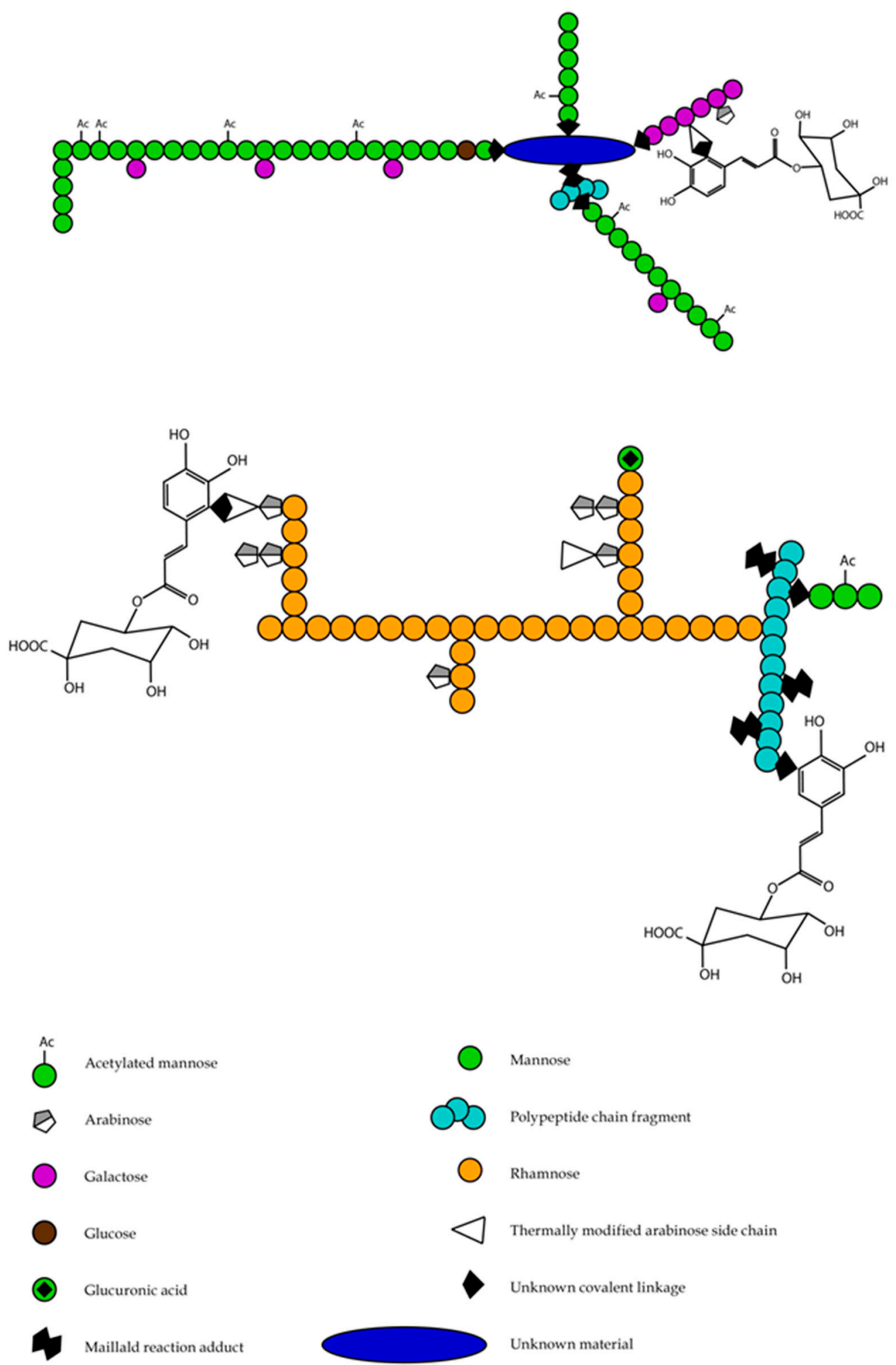

Figure 2. Examples of the structure of coffee melanoidins $[38,39]$.

2. Bioavailability and Pharmacokinetics of Coffee Bioactive Compounds

2.1. Caffeine

Caffeine is rapidly absorbed-primarily from the small intestine, but also partially from the stomach. According to Arnoud [40], the peak plasma concentration of caffeine (4-5 mg/kg) is observed within 30-120 min after administration with half-lives usually 
ranged between 2.5 and $5 \mathrm{~h}$. It seems that caffeine absorption is not influenced by age, gender, genetics, undergoing disease, concomitant drugs, or stimulants such as alcohol and nicotine. Caffeine is distributed to all body fluids (including plasma, saliva, bile, cerebrospinal fluid, breast milk, semen, and umbilical cord blood) and to all tissue organs. Due to its lipophilic properties, it crosses cellular membranes easily, including the placental barrier and the blood-brain barrier. Caffeine's plasma protein binding is limited since its blood/plasma ratio is almost equal to 1 . Physiologically no long-term accumulation of this compound or its metabolites is observed [41-44].

Table 1. The chemical composition of green and roasted coffee beans $[17,35,36]$.

\begin{tabular}{|c|c|c|}
\hline \multirow{2}{*}{ Compounds } & \multicolumn{2}{|c|}{$\%$ Content in Dry Weight of Coffee Beans } \\
\hline & Green Coffee & Roasted Coffee \\
\hline \multicolumn{3}{|l|}{ Carbohydrates } \\
\hline $\begin{array}{ll}\text { - } & \text { polysaccharides-cellulose, arabinogalactan, galactomannan } \\
\text { - } & \text { oligosaccharides-stachyose, raffinose } \\
\text { - } & \text { disaccharides-sucrose } \\
\text { - } & \text { monosaccharides-glucose, galactose, arabinose, fructose, mannose, } \\
\text { mannitol, xylose, ribose }\end{array}$ & 60 & 43 \\
\hline $\begin{array}{ll}\text { Lipids } \\
- & \text { triglyceride } \\
- & \text { sterols-stigmasterol, sitosterol } \\
- & \text { fatty acids-linoleic, linolenic, oleic, palmitic, stearic, arachidic, } \\
& \text { lignoceric, behenic acid } \\
- & \text { fatty acids with pentacyclic } \\
- & \text { diterpenes-cafestol, kahweol } \\
- & \text { waxes } \\
- & \text { tocopherols } \\
- & \text { phosphatides }\end{array}$ & $8-18$ & $10-15$ \\
\hline $\begin{array}{l}\text { Proteins } \\
-\quad \text { amino acids—asparagines, glutamic acid, alanine, aspartic acid, lysine }\end{array}$ & $9-16$ & $7.5-10$ \\
\hline $\begin{array}{l}\text { Other nitrogenous compounds } \\
-\quad \text { caffeine } \\
-\quad \text { trigonelline } \\
-\quad \text { nicotinic acid }\end{array}$ & $\begin{array}{c}1-6 \\
0.9-3.33 \\
0.88-3.42 \\
2 \times 10^{-6}-3 \times 10^{-6}\end{array}$ & $\begin{array}{c}1-2 \\
1 \\
0.7-1 \\
0.01-0.04\end{array}$ \\
\hline Melanoidins & - & 25 \\
\hline Minerals & 4 & $3.7-5$ \\
\hline $\begin{array}{l}\text { Organic and inorganic acids and esters } \\
-\quad \text { chlorogenic acids } \\
-\quad \text { aliphatic acids and quinic acid } \\
-\quad \text { other organic and inorganic acids }\end{array}$ & $\begin{array}{c}6-15 \\
4-14.4 \\
0.7-2.5 \\
2\end{array}$ & $\begin{array}{c}6 \\
1-4 \\
1.4-2.5 \\
<0.3\end{array}$ \\
\hline
\end{tabular}

In humans, pharmacokinetics of caffeine also is not affected by the hepatic first-pass effect, and its elimination is regarded as a first-order process described by a one-compartment open model system within the intake range of $2-10 \mathrm{mg} / \mathrm{kg}$ [45-47]. Caffeine pharmacokinetics may be affected by food and gastric emptying [48], fluid intake [49], and genetic and environmental factors [50], but not by chronovariation [51] or gender [52]. The major caffeine metabolites are paraxanthine, theobromine, and theophylline. All of them are biologically active. Several cytochrome P450 (CYP) isoforms are implicated in caffeine demethylation and C8 hydroxylation (i.e., CYP1A2, CYP1A1, CYP2E1, CYP2D6-Met, and CYP3A), but liver CYP1A2 is mainly responsible for caffeine clearance. Therefore, disturbances of CYP1A2 functioning due to for example genetic polymorphisms or exposure to its inducers significantly influence caffeine metabolism [53,54]. CYP1A2-related modifications 
in caffeine metabolism were observed during pregnancy or in smoking women taking oral contraceptives [55]. Pharmacokinetics of this methylxanthine may also be affected by genetic determinants [56], specific diet (grapefruit juice, quercetin, brassica vegetables, apiaceous vegetables, large quantities of vitamin C, curcumin, turmeric) [57-61] and lifestyle (i.e., smoking) [62], environmental factors, diseases (particularly liver conditions) [63,64] or concurrent drugs (i.e., clozapine, rofecoxib, quinolones, calcium antagonists, and antiarrhythmics) [65-68]. However, at least in humans, aging does not impact caffeine metabolism $[69,70]$. Renal excretion of caffeine dominates in both animals and humans, and ca. $70 \%$ of the received caffeine dose is recovered in urine. Approximately $0.5-2 \%$ of caffeine is excreted in an unchanged form [71].

\subsection{Chlorogenic Acids}

Chlorogenic acids are a family of esters formed between trans-cinnamic acids and quinic acid. They can be divided into three main groups: caffeoylquinic acids, dicaffeoylquinic acids, and feruloylquinic acids. The most abundant chlorogenic acid in coffee beans and other plant sources is 5-O-caffeoylquinic acid, also called chlorogenic acid or wrongly 3-O-caffeoylquinic acid. This is due to the fact that the term "chlorogenic acid" originally referred to 3-O-caffeoylquinic acid. In 1976, the International Union of Pure and Applied Chemistry reversed the order of numbering of atoms on the quinic acid ring and the name for 3-O-caffeoylquinic acid is really 5-O-caffeoylquinic acid [72,73].

In humans, chlorogenic acids are either absorbed untransformed in the stomach and/or duodenum, or absorbed in the stomach and/or small intestine and further metabolized, or subjected to metabolism mediated by gut microbiota with subsequent absorption of catabolites that are not further metabolized or subjected to metabolism mediated by gut microbiota with subsequent absorption of catabolites that are further metabolized (i.e., by reduction, demethylation, dehydroxylation, isomerization, and others) [74]. About $1 / 3$ of consumed chlorogenic acids are absorbed in the small intestine $[75,76]$ and about $2 / 3$ of consumed chlorogenic acids is absorbed in the large intestine. According to the literature data [77-79], absorption of the chlorogenic acids in the stomach and in the intestine occurs mainly by passive diffusion with contribution of the active/facilitated transport for several compounds. Though individual differences are noted $[75,80], \mathrm{C}_{\max }$ of chlorogenic acids that are metabolized in the stomach and/or small intestine is detected relatively quickly, i.e., within 1-2 h. Fatty or sweet food as well as pectins due to diminished rate of gastric emptying can delay detection of their $t_{\max }$ values which may result in prolonged plasma clearance. $C_{\max }$ of chlorogenic acids that require gut microbiota-related metabolism occurs much later, i.e., within $\geq 5 \mathrm{~h}$. Absorption of the chlorogenic acids metabolized by gut microbiota is only observed in patients with intact colon. Metabolites obtained after absorption in the stomach and/or small intestine are cleared from plasma within 5-6 h, but colon-associated metabolites may be detectable in plasma after $24 \mathrm{~h}$. Some metabolites are biphasic and show both an early and a late $t_{\max }$ values. They also can be still present in plasma after $24 \mathrm{~h}$ [81]. Apart from the primary metabolites, chlorogenic acids are also detected in plasma in conjugated forms. Usually chlorogenic acids from green and roasted coffee are absorbed in ca. 33\% [82-84], but in ileostomized patients the absorption range is between $8 \%$ and $34 \%$ [80,84]. Chlorogenic acids mainly undergo phase II metabolism (in the intestine, liver and/or kidney), being sulphated by sulfotransferases (i.e., SULT1A1 and SULT1A3 isoforms) and glucuronidated by uridine $5^{\prime}$-diphosphate (UDP)-glucuronyltransferases (i.e., UGT1A1 and UGT1A9 isoforms) [79,85]. Furthermore, both primary and secondary metabolites can be conjugated with glycine [76,80]. Several authors found that chlorogenic acids can be excreted by digestive fluids and that they can be recycling by enterohepatic recirculation. Urinary excretion of chlorogenic acids occurs primarily in sulphated, glucuronidated and glycine conjugated form. Apart from that, about 40 other compounds identified as the primary or secondary metabolites of chlorogenic acids are found in urine $[76,80,86]$. 
Table 2. The chemical composition of coffee beverages or drew [35].

\begin{tabular}{|c|c|}
\hline Compound & $\begin{array}{l}\text { Content in Coffee Beverages or Brew } \\
\text { Obtained from Blends of Arabica and } \\
\text { Robusta Coffee [mg per } 100 \mathrm{~mL}]\end{array}$ \\
\hline Water & $94,000-98,500$ \\
\hline Aliphatic acids and quinic acid & $692-2140$ \\
\hline $\begin{array}{l}\text { Polysaccharides } \\
\text { (galactomannans and type II arabinogalactans) }\end{array}$ & $200-700$ \\
\hline Lipids & $180-400$ \\
\hline Proteins & $120-400$ \\
\hline $\begin{array}{c}\text { Simple saccharides } \\
\text { (arabinose, mannose, galactose, sucrose) }\end{array}$ & $0-200$ \\
\hline $\begin{array}{c}\text { Bioactive ingredients: } \\
\text { Melanoidins } \\
\text { Chlorogenic acids } \\
\text { Caffeine } \\
\text { Trigonelline } \\
\text { Diterpenes (cafestol and kahweol) } \\
N \text {-methylpyridinium } \\
\text { Serotonin } \\
\text { Polyamines (spermine and spermidine) } \\
\text { Phenolic substances } \\
\beta \text {-carbolins (norharman and harman) } \\
\text { Melatonin }\end{array}$ & $\begin{array}{c}500-1500 \\
32-500 \\
50-380 \\
12-50 \\
0.2-10 \\
2.9-8.7 \\
0-1.4 \\
0.4 \\
0.1-0.2 \\
0.004-0.08 \\
0.006-0.008\end{array}$ \\
\hline $\begin{array}{c}\text { Minerals: } \\
\text { Total ashes } \\
\text { Potassium }(\mathrm{K}) \\
\text { Sodium }(\mathrm{Na}) \\
\text { Phosphorous }(\mathrm{P}) \\
\text { Calcium }(\mathrm{Ca}) \\
\text { Iron }(\mathrm{Fe}) \\
\text { Manganese }(\mathrm{Mn}) \\
\text { Zinc }(\mathrm{Zn})\end{array}$ & $\begin{array}{c}150-500 \\
115-320 \\
1-14 \\
3-7 \\
2-4 \\
0.02-0.13 \\
0.02-0.05 \\
0.01-0.05\end{array}$ \\
\hline $\begin{array}{c}\text { Vitamins: } \\
\mathrm{B}_{3} \\
\mathrm{~B}_{9} \\
\mathrm{C} \\
\mathrm{B}_{2} \\
\mathrm{~K} \\
\mathrm{E} \\
\mathrm{B}_{6} \\
\mathrm{~B}_{1}\end{array}$ & $\begin{array}{c}0.8-10 \\
1 \\
0.2 \\
0.177 \\
0.1 \\
0.01 \\
0.002 \\
0.001 \\
\end{array}$ \\
\hline $\begin{array}{c}\text { Undesirable substances: } \\
\text { Acrylamide } \\
\text { Furan } \\
N \text {-alkanoyl-5-hydroxytryptamides }\end{array}$ & $\begin{array}{l}3.9-840 \\
3.8-262 \\
1.2-34.3\end{array}$ \\
\hline
\end{tabular}

\subsection{Caffeic Acid}

According to Olholf et al. [86] about 95\% of caffeic acid is absorbed in the first parts of the alimentary system in humans, i.e., in the stomach and/or small intestine. Most probably, in the stomach caffeic acid is absorbed by passive non-ionic mechanism, whereas in the small intestine, this compound can be absorbed via active transport. Its maximum plasma concentration occurs within $1 \mathrm{~h}$ after consumption and decreases quite rapidly $[87,88]$. After absorption, caffeic acid undergoes enzymatic conjugation, i.e., methylation, sulphation, and glucuronidation by sulfotransferases, UDP-glucotransferases, and 
catechol-O-methyltransferases, respectively [89]. Manach and colleagues [87] found out that caffeic acid is primarily excreted in urine (up to $27 \%$ ). Free caffeic acid that has not been absorbed in the small intestine can be reduced (by gut microbiota) into dihydrocaffeic acid (3-(3,4-dihydroxyphenyl)-propionic acid) which in turn is transformed into 3-(3-hydroxyphenyl)-propionic acid and 3-phenylpropionic acid. After that, the latter compounds are absorbed in the colon. In the liver, they undergo beta-oxidation, and in consequence, benzoic acid and hydroxybenzoic acid are produced. Benzoic acid and hydroxybenzoic acid conjugated with glycine and the obtained metabolites (i.e., hippuric acid and 3-hydroxyhippuric acid) are excreted with urine [90].

\subsection{Trigonelline}

In humans, plasma levels of trigonelline vary depending on the coffee type, and the amount of consumed coffee is a reliable predictor of plasma trigonelline values [91,92]. Considerably higher $\mathrm{C}_{\max }, \mathrm{C}_{\min }, \mathrm{C}_{\mathrm{avg}}, \mathrm{AUC}_{0-24}$ values as well as the 24-h total excretion concentrations for trigonelline were detected in subjects that drank three cups of espresso coffee per day when compared to volunteers drinking only one cup of espresso coffee with or without two cocoa-based products containing coffee [91]. Most probably, absorption of trigonelline took place primarily in the small intestine, and the circulating levels of this compound are significantly elevated within the first hours after coffee consumption [91,93]. Trigonelline levels seem to drop to the basal values after $24 \mathrm{~h}$ post-coffee exposure, though Bresciani et al. [91] suggested a sort of plasma accumulation after its repeated administration. This feature can be related to the long elimination half-life (ca. $5 \mathrm{~h}$ ) [94]. It seems that trigonelline plasma levels were influenced by food and age since nonfasting subjects presented its higher values (by $20 \%$ ) as compared to the fasting ones. Trigonelline plasma concentrations augmented with age (i.e., by $9 \% / 10$ years) [92]. Furthermore, sex-dependent differences in trigonelline pharmacokinetics were observed, with higher $C_{\max }$ or $C_{\text {avg }}$ values in women [91,93]. In experiments by Yuyama and colleagues [95,96], about $10 \%$ of the oral dose of trigonelline was excreted in urine as $N^{\prime}$-methyl-2-pyridone-5-carboxylic (an oxidation product), and ca. $20 \%$ was recovered unchanged. Sex-dependent differences in relation to trigonelline renal excretion have been detected [93].

\subsection{Kahweol and Cafestol}

There is scarce availability of data on pharmacokinetics of cafestol and kahweol in humans. Most of them are from studies by de Roos et al. [97] carried out on healthy ileostomy volunteers. The authors found that ca. $30 \%$ of consumed cafestol is broken down by gastric juices, whereas about $64-70 \%$ of ingested cafestol is absorbed, with duodenal absorption ranging between 84 and $93 \%$. Furthermore, it was observed that only $1.2 \%$ of ingested cafestol is excreted in a form of glucuronidated or sulphated conjugates in urine. As for kahweol, when consumed, ca. 70-73\% of this compound is absorbed by healthy ileostomists, with the small intestine absorption within the range of $91-95 \%$. The rest of it is degraded by gastric enzymes. Only insignificant amount of consumed kahweol (i.e., $0.4 \%$ ) is excreted in a glucuronidated or sulphated form in urine.

\section{Neurodegenerative Diseases}

Neurodegenerative disorders encompass a heterogeneous group of diseases that are related to progressive deterioration of the structure and functioning of the central or peripheral nervous system. Neurons, synapses, glial cells, and their networks are affected. Usually, accumulation of pathological proteins in both neurons and glial cells of the human brain and the spinal cord or their extracellular depositions (plaques) are responsible for the nervous system damage. Classification of the neurodegenerative disorders depends on clinical symptoms, impaired brain areas, affected cell types, altered proteins, and etiology. Patients suffering from these diseases present movement disorders (such as hyperor hypokinesia, cerebellar dysfunctions, and problems with the upper and lower motor 
neurons), cognitive decline, dementia, and disturbances in many high-order brain functions. Affected brain areas have signs of atrophy and/or defective metabolic activity [98].

\subsection{Dementias, Including Alzheimer's Disease}

According to the literature data [99], about 50 million people worldwide currently suffer from dementia. This number is increasing all the time due to population growth and aging, and most probably by 2050, it will be doubled [100]. Dementia, defined as an acquired chronic or progressive cognitive impairment is one of the major causes of dependence, disability and even mortality in elderly people. In this syndrome, deterioration of cognitive functions is far beyond the aging-related physiological decline, and it affects profoundly the quality of patient's life. Though the consciousness of people with dementia is not usually disturbed, they present deteriorated learning capacity, reduced visuospatial, language, calculation, and judgment skills as well as worsened memory, thinking, and orientation. Furthermore, their emotional control, social behavior, and motivation are also negatively changed. There are several different forms of dementia, including Alzheimer's disease (about $60-70 \%$ of all cases), vascular dementia, dementia with Lewy bodies, frontotemporal dementia, mixed dementia, and others [101].

Typical, sporadic Alzheimer's disease with a late onset is usually associated with an interplay between environmental factors and genetics. Apart from that, a familial form of Alzheimer's disease is also known, which is related to mutations in amyloid precursor protein (APP), PS1 presenilin 1 (PS1), and presenilin 2 (PS2) genes [102]. It has been suggested that cognitive impairment in patients with Alzheimer's disease is induced by the progressive degeneration of the neocortex [103], basal forebrain [104], and the limbic system [105], with an initial damage of synapses, followed by deterioration of axons, and atrophy of dendrites and somas [106-109]. Both "positive" and "negative" lesions, with their characteristic distribution, are implicated in the pathogenesis of Alzheimer's disease. Amongst the positive ones, amyloid plaques and neurofibrillary tangles seem to be most important, but neuropil threads and dystrophic neurites with hyperphosphorylated protein tau are also mentioned. They may co-exist with formation of Hirano bodies, congophilic amyloid angiopathy, astrogliosis, microglial cell activation, and granulovacuolar degeneration. As for the negative lesions, neuronal, synapse, and neuropil loss are observed.

Amyloid plaques are accumulated outside neurons, mainly in the isocortex. However, in advanced cases, they can also be found in the subcortical structure. Amyloid plaques mostly consist of the abnormally folded amyloid beta (A $\beta$ ) peptide with 40 or 42 amino acids. They are produced during metabolism of the amyloid precursor protein. Since $A \beta$ peptide with 42 amino acids is less soluble and presents higher rate of fibrillization, it is more abundant within the plaques [110]. Unfortunately, A $\beta$ pathology is not a reliable indicator of the disease progression, since it relatively quickly reaches the plateau level [111]. Neurofibrillary degeneration seems to be a better marker. A number of studies have revealed that the density and distribution of the neurofibrillary tangles correspond to the severity of the disease. The intracellular neurofibrillary tangles consist of paired helical filaments that are built of the aberrantly misfolded and hyperphosphorylated microtubuleassociated protein tau. Neurofibrillary pathology begins in the allocortex of the medial temporal lobe, and then, it spreads to the associative isocortex. The primary sensory, motor, and visual areas are involved only at the latest stage of the disease [110]. It has been suggested that $A \beta$ plaques perturb communication between neurons in synapses, and consequently, they contribute to cell death and brain atrophy. Tau tangles most probably inhibit transportation of nutrients and other vital compounds inside neurons. Furthermore, it is believed that both amyloid plaques and neurofibrillary tangles stimulate immune cells in microglia, which results in chronic inflammation. Thus, it is certain that both amyloid and tau pathologies are crucial for the development of Alzheimer's disease. However, scientists are not unanimous in relation to which of them is the primary process. The tau hypothesis of Alzheimer's disease assumes that the hyperphosphorylation of tau is the predominant mechanism [112], whereas according to the amyloid hypothesis of Alzheimer's disease, 
accumulation of the amyloid plaque as a result of imbalance between production and clearance of $A \beta$ peptide is the primary cause of the disease with development of neurofibrillary tangles, neuronal dysfunction, and degeneration as the secondary processes [113]. In fact, mutations in $A \beta$ genes can be causative factors of Alzheimer's disease [114], while tau mutations by themselves do not induce this disease [115]. Available literature provides also other explanations for Alzheimer's disease development, suggesting that progressive loss of cholinergic neurons with subsequent reduction in acetylcholine levels in the cerebral cortex [116,117], dysfunction of the brain mitochondria [118], reduced cerebral blood flow [119], or imbalance in metabolic processes (i.e., diabetes, obesity, hypercholesterolemia) $[120,121]$ contributes at least partially to Alzheimer's disease onset. Furthermore, patients with Alzheimer's disease present signs of neuroinflammation [122] and oxidative stress [123].

For the time being, there is no effective prophylactic or causative therapy for Alzheimer's disease. Symptomatic drugs are used, including cholinesterase inhibitors (i.e., donepezil, rivastigmine, and galantamine) and memantine (i.e., an antagonist of the $N$-methyl-Daspartate (NMDA) receptor). Additionally, antipsychotics and antidepressants for the treatment of behavioral symptoms are prescribed [124].

\subsection{Parkinson's Disease}

Parkinson's disease is another progressive and degenerative disorder that globally affects more than 6 million people [125]. It is manifested by both motor and nonmotor symptoms. The motor symptoms include resting tremor (usually unilateral in extremity, though the head, jaw, and tongue can also be involved), bradykinesia, postural instability, and rigidity. Spontaneous movement are significantly decreased, with the loss of facial expression, reduced blink rate, and impaired spontaneous swallowing that results in sialorrhea. Furthermore, hand movements are limited and periods of "freezing" and gait changes are noted. Patients with Parkinson's disease may experience propulsion or retropulsion, and festination [126,127]. Amongst the nonmotor symptoms cognitive decline, anosmia, depression, anxiety, dysautonomia, gastrointestinal and urinary complaints, sleep disturbances, and orthostatic hypotension are listed [128-132]. On the cellular level, substantia nigra and locus coeruleus depigmentation as well as neuronal deficits in the pars compacta of the substantia nigra are observed. These pathologies seem to be related to apoptosis and autophagy [133]. Furthermore, Lewy bodies or Lewy neuritis, i.e., cytoplasmic abnormal aggregations of misfolded $\alpha$-synuclein, are detected in certain regions of the central and peripheral nervous system [134], including basal and celiac ganglia, locus coeruleus, dorsal motor nucleus of the vagus, olfactory bulb, or the intermediolateral nucleus in the spinal cord $[135,136]$. It was demonstrated that phosphorylation and fibrillization of $\alpha$-synuclein induce neuronal death [137]. There is a general notion that the neurodegeneration in Parkinson's disease concerns mainly dopaminergic neurons and thus, it has a noxious impact on dopamine levels and dopamine-related neurotransmission $[138,139]$. However, neuronal deficits and Lewy formations have been found in the noradrenergic, serotonergic, and cholinergic systems, as well [140]. Therefore, the abovementioned pathways can also be affected. Though in some patients Parkinson's disease has a genetic origin, the primary cause of the most Parkinson's disease cases has not been discovered yet. Inflammation, oxidative stress, mitochondrial dysfunction along with disturbances in protein handling and in activity of calcium channels are mentioned as the contributing factors to the observed neuronal loss [134].

Currently, there is no effective cure for Parkinson's disease. Prescribed medications help to alleviate symptoms and improve the quality of patient's life. Most of them stimulate dopaminergic neurotransmission. Levodopa, i.e., a precursor of dopamine, is still considered as the most potent active substance that controls Parkinson's disease manifestations. Usually, it is given with carbidopa that increases its bioavailability and inhibits its peripheral metabolism. Dopaminergic agonists (pramipexole, ropinirole, rotigotine, or apomorphine) activating dopaminergic receptors as well as inhibitors of catechol-O-methyl 
transferase (entacapone, opicapone) and monoamine oxidase aldehyde dehydrogenase B (rasagiline, selegiline, safinamide) that slow down enzymatic degradation of levodopa and dopamine are also used. Rigidity, dystonia, and tremor are usually treated with anticholinergic drugs (trihexyphenidyl and benztropine), whereas hallucinations and delusions are controlled with antipsychotics, such as quetiapine, clozapine, or pimavanserin [141,142].

\subsection{Ischemic Stroke}

It has been estimated that globally about 13-15 million people undergo stroke each year, which results in more than 5 million deaths [143]. About $85 \%$ of strokes are ischemic ones. Ischemic stroke occurs when the blood flow to the brain is decreased. It may be caused by a thrombotic event or an embolic event. In the thrombotic event, the blood flow is obstructed due to vessel problems (i.e., as a consequence of arterial dissection, atherosclerotic disease, fibromuscular dysplasia), whereas in the embolic event, the blood flow is obstructed due to a clot that originated in another location within the body (frequently in the heart) and was dislodged to the brain vasculature. Depending on the affected artery, several ischemic stroke syndromes are diagnosed, including middle cerebral artery infarction, anterior cerebral artery infarction, vertebrobasilar infarction, cerebellar infarction, and lacunar infarction. Thus, the clinical presentation of a given ischemic stroke is different depending on the brain regions that are supplied by the involved vessel. The observed deficits in motor functions and cognition are caused by the loss (necrosis) of brain tissue in the influenced areas. Most frequently, weakness of the face, tongue, and/or laryngeal muscles, speech disorders, contralateral hemiparesis, visual disturbances, impaired coordination and balance, severe headaches, or impaired consciousness are reported [144-148]. The main treatment goal in an acute ischemic stroke is to avoid necrosis of the tissue in the affected region. Therefore, when possible, a thrombolytic compound (i.e., tissue plasminogen activator) is administered. Apart from that, mechanical thrombectomy, aspirin or heparin, and antihypertensive drugs (i.e., labetalol, nicardipine, clevidipine, hydralazine, enalaprilat) are used. In order to obtain neuroprotective effect, drugs should be given as soon as possible after the stroke onset [149-151].

There are several mechanisms responsible for the brain sensitivity to ischemia. One of them is the excitatory activity of glutamate. It has been found that ischemia causes a significant decrease in adenosine-5'-triphosphate (ATP), which in consequence disturbs activity of glutamate transporters responsible for removal of glutamate from the synaptic cleft. Elevated level of glutamate leads to overstimulation of glutamate receptors and excessive increase of calcium levels. These processes generate excitotoxicity, neurons damage and their death [152]. Furthermore, acidification of brain tissue observed after stroke worsens the brain injury $[153,154]$. Most probably, acidosis-mediated stimulation of the so-called acid-sensing ion channels and the subsequent influx of calcium ions are implicated in this pathological mechanism [155]. After ischemic stroke, neuroinflammation, oxidative stress, and disruption of the blood-brain barrier are also detected. Microglia and astrocytes are activated which intensifies production of chemokines and cytokines along with infiltration of leukocytes [156]. Eventually, epigenetic remodeling including DNA methylation and histone modifications may be responsible for memory deficits diagnosed in patients that underwent ischemic stroke [157]. Unfortunately, necrosis of tissues at the site of infarction may instigate further damage of the brain, spreading to the regions anatomically related to that site. This process is called the secondary neurodegeneration [158]. Surprisingly, areas affected by the secondary neurodegeneration share common features with typical neurodegenerative disorders, such as neuroinflammation, progressive neuronal loss, or accumulation of $A \beta$ which is specific to Alzheimer's disease [159]. It seems that the thalamus is particularly vulnerable to the secondary degeneration after stroke. Its disturbances are detected within few weeks after infarction and can persist for several years. Stroke-induced degenerations in thalamus include neuronal loss, severe glial dysfunction [160-162], and A $\beta$ accumulation [163]. Preclinical studies by Ong et al. [164] confirmed that stroke-induced accumulation of $A \beta$ in the thalamus may be connected not 
only with an increase of the high molecular weight soluble amyloids but also with $A \beta$ oligomers and that this form of $\mathrm{A} \beta$ may also be implicated in neuronal loss after stroke. Interestingly, chronic stress [164] or administration of the human bone marrow-derived mesenchymal stem cells [165] in a rodent stroke model aggravate accumulation of $A \beta$ in the thalamus, whereas administration of a $\gamma$-secretase inhibitor [166], calcium channel blocker [167], or autophagy inhibitor [168] reduces amounts of A $\beta$ in the thalamus as well as improves functioning of neurons after stroke.

\subsection{Epilepsy}

One of the most common neurological diseases is epilepsy, which affects about 50 million people worldwide. It has been estimated that ca. 5 million people are diagnosed with epilepsy per year [169]. The disease is characterized by recurrent seizures that can be generalized (tonic-clonic, involving both hemispheres and multiple structures) or focal (limited to one hemisphere). Though up to $70 \%$ of epileptic patients can be seizure-free taking antiepileptic drugs, there is still a great number of people that do not respond to the available treatment. Drugs are selected individually (usually starting with monotherapy) with several different factors taken into consideration, including seizure type, comorbidities, concomitant drugs, patient's lifestyle, and their preferences [170].

Hippocampal sclerosis, i.e., pyramidal cell loss in Ammon's horn, gliosis, granule cell dispersion, and axonal fiber sprouting, has been found in epileptic patients [171-173]. Briellmann et al. [174] and Jackson et al. [175] reported a significant reduction in hippocampal volume and altered hippocampal architecture associated with seizure episodes. Most probably, the seizure-induced neuronal death is caused by upregulated glutamatergic neurotransmission (excitotoxicity) which results in extensive influx of calcium ions into cells, osmolytic stress, and stimulation of cell death pathways [176]. Proliferation and hypertrophy of microglia, astrocytes, and oligodendrocytes detected in patients with epilepsy is associated with elevated levels of proinflammatory cytokines in the brain $[177,178]$. Impairments in the blood-brain barrier as well as changes in the brain vascular system are also observed in epilepsy. However, it has not been determined whether microvessel proliferation and disruption in the blood-brain barrier are the causative factors of seizures or they occur as a consequence of seizures $[179,180]$.

\section{Neuroprotective Effects of Coffee Bioactive Compounds}

Epidemiological studies suggest that regular coffee consumption may be associated with a reduced risk of numerous neurodegenerative disorders (including Parkinson's disease, Alzheimer's disease, and neurocognitive decline), though conflicting results have also been reported [181-183]. When consumed in moderate amount, coffee may reduce dementia and improve cognitive performance [183,184]. Moreover, habitual coffee consumption can potentially decrease the risk of stroke incidence and stroke mortality $[182,183,185]$ and has positive impact on the course of autoimmune diseases such as multiple sclerosis $[183,184]$. Caffeine is the most widely investigated coffee component, and benefits from regular coffee intake are typically attributed to caffeine. However, coffee is a mixture of many bioactive compounds and some of them have the potential to produce neuroprotective effects as well. Here, we provide a comprehensive overview of the data from in vitro and in vivo studies on the neuroprotective potential of the main bioactive coffee components. Studies in humans, although limited, are also discussed.

\subsection{Neuroprotective Effects of Caffeine}

Caffeine (1,3,7-trimethylxanthine), because of its chemical structure, is classified as a purine alkaloid and is the dominant physiologically active compound in coffee beans and soft beverages. This methylxanthine belongs to the most favorable used psychostimulant worldwide $[7,12,186]$. By consuming a cup of brewed coffee (about $430-440 \mathrm{~mL}$ ), an average of $188 \mathrm{mg}$ caffeine is delivered to the body (range 147-259 mg depending on the genus of coffee beans) [187]. Moderate caffeine intake (3-5 cups/24 h) is associated with reducing 
fatigue, revised cognitive, and improved alertness, leading to better yield in psychomotor tasks needing quick response [188,189]. Furthermore, studies have shown that caffeine has antioxidant $[20,190,191]$, anti-inflammatory [15,191], anti-cancer [22,24,25], as well as neuroprotective properties. The mechanisms underlying these caffeine activities have been thoroughly investigated over the last decade. In this paragraph, an overview of the most important preclinical and clinical studies that investigated the neuroprotective effects of caffeine has been presented.

Preclinical studies. Both neuroprotective effects of caffeine and the mechanism of this action have been examined in different experimental models of central nervous system (CNS) diseases. Preliminary studies on a long-term caffeine administration on behavior of naïve rodents revealed no effect on spatial learning and memory responses [192]. However, later, the protective impact of the chronic caffeine administration on the onset of cognitive impairment in Alzheimer's mice has been revealed in several works. Costa et al. [193] demonstrated that a 12-month treatment with caffeine averts memory impairment in aging rodents. The caffeine-treated aging mice presented a similar recognition memory as adult mice and an improved recognition memory when compared to their age-matched control animals. Furthermore, it was noted that caffeine prevents the age-depending enhancement in the hippocampal immunocontent of the brain-derived neurotrophic factor (BDNF) and tirosine kinase receptor (TrkB), which might be a mechanism for caffeine's neuroprotective action [193]. Citied outcomes are corroborated with results of preclinical studies conducted by Arendash et al. [194,195]. This research team demonstrated that giving caffeine in the daily diet to Swedish mutation transgenic mice (animals carrying the

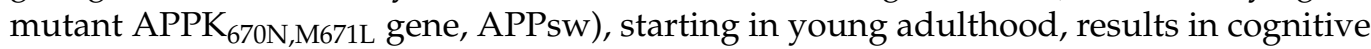
protection in various tests across a multiple of cognitive domains, such as spatial learning, memory, identification, strategy switching, and working memory. Moreover, these comprehensive cognitive profits did not contribute to the occurrence of undesirable effects, such as disturbances in sensorimotor functions or an increase in the level of anxiety, which may be caused by a single caffeine administration [194,195]. More recent research by Arendesh and co-workers [195] indicated that a long-term moderate caffeine consumption has also a desirable effect on already existing Alzheimer's disease symptoms in older (18-19 month old) APPsw mice [195]. They observed that aged APPsw rodents after 4-5 weeks caffeine administration in drinking water characterized significantly better working memory in comparison to the control APPsw animal group [195]. In both studies, they indicated, that prolonged caffeine intake decreases hippocampal $A \beta$ levels, which are most likely associated with reduced expression of both PS1 and $\beta$-secretase- 1 , and hence diminished production of A $\beta$ in caffeine-treated APPsw mice [194,195]. Besides, an evidence that observed $\beta$-secretase- 1 suppression after caffeine treatment involves the cRaf- $1 / N F k B$ (nuclear factor $\kappa$-light-chain-enhancer of activated B cells) inflammatory pathway was presented [195]. Additionally, the ability of caffeine to impair A $\beta$ synthesis (in a concentrationdependent manner) [194] and to decrease total glycogen synthase kinase 3 (GSK-3) levels (in a concentration- and time-dependent manner) [195] were revealed in the nerve cell cultures SweAPP N2a. As emphasized by the authors, it is also probable that the mechanism of caffeine's protective effect on cognition may be due to the restoration of adenosine levels to normal in transgenic mice, despite the lack of effect on the density of $A_{1}$ and $A_{2 A}$ adenosine receptors [194]. Moreover, they showed that chronic caffeine consumption from adulthood to old age does not provide cognitive benefits in normal mice [195]. These findings are in agreement with the outcomes of Dall'Igna et al. [196,197] showing that chronic as well as sub-chronic caffeine administration resulted in a robust protection against $\mathrm{A} \beta$ peptide toxicity in cerebellar neuron cultures [196] and prevented the A $\beta$-induced cognitive impairment [197]. Recent in vitro analyses conducted by Giunta et al. [198] also showed that caffeine prevents neuroblastoma cell death induced by co-exposure to $\mathrm{A} \beta$ and aluminum chloride $\left(\mathrm{AlCl}_{3}\right)$. Additionally, they demonstrated, that caffeine treatment, through a non-selective blockade of $\mathrm{A}_{1}$ and $\mathrm{A}_{2 \mathrm{~A}}$ adenosine receptors, inhibits the co-neurotoxicity of $\mathrm{A} \beta$ and $\mathrm{AlCl}_{3}[198]$. 
The impact of prolonged caffeine administration on memory impairment and oxidative stress generated by aging in rats was investigated by Leite et al. [199]. The obtained outcomes indicated that the memory deficits appearing with age are reversed by oral administration of caffeine. In addition, biochemical studies demonstrated that the applied treatment contributes to the normalization of the enhanced levels of oxygen and nitrogen reactive species (ROS and RNS, respectively) and the inhibited $\mathrm{Na}^{+} / \mathrm{K}^{+}$-ATPase activity noted in the brain of elderly rats [199]. Antioxidant-like properties of chronic caffeine administration as a mechanism of its protective effect on memory deficits, neuroinflammation and neurodegeneration induced by D-galactose treatment were indicated by Ullah et al. [191]. Results of these studies demonstrated that prolonged caffeine administration in the D-galactose-treated rats: (1) reverses oxidative stress via decrease of 8-oxoguanine; (2) attenuates phoshorylation of key stress-responsive kinases level, i.e., C-Jun $N$-terminal kinases (p-JNK); (3) normalizes the level of inflammatory mediators, such as cyclooxygenase-2 (COX-2), nitric oxide synthase-2 (NOS-2), tumor necrosis factor $\alpha($ TNF- $\alpha$ ), and interleukin-1 $\beta$ (IL-1 $\beta) ;(4)$ prevents apoptosis and neurodegeneration (decreased level of cytochrome C, Bax/Bcl2 ratio, caspase-9, caspase-3, and PARP-1); (5) improves the pre-synaptic proteins synaptophysin and post-synaptic density proteins (PSD95) level, and (6) improves spontaneous alternation behavior [191]. Beneficial caffeine effects on the parameters of oxidative stress have also been demonstrated in in vitro examinations using human neuroblastoma cells exposed to the toxic effect of $\mathrm{A} \beta$ and $\mathrm{AlCl}_{3}$. In addition, Giunta et al. [198] presented caffeine ability to prevent the activation of the NF-kB pathway, elevation of both $\beta$-secretase- 1 and APP levels, and ability to inhibit ROS production. Caffeine effects in the cell toxicity model were similar to these noted for an antioxidant- $N$-acetylcysteine and a metal chelator-desferrioxamine [198].

In 2014, Laurent et al. [200] provided the evidence that chronic caffeine intake in drinking water is sufficient to prevent the development of spatial memory deficits in a mice model of progressive Alzheimer's disease-like tau pathology. Further, the improvement of memory was connected with decreased phosphorylation of hippocampal tau and proteolytic fragments. In addition, in the hippocampus of THY-Tau22 mice, caffeine reduced levels of several pro-inflammatory and oxidative stress markers (i.e., CD45, TLR2, $\mathrm{CCl} 4$, and TNF- $\alpha$ ) which were upregulated in animals with Alzheimer's disease [200]. The evidence for the protective activity of caffeine against oxidative stress and Alzheimer's disease-like pathology has also been presented by Prasanthi et al. [201]. They demonstrated that caffeine treatment reversed changes induced by cholesterol-enriched diet, i.e., it decreased ROS generation, glutathione depletion, as well as $\mathrm{A} \beta$ synthesis, whereas it increased adenosine $A_{1}$ receptors concentration in the rabbit hippocampus [201]. Another hypothesis assumes that increased cerebrospinal fluid (CSF) production is a possible mechanism underlying caffeine's protective effect against Alzheimer's disease. Han et al. [202] showed that the long-term caffeine consumption might induce ventriculomegaly and intensify production of CSF as a result of the enhancement of expression of $\mathrm{Na}^{+} / \mathrm{K}^{+}$-ATPase and cerebral blood flow (CBF). In contrast, acute caffeine administration has an opposite effect on the production of CSF [202] (for review see [203]).

Numerous studies have attempted to determine the effects of caffeine consumption on the development and course of Parkinson's disease in various animal models. It has been demonstrated that caffeine attenuated dopaminergic lesions caused by 1-methyl-4-phenyl1,2,3,6-tetrahydropyridine (MPTP) [204-209], 6-hydroxydopamine (6-OHDA) [210,211], and pesticides (paraquat/maneb) [212]. What is more, caffeine pre-treatment decreased neuronal damage and improved motor activity [204] and attenuated dopamine loss [208] and microglia activation in the substantia nigra [213]. Additionally, Sonsalla et al. [213] recorded that both caffeine administration for 1 week and 3 weeks after initiating MPTP infusion (the early stage of loss of nigrostriatal dopamine and the late stage of loss of nigrostriatal dopamine, respectively) decreased the decline of nigral cells in rats by $94 \%$ and $69 \%$, respectively. Reduction in the loss of nigrostriatal dopamine neurons in rats was also observed when caffeine was taken orally after MPTP administration [213]. In 
turn, an acute caffeine pretreatment was demonstrated to be only partially beneficial against neurotoxic changes obtained in the MPTP [209] and 6-OHDA [214] of Parkinson's disease rodent models. Some of these studies have shown that the observed protective activity on dopaminergic neurons/dopamine levels is dose-dependent, and that the maximum neuroprotective effect is achieved after caffeine administration at a daily dose of $10 \mathrm{mg} / \mathrm{kg}$. Moreover, this effect was grater in young (10 weeks) mice in comparison to the old (6-9 months) ones [208]. Moreover, Xu et al. [209] indicated that caffeine metabolites (both theophylline and paraxanthine) also significantly attenuated the MPTP-induced dopamine depletion in mice, thus also providing neuroprotective effects in this model of Parkinson's disease.

The exact mechanism by which caffeine provides neuroprotection against toxins is still unclear. The most prominent theory about antiparkinsonian potential of caffeine is that this methylxanthine acts as an antagonist of adenosine $\mathrm{A}_{2 \mathrm{~A}}$ receptors. In the substantia nigra, caffeine via competitive inhibition of these receptors might prevent the adenosine-mediated neuroinflammatory actions [213]. Laboratory data showed that various $A_{2 A}$ antagonists (both non-selective and selective) protect against acute toxin exposure in Parkinson's disease models [208,212,215-219]. Through blockade of adenosine $A_{2 A}$ receptors, caffeine inhibits activation of adenylyl cyclase and consequently protein kinase A. Therefore, it restrains the extracellular calcium influx into a cell and reduces the excitotoxic glutamate release in the CNS [204,218,220,221]. Moreover, Morelli et al. [222] indicated that caffeine by blocking $\mathrm{A}_{2 \mathrm{~A}}$ receptors and reducing glutamate release contributes to attenuation of microglia activation and production of both cytokines and free radicals, hence precluding further damage of striatal and nigral neurons [222]. Caffeine is also capable to bind to adenosine $\mathrm{A}_{2 \mathrm{~A}}$ receptors situated on astroglial cells, thereby inhibiting their activity and regulating the neuroinflammation generated by astroglia in the vicinity of dopaminergic neurons [214,217]. The essential role of neuronal adenosine $A_{2 A}$ receptors in chronic neurodegeneration was confirmed in mice with the $\mathrm{A}_{2 \mathrm{~A}}$ receptors knockout. Such animals showed resistance to dopaminergic neuron damage caused by a chronic [223], although not an acute [219] exposure to MPTP. However, adenosine $A_{1}$ receptors antagonism did not produce the neuroprotective effect observed after caffeine treatment [215]. Likewise, neurochemical and immunohistochemical studies conducted in recent years indicated that long-term caffeine intake in various animal models of Parkinson's disease: (1) increased dopamine levels, (2) reversed the enhanced dopamine and noradrenalin levels in striatum, (3) improved the hippocampal neuronal viability, (4) increased tyrosine hydroxylase immunoreactivity in the striatum, (5) reduced the number of immunopositive cells for histone deacetylase, (6) decreased the level of pro-inflammatory cytokines, such as TNF- $\alpha$ and IL-1ß [204,210,212-215].

The anti-ischemic effect of caffeine has been examined using animal models of ischemic brain injury. Rudolphi et al. [224] observed that chronic oral pretreatment with caffeine greatly reduces the degree of ischemic necrosis of pyramidal cells of the CA1 hippocampal area in Mongolian gerbils subjected the bilateral carotid occlusion. Moreover, this study outcome provided the evidence that a caffeine-induced upregulation of $\mathrm{A}_{1}$ adenosine receptors in the CNS impairs the level of experimentally induced ischemic brain injury [224]. Similar outcomes following chronic treatment of mice with very low doses of caffeine were reported by Georgiev et al. [225]. In the study by Evans et al. [226], caffeine administered to the cortex $60 \mathrm{~min}$ prior to the development of ischemia decreased the ischemia-induced attenuation of the amplitude of recorded somatosensory evoked potentials and accelerated recovery to control levels [226].

The effect of caffeine on ischemic neuronal injury in rats using magnetic resonance imaging (MRI) and histopathological examination was investigated by Sutherland et al. [227]. Acute caffeine-treated animals exhibited accelerated changes in the MRI scans, while quantification of the histopathological evidence revealed no meaningful distinction in neuronal injury in any brain region in comparison with control-ischemic rats. Moreover, chronic caffeine-treated rodents had significantly minor neuronal damage in all sensitive brain 
areas (including cerebral cortex, striatum, and hippocampus) than either of the other ischemic rats' groups. Additionally, on the basis of the obtained results, they indicated that protection against ischemic injury after chronic administration of caffeine might be effectuated via an enhancement in the concentration of adenosine receptors [227] in the CNS, which is consistent with the caffeine neuroprotection mechanism in ischemic brain injury proposed by Rudolphi et al. [224].

Therapeutic activity of caffeine treatment in neonatal hypoxic-ischemic (HI) injury model was studied by Alexander et al. [228]. Results of this research showed that caffeineuntreated HI animals had significant deficits in the Morris water maze test, which have been attenuated by caffeine administration immediately after the induction of HI. Furthermore, they also found a decrease in cortical volume in the HI saline-treated animals, while cortical volume in the HI caffeine-treated animals was intermediate. Similarly, Kilicdag and co-workers [229] observed the reduced neuronal apoptosis in the developing brain in caffeine-treated rats in a HI neonatal model. Moreover, later findings presented by Potter et al. [230] supported the continued investigation of caffeine as a neuroprotectant in a preterm model of $\mathrm{HI}$. All of these research teams concluded that caffeine might be efficacious in extenuating ischemic brain injury [228-230].

Summary of in vivo studies on the neuroprotective effects of caffeine is presented in Table 3. Clinical studies. A case-control study carried out by Maia and de Mendonça [231] with 74 patients with Alzheimer's disease and 72 healthy subjects aimed to answer the question whether caffeine intake protects from Alzheimer's disease [231]. Consequently, the authors calculated the average daily caffeine intake ( $\mathrm{mg} /$ day) by estimated caffeine content in various food products, which are widely recognized as the primary sources of this methylxanthine (e.g., instantaneous coffee- $60 \mathrm{mg}$, decaffeinated coffee- $3 \mathrm{mg}$, espresso coffee-100 mg, instantaneous tea-20 mg, leaf tea- $-30 \mathrm{mg}$, and cola-drinks-18 mg) and counted how many dosages each patient consumed for the period of 20 years before diagnosis of Alzheimer's disease and the period from early adulthood to 20 years before diagnosis of Alzheimer's disease, as well as for the period after the diagnosis of Alzheimer's disease until the time the questionnaire. This study showed that caffeine intake was inversely correlated with the hazard ratio of developing Alzheimer's diseasean increased caffeine consumption was associated with a $60 \%$ reduction in the risk of Alzheimer's disease (average consumption was $199 \pm 136 \mathrm{mg} /$ day in healthy subjects compared to $74 \pm 98 \mathrm{mg} / \mathrm{kg}$ in patients with Alzheimer's disease) [231]. Caffeine's beneficial effects in Alzheimer's disease patients were also observed in the Canadian Study of Health and Aging. A prospective analysis of risk factors for Alzheimer's disease was conducted on a group of 1023 individuals aged 65 years or older in 1991-1992, and its outcomes showed that coffee consumption was associated with a reduced risk of Alzheimer's disease and amounted to 31\% [232]. Interesting results were also obtained by Eskelinen and co-workers $[233,234]$ in studies assessing the association between the long-term coffee consumption at midlife and Alzheimer's disease/dementia risk in late-life. After an average follow-up of 21 years, in the group of 1409 individuals (534 men and 875 women) aged 50 years in 1972-1977, moderate coffee drinkers ( $3-5$ cups / 24 h) had lower risk of Alzheimer's disease and dementia (by $62-64 \%$ and $65-70 \%$, respectively) in comparison with low coffee consumers $(0-2$ cups $/ 24 \mathrm{~h})$. Results from this clinical study indicate that regular consumption of coffee/caffeine seems to be protective for Alzheimer's disease and dementia $[233,234]$. Likewise, several meta-analyses $[235,236]$ and some systematic reviews [237-239] demonstrated an inverse association between cognitive impairment/decline and the risk of Alzheimer's disease. Furthermore, there are several trials in which caffeine seemed to have no beneficial properties in patients with Alzheimer's disease/dementia. In a large prospective population study (4197 women and 2820 men aged 65 years and over) by Ritchie et al. [240] no impact on dementia incidence in women and men and no association between caffeine intake and cognitive decline in men were found. In turn, in women with a high level of caffeine intake ( $>3$ cups/day) a lesser decline in the visuospatial memory over 4 years than in women consuming $\leq 1$ cup/day was noted. 
Moreover, it was noticed that the protective activity of caffeine increased with age [240]. The meta-analysis of the observational epidemiological research by Kim et al. [241] also showed no significant relationship between caffeine intake from coffee and the hazard ratio of cognitive disorders, including Alzheimer's disease and dementia, as well as cognitive decline, in spite of the $18 \%$ tendency to reduce the risk of developing these disorders.

Numerous clinical studies and meta-analysis/systematic reviews have also linked caffeine use with a lower risk of Parkinson's disease. The possible association between Parkinson's disease risk and caffeinated beverages has been examined since the early 1970s. A significant negative relationship was found for caffeine consumption and hazard ratio of Parkinson's disease in one of the recent systematic review and meta-analysis-in caffeine drinkers the relative risk of Parkinson's disease was reduced by approximately 30-38\% [242-245]. Moreover, in 2014 Qi and Li [245] presented the dose-response metaanalysis which suggested a linear association between the decreased risk of Parkinson's disease and caffeine use, and a non-linear relationship between the decreased risk of Parkinson's disease and coffee consumption. A five-time lower risk of developing Parkinson's disease in 45-68 year old people drinking coffee in the amount of $\geq 794 \mathrm{~g} /$ day (which corresponds to $421 \mathrm{mg}$ of caffeine per day) and a lower risk of Parkinson's disease depending on the amount of consumed caffeine, was reported by Ross et al. [246] based on 27 years of follow-up American Japanese. Convergent results were obtained by Hu et al. [247] in a nearly 13-year control study involving about 14,500 people (approximately 62 years old). The Parkinson's disease hazard ratio was estimated at 1.00, 0.55 , and 0.41 for subjects drinking $0,1-4$ and $\geq 5$ cups of coffee per day, respectively [247]. Liu et al. [248] noted that the level of Parkinson's disease risk reduction is similar in 61 year old women and men consuming $\geq 5$ cups of coffee a day for 10 years. Similarly, Hu et al. [247] reported that the inverse relationship between coffee consumption and the Parkinson's disease hazard ratio did not differ significantly between men and women in Finland. Palacios et al. [249] indicated that men who consumed $\geq 2$ cups of coffee/day (i.e., $274 \mathrm{mg} /$ day of caffeine) had a lower risk of Parkinson's disease than women who consumed 3.2 cups of coffee/day (i.e., $435 \mathrm{mg} /$ day of caffeine) (50\% and 40\% lower risk of Parkinson's disease, respectively).

In 2011, Altman et al. [250] demonstrated that caffeine may have positive effects on some motor as well as nonmotor aspects in patients suffering from Parkinson's disease. Moreover, the maximum tolerated dose of caffeine in Parkinson's disease subjects was 200-400 mg/day [250]. A year later, Postuma et al. [251] in a randomized, controlled trial showed that administration of caffeine at a dose of $200 \mathrm{mg} /$ day for 3 weeks followed by a further 3 weeks at a dose of $400 \mathrm{mg} /$ day significantly improved the overall unified Parkinson's disease rating scale and motor manifestation (by 4.7 and 3.2 points, respectively). However, results of these studies are in contrast to the recent randomized trial that indicated that caffeine did not produce sustained motor improvement in Parkinson's disease [252].

Based on the cited clinical studies, meta-analyses and systematic reviews, it is not possible to establish the biological mechanism(s) behind the correlation between coffee/caffeine intake and the risk of Alzheimer's disease/dementia and/or Parkinson's disease. Tan et al. [253] analyzing the association between caffeine consumption and hazard ratio of Parkinson's disease in both fast and slow caffeine metabolizers suggested that both caffeine and its major metabolite, paraxanthine, have neuroprotective properties. These observations supported experimental evidence obtained in animal models (see preclinical studies). Furthermore, several studies showed that decaffeinated coffee consumption was not associated with neurodegenerative disorders risk, including Alzheimer's disease and Parkinson's disease $[29,249,254]$. Therefore, it can be assumed that caffeine is responsible for the observed inverse correlation between coffee intake and the hazard ratio of Alzheimer's disease and Parkinson's disease incidents.

Until recently, coffee was classified as one of the cardiovascular risk factors [255-259]. While, caffeine is known to increase peripheral vascular resistance, but also to reduce blood flow in the brain through its vasoconstrictive effects and consequently poses a 
risk of hypertension (one of the risk factors of stroke) [260], some epidemiological and cohort studies, as well as meta-analysis found there was no significant association between coffee consumption and stroke risk [261-266], and several showed a prophylactic effect of coffee consumption on stroke incidence [18,185,267-269]. In turn, a study conducted by Mostofsky et al. [270] found an increase in the hazard ratio of an ischemic stroke within 60 min after drinking coffee. Likewise, an acute increase in the risk of ischemic stroke was observed immediately after drinking coffee by Washio et al. [271], but as these authors emphasized, the reason of observed coffee impact may be caused by other factors rather than an elevation in pressure in the cerebral circulation [271].

In 2011, Larsson and Orsini [272] published results of meta-analysis involving 11 prospective studies (a total of 479,689 individuals and 10,003 stroke incidents) which showed a non-linear connection between coffee consumption and the hazard ratio of stroke. In comparison to the absolute risk of total stroke, the relative risk of total stroke amounted to $0.87,0.84,0.88$, and 0.94 for $2,3-4,6$, and 8 cups of coffee per day, respectively. Additionally, estimated hazard ratios were suchlike for hemorrhagic and ischemic stroke [272]. A nonlinear relationship between coffee consumption and a lower risk of stroke (relative risk 0.80 , $95 \%$ confidence interval 0.75 to 0.86 ) was also presented by Poole et al. [18] in umbrella review of meta-analyses (including 201 meta-analyses of observational studies, 67 unique health outcomes, and 17 meta-analyses of interventional studies). A $5 \%$ and $15 \%$ reduction in a relative hazard ratio of stroke with an average consumption of 5 and 3.5 cups per day versus non-drinkers, respectively, were noted by Ding et al. [267] in a large meta-analysis of 36 cohort studies ( 36,352 patients with cardiovascular diseases including stroke). Likewise, a prospective study by Larsson [255] confirmed an inverse relationship, but not very marked, between moderate coffee drinking and the risk of stroke.

Otherwise, in some large cohort studies/meta-analyses the association between coffee consumption and the risk of stroke in women and in men was assessed. Larsson and Orsini [272] found that hazard ratios were similar for women and men at lower coffee intake ( $\leq 2$ cups per day). These results are consistent with those obtained by Lopez-Garcia et al. [261] in the cohort study of women, in which they indicated that longterm coffee drinking was not associated with an increased risk of stroke in women. Furthermore, coffee intake may modestly decrease hazard ratio of stroke in that sex. In this research, women who drank moderate to high amounts of coffee had a lower risk of stroke than women who consumed $<1$ cup/month coffee (relative risks of stroke: $0.98,0.88,0.81$, and 0.80 for women drinking 1-16 cup/month, 20-28 cups/month, $60-90$ cups/month and $\geq 120$ cups/month, respectively) [261]. As for men, when coffee drinkers were compared to non-coffee drinkers, the stroke risk ratio for those drinking 1-6 cups per week, 1-2 cups per day, and $\geq 3$ cups per day were estimated at $0.78,0.67$, and 0.45 , respectively [264]. To explain the likely causal association and elucidate the mechanisms underlying caffeine's protective effects on stroke, further studies are required.

Both clinical and preclinical studies have shown a beneficial effect of the combination of caffeine and alcohol (caffeinol) in acute ischemic stroke. Strong et al. [273] indicated that co-administration of a low dose of ethanol and caffeine protects the CNS from damage produced by focal ischemia in rats. Moreover, caffeine at a dose of $6 \mathrm{mg} / \mathrm{kg}$ with ethanol at a dose of $0.2 \mathrm{~g} / \mathrm{kg}$ in the caffeinol were effective in decreasing volume of cortical infarct and behavioral dysfunction after reversible common carotid/middle cerebral artery occlusion in rat [274]. Beneficial therapeutic effects as well as safety and tolerability of caffeinol observed in animal studies were later examined and confirmed in clinical research $[275,276]$. Zhao et al. [277] based on in vivo studies results suggested that observed anti-excitotoxic activity may be the possible anti-ischemic effect of caffeinol, and caffeine can augment anti-ischemic properties of the NMDA receptors antagonists [277]. 
Table 3. Summary of in vivo studies on the neuroprotective effects of caffeine.

\begin{tabular}{|c|c|c|c|}
\hline Animals & Treatment & Model & Behavioral Tests \\
\hline $\begin{array}{l}\text { APPsw transgenic mice } \\
\text { (background C57, B6, SJL } \\
\text { and Swiss-Webster mice) }\end{array}$ & $\begin{array}{l}0.3 \mathrm{mg} / \mathrm{mL} \text { caffeinated water } \\
\text { beginning at } 4 \text { months of age for } \\
4 \text { months (daily dose of } 1.5 \mathrm{mg} \\
\text { caffeine to each mouse) }\end{array}$ & $\begin{array}{l}\text { Genetic model of } \\
\text { Alzheimer's disease }\end{array}$ & $\begin{array}{l}\text { Open-field test, balance beam } \\
\text { test, string-suspension, } \\
\text { Y-maze test, elevated } \\
\text { plus-maze test, Morris water } \\
\text { maze test, circular platform } \\
\text { test, platform recognition test, } \\
\text { radial arm water maze test }\end{array}$ \\
\hline
\end{tabular}

\section{Main Outcomes}

Ref.

(1) Improvement of cognitive task of spatial learning/reference memory, working memory, and recognition/identification, (2) decrease in $A \beta$ production due to reduced expression of presenilin 1 and $\beta$-secretase, (3) restored adenosine levels in the brain to normal

(1) Improvement of superior working

Open-field test, balance beam test, string-suspension,

Y-maze test, elevated

$0.3 \mathrm{mg} / \mathrm{mL}$ caffeinated water

APPsw transgenic mice (background C57, B6, SJL and Swiss-Webster mice) beginning at $18-19$ months of age Alzheimer's disease plus-maze test, Morris water maze test, circular platform test, platform recognition tes radial arm water maze test

memory, (2) reduced $A \beta$ deposition in the hippocampus and entorhinal cortex, (3) decrease in brain soluble $A \beta$ levels, (4) aged APPsw mice exhibited memory restoration and reversal of AD pathology, (5) caffeine suppression of $\beta$-secretase involves the cRaf-1/NFkB pathway

\begin{tabular}{ll}
\hline $\begin{array}{l}\text { Albino rats (Morini, Wistar } \\
\text { derived strain) }\end{array}$ & $\begin{array}{l}15,45, \text { and } 80 \mathrm{mg} / \mathrm{kg} / \text { day (s.c.) for } \\
15 \text { days }\end{array}$
\end{tabular}

$-$

Staircase test

No effect on memory retention

(1) Aged mice exhibited lower performance in the recognition memory compared with adults, (2) caffeine-treated mice showed similar performance to adult mice in the object recognition test and an improvement compared with their age-matched control mice, (3) caffeine counteracted the age-related increase in BDNF and TrkB immunocontent

chronic (12 days) treatment with caffeine (1 mg/mL, p.o.); subchronic (4 days) treatment with

CF1 mice caffeine (30 mg/kg, i.p.); acute caffeine treatment ( 30 or $80 \mathrm{mg} / \mathrm{kg}$

i.p.) 30 min treatment before $A \beta$
$A \beta_{25-35}$-induced neurotoxicity
Object recognition test administration
(1) Chronic and subchronic treatment with caffeine prevent $A \beta$-induced cognitive impairment, (2) $A_{2 A}$ receptors are engaged in the control of $\mathrm{A} \beta$-induced cognitive dysfunction
Inhibitory avoidance test, Y-maze test 
Table 3. Cont.

\begin{tabular}{|c|c|c|c|c|c|}
\hline Animals & Treatment & Model & Behavioral Tests & Main Outcomes & Ref. \\
\hline Wistar rats & $30 \mathrm{mg} / \mathrm{kg}$ (p.o.) daily per 10 days & Aging & $\begin{array}{l}\text { Novel object recognition } \\
\text { memory test, open field test }\end{array}$ & $\begin{array}{l}\text { (1) Reversed age-related memory deficit, (2) } \\
\text { normalized oxygen and NRS levels } \\
\text { increased in brains of aged rats, }(3) \\
\text { normalized } \mathrm{Na}^{+} / \mathrm{K}^{+} \text {-ATPase activity } \\
\text { inhibited in brains of aged rats, (4) } \mathrm{A}_{2 \mathrm{~A}} \\
\text { receptors affect the impact and formation of } \\
\text { free radicals in neuronal preparations }\end{array}$ & [199] \\
\hline Sprague-Dawley rats & $3 \mathrm{mg} / \mathrm{kg} /$ day (i.p.) for 60 days & $\begin{array}{l}\mathrm{D}-\text { Galactose induced } \\
\text { neurodegeneration }\end{array}$ & Y-maze test & $\begin{array}{l}\text { (1) Attenuated memory impairment; (2) } \\
\text { reduced oxidative stress via the reduction of } \\
\text { 8-oxoguanine; (3) suppressed stress kinases } \\
\text { p-JNK; (4) reduced D-galactose-induced } \\
\text { neuroinflammation through alleviation of } \\
\text { COX-2, NOS-2, TNF } \alpha \text {, and IL-1 } \beta ;(5) \\
\text { reduced cytochrome C, Bax/Bcl2 ratio, } \\
\text { caspase-9, caspase-3, and PARP-1 levels; (6) } \\
\text { prevented neurodegeneration }\end{array}$ & [191] \\
\hline $\begin{array}{l}\text { THY-Tau22 male mice } \\
\text { (C57B16/J background) }\end{array}$ & $\begin{array}{l}0.3 \mathrm{mg} / \mathrm{mL} \text { caffeinated water } \\
\text { beginning at } 2 \text { months until } \\
12 \text { months of age (daily dose of } \\
1.5 \mathrm{mg} \text { caffeine to each mouse) }\end{array}$ & $\begin{array}{l}\text { Genetic model of } \\
\text { Alzheimer's disease }\end{array}$ & Morris water maze test & $\begin{array}{l}\text { (1) Prevented development of spatial } \\
\text { memory impairments, (2) reduced tau } \\
\text { phosphorylation and proteolytic fragments, } \\
\text { (3) modulated hippocampal } \\
\text { neuroinflammatory and oxidative stress } \\
\text { markers }\end{array}$ & [200] \\
\hline Sprague-Dawley rats & $\begin{array}{l}0.3 \text { or } 0.6 \mathrm{mg} / \mathrm{mL} \text { caffeinated water } \\
\text { for } 3 \text { weeks or just once }\end{array}$ & - & - & $\begin{array}{l}\text { Chronic caffeine treatment (1) induced } \\
\text { ventriculomegaly, (2) increased production } \\
\text { of CSF, which were associated with the } \\
\text { enhancement of the expression of } \\
\mathrm{Na}^{+} / \mathrm{K}^{+} \text {-ATPase and increased CBF }\end{array}$ & [202] \\
\hline
\end{tabular}


Table 3. Cont.

\begin{tabular}{|c|c|c|c|c|c|}
\hline Animals & Treatment & Model & Behavioral Tests & Main Outcomes & Ref. \\
\hline New Zealand white rabbits & $\begin{array}{l}0.5 \mathrm{mg} / \text { day or } 30 \mathrm{mg} / \text { day in the } \\
\text { drinking water for } 12 \text { weeks }\end{array}$ & $\begin{array}{l}2 \% \text { cholesterol-enriched } \\
\text { diet }\end{array}$ & - & $\begin{array}{l}\text { (1) Decreased cholesterol-enriched } \\
\text { diet-induced increase in A } \beta \text { production and } \\
\text { accumulation, (2) reduced } \\
\text { cholesterol-induced increase in tau } \\
\text { phosphorylation, (3) attenuated } \\
\text { cholesterol-induced increase in ROS and } \\
\text { 8-Iso-PGF } \alpha \text { levels, (4) reduced glutathione } \\
\text { depletion, (5) protection against } \\
\text { cholesterol-induced endoplasmic reticulum } \\
\text { stress, }(6) \text { reversed cholesterol-induced } \\
\text { decrease in } \mathrm{A}_{1} \text { receptor levels }\end{array}$ & [201] \\
\hline C57BL/6NCrl mice & $\begin{array}{l}\text { chronically (twice weekly for } \\
8 \text { weeks) caffeine } 5 \mathrm{mg} / \mathrm{kg} \text { or } \\
20 \mathrm{mg} / \mathrm{kg} \text { (i.p.), followed } 10 \mathrm{~min} \\
\text { later } 10 \mathrm{mg} / \mathrm{kg} \text { PQ first and } \\
30 \mathrm{mg} / \mathrm{kg} \mathrm{MB} \text { second }\end{array}$ & $\begin{array}{l}\text { Chronic dual-pesticide } \\
\text { exposure model of } \\
\text { Parkinson's disease }\end{array}$ & $\begin{array}{l}\text { Horizontal locomotor activity } \\
\text { test }\end{array}$ & $\begin{array}{l}\text { Caffeine at } 20 \mathrm{mg} / \mathrm{kg} \text { reduced } \mathrm{TH}+\text { neuron } \\
\text { loss }\end{array}$ & [212] \\
\hline Wistar rats & $\begin{array}{l}20 \mathrm{mg} / \mathrm{kg} \text { (i.p.) } 1 \mathrm{~h} \text { before surgery } \\
\text { and twice a day }(10 \mathrm{mg} / \mathrm{kg} \text {, i.p.) } \\
\text { for } 1 \text { month; apomorphine } \\
\text { hydrochloride }(0.5 \mathrm{mg} / \mathrm{kg} \text {, i.p.) } \\
1 \text { week before (baseline) and } \\
4 \text { weeks after the surgery with } \\
\text { 1-day interval after the last caffeine } \\
\text { injection }\end{array}$ & $\begin{array}{l}\text { 6-OHDA-induced } \\
\text { neurotoxicity }\end{array}$ & $\begin{array}{l}\text { Apomorphine-induced } \\
\text { rotation tests }\end{array}$ & $\begin{array}{l}\text { Caffeine (1) reduced apomorphine-induced } \\
\text { rotations in a 6-OHDA toxicity model, }(2) \\
\text { protected the neurons of substantia nigra } \\
\text { pars compacta against 6-OHDA toxicity }\end{array}$ & [211] \\
\hline Wistar rats & $\begin{array}{l}10 \text { and } 20 \mathrm{mg} / \mathrm{kg} \text { (i.p.) daily for } \\
14 \text { days }\end{array}$ & $\begin{array}{l}\text { 6-OHDA-induced } \\
\text { neurotoxicity }\end{array}$ & $\begin{array}{l}\text { Apomorphine-induced } \\
\text { rotation tests }\end{array}$ & $\begin{array}{l}\text { Caffeine (1) reduced apomorphine-induced } \\
\text { rotations in a 6-OHDA toxicity model, (2) } \\
\text { reversed decreased noradrenaline and } \\
\text { dopamine levels caused by 6-OHDA } \\
\text { unilateral intrastriatal injection }\end{array}$ & [210] \\
\hline
\end{tabular}


Table 3. Cont

\begin{tabular}{|c|c|c|c|c|c|}
\hline Animals & Treatment & Model & Behavioral Tests & Main Outcomes & Ref. \\
\hline Swiss Albino mice & $20 \mathrm{mg} / \mathrm{kg}$ (i.p.) for 8 weeks & $\begin{array}{l}\text { MPTP-induced } \\
\text { neurotoxicity }\end{array}$ & - & $\begin{array}{l}\text { Caffeine (1) partially protected } \\
\text { MPTP-induced neurodegenerative changes, } \\
\text { (2) modulated MPTP-mediated alterations in } \\
\text { the expression and catalytic activity of } \\
\text { CYP1A2, expression of adenosine } A_{2 A} \\
\text { receptor and DAT }\end{array}$ & [207] \\
\hline Wistar rats & $\begin{array}{l}0.1,0.3 \text {, or } 1.0 \mathrm{mg} / \mathrm{kg} \text { (i.p.) } 45 \mathrm{~min} \\
\text { before the training session }\end{array}$ & $\begin{array}{l}\text { MPTP-induced } \\
\text { neurotoxicity }\end{array}$ & $\begin{array}{l}\text { Two-way active avoidance } \\
\text { test }\end{array}$ & $\begin{array}{l}\text { Caffeine induced learning and memory } \\
\text { improvement, what was independent of the } \\
\text { locomotor stimulant effect; observed effects } \\
\text { may be realized via } \\
\text { dopamine/adenosine-receptor interaction }\end{array}$ & [206] \\
\hline FVB mice & $10 \mathrm{mg} / \mathrm{kg} /$ day (i.p.) for 2 weeks & $\begin{array}{l}\text { MPTP-induced } \\
\text { neurotoxicity }\end{array}$ & - & $\begin{array}{l}\text { Caffeine (1) protected against loss of } \\
\text { dopaminergic neuron in striatum, (2) } \\
\text { attenuated gliosis, (3) blocked leakage of the } \\
\text { blood-brain barrier in striatum, (3) blocked } \\
\text { decreases in levels of striatal tight junction } \\
\text { proteins, (4) blocked increases in MMP9 } \\
\text { activity }\end{array}$ & [205] \\
\hline C57BL6 mice & $30 \mathrm{mg} / \mathrm{kg}$ (i.p.) for 8 days & $\begin{array}{l}\text { MPTP-induced } \\
\text { neurotoxicity }\end{array}$ & Paw grip strength test & $\begin{array}{l}\text { Caffeine protected against (1) the reduction } \\
\text { of paw grip strength, (2) perturbation in the } \\
\text { homeostasis of neurometabolites in the } \\
\text { striatum and olfactory bulb }\end{array}$ & [204] \\
\hline C57BL6 mice & $10,20,40 \mathrm{mg} / \mathrm{kg}$ (i.p.) & $\begin{array}{l}\text { MPTP-induced } \\
\text { neurotoxicity }\end{array}$ & - & $\begin{array}{l}\text { Caffeine (1) produced a dose-dependent } \\
\text { attenuation of MPTP-induced striatal } \\
\text { dopamine loss in both young and retired } \\
\text { breeder male, but not female, mice; (2) was } \\
\text { less potent or altogether ineffective in female } \\
\text { mice as a neuroprotectant after sham } \\
\text { surgery compared to ovariectomy or after } \\
\text { ovariectomy plus estrogen replacement } \\
\text { compared to ovariectomy plus placebo } \\
\text { treatment; (3) protection against dopamine } \\
\text { loss in young male mice was blocked by } \\
\text { estrogen administration }\end{array}$ & [208] \\
\hline
\end{tabular}


Table 3. Cont.

\begin{tabular}{|c|c|c|c|c|c|}
\hline Animals & Treatment & Model & Behavioral Tests & Main Outcomes & Ref. \\
\hline C57BL6 mice & $30 \mathrm{mg} / \mathrm{kg}$ (i.p.) & $\begin{array}{l}\text { MPTP-induced } \\
\text { neurotoxicity }\end{array}$ & - & $\begin{array}{l}\text { Caffeine (1) pre-treatment attenuated } \\
\text { MPTP-induced striatal dopamine depletion } \\
\text { when it was given } 10 \mathrm{~min}, 30 \mathrm{~min}, 1 \mathrm{~h} \text {, or } 2 \mathrm{~h} \\
\text { but not } 6 \mathrm{~h} \text { before MPTP treatment; ( } 2 \text { ) } \\
\text { post-treatment attenuated striatal dopamine } \\
\text { loss when it was given } 10 \mathrm{~min}, 30 \mathrm{~min}, 1 \mathrm{~h} \text { or } \\
2 \mathrm{~h} \text { but not } 4 \mathrm{~h}, 8 \mathrm{~h} \text { or } 24 \mathrm{~h} \text { after MPTP } \\
\text { injection; (3) metabolites also provide } \\
\text { neuroprotective effect }\end{array}$ & [209] \\
\hline Sprague-Dawley rats & $1 \mathrm{~g} / 1$ in drinking water & $\begin{array}{l}\text { MPTP-induced } \\
\text { neurotoxicity }\end{array}$ & - & $\begin{array}{l}\text { Caffeine treatment (1) initiated } \\
\text { simultaneously or during the course of } \\
\text { ongoing neurodegeneration reduces loss of } \\
\text { nigral dopaminergic neurons, (2) did not } \\
\text { modify MPTP-induced decreases in striatal } \\
\text { dopamine or tyrosine hydroxylase, (3) } \\
\text { attenuated microglia activation in the } \\
\text { substantia nigra but not in the striatum of } \\
\text { MPTP-treated rats }\end{array}$ & [213] \\
\hline Wistar rats & $\begin{array}{l}10 \text { or } 20 \mathrm{mg} / \mathrm{kg} / \text { day in the } \\
\text { drinking water }\end{array}$ & $\begin{array}{l}\text { 6-OHDA-induced } \\
\text { neurotoxicity }\end{array}$ & $\begin{array}{l}\text { Open field test, } \\
\text { apomorphine-induced } \\
\text { rotation tests }\end{array}$ & $\begin{array}{l}\text { Caffeine treatment (1) blocked partially } \\
\text { decreased locomotor activity and a high } \\
\text { number of apomorphine-induced rotations, } \\
\text { (2) increased dopamine contents and } \\
\text { reversed the decrease dopamine level in the } \\
\text { striatum, (3) improved the hippocampal } \\
\text { neuronal viability, (4) increased TH+ in the } \\
\text { striatum, (5) decreased the number of } \\
\text { immunopositive cells for histone deacetylase } \\
\text { and pro-inflammatory cytokines TNF- } \alpha \text { and } \\
\text { IL-1 } \beta \text { in the 6-OHDA-lesioned group }\end{array}$ & [214] \\
\hline
\end{tabular}


Table 3. Cont.

\begin{tabular}{|c|c|c|c|c|c|}
\hline Animals & Treatment & Model & Behavioral Tests & Main Outcomes & Ref. \\
\hline Mongolian gerbils & $\begin{array}{l}0.1 \% \text { caffeine drinking solution for } \\
4 \text { weeks }\end{array}$ & Ischemia model & - & $\begin{array}{l}\text { Caffeine treatment (1) reduced the degree of } \\
\text { ischemic necrosis of pyramidal cells of the } \\
\text { CA1 hippocampal area after } 5 \text { min of } \\
\text { bilateral carotid occlusion, (2) induced } \\
\text { upregulation of A1 adenosine receptors in } \\
\text { the CNS, what probably impaired the level } \\
\text { of experimentally induced ischemic brain } \\
\text { injury }\end{array}$ & [224] \\
\hline Wistar rat pups & $\begin{array}{l}10 \mathrm{mg} / \mathrm{kg} / \text { day (i.p.) immediately } \\
\text { before } \mathrm{HI} \text { and at } 0,24,48 \text { and } 72 \mathrm{~h} \\
\text { post hypoxia }\end{array}$ & HI neonatal model & - & $\begin{array}{l}\text { Caffeine treatment (1) reduced neuronal } \\
\text { apoptosis in the developing brain, (2) might } \\
\text { be effective in reducing ischemic brain injury }\end{array}$ & [229] \\
\hline Wistar rat pups & $\begin{array}{l}10 \mathrm{mg} / \mathrm{kg} \text { (i.p.) immediately after } \\
\text { the } 120 \mathrm{~min} \text { of } \mathrm{HI} \text { and } 24 \mathrm{~h} \\
\text { following the initial injection }\end{array}$ & HI neonatal model & $\begin{array}{l}\text { Rota rod test, silent gap } \\
\text { detection, non-spatial water } \\
\text { maze test }\end{array}$ & $\begin{array}{l}\text { Caffeine treatment (1) significantly } \\
\text { improved some behavioral outcomes in rat } \\
\text { with a neonatal HI brain injury induced on } \\
\text { postnatal day } 6 \text { and (2) partially rescued } \\
\text { neuropathology }\end{array}$ & [230] \\
\hline Sprague-Dawley rat & $\begin{array}{l}10 \mathrm{mg} / \mathrm{kg} \text { (i.v.) } 30 \mathrm{~min} \text { prior to the } \\
\text { induction of ischemia (acute } \\
\text { treatment) } 20 \mathrm{mg} / \mathrm{kg} \text { (p.o.) three } \\
\text { times daily per dose for the } \\
\text { first week and } 30 \mathrm{mg} / \mathrm{kg} \text { (p.o.) } \\
\text { three times daily for the second } \\
\text { and third weeks; caffeine was } \\
\text { withdrawn } 24 \mathrm{~h} \text { prior to ischemia. } \\
\text { (chronic treatment) }\end{array}$ & $\begin{array}{l}\text { Reversible forebrain } \\
\text { ischemia model }\end{array}$ & - & $\begin{array}{l}\text { Acute caffeine treatment (1) accelerated } \\
\text { changes in the magnetic resonance images } \\
\text { with increased hippocampal intensity } \\
\text { appearing at } 24 \mathrm{~h} \text { post-ischemia, but ( } 2) \\
\text { caused no changes in the extent of neuronal } \\
\text { injury in any brain region compared to } \\
\text { control-ischemic rats; (3) chronic caffeine } \\
\text { treatment caused significantly less neuronal } \\
\text { injury }\end{array}$ & [227] \\
\hline
\end{tabular}


Table 3. Cont.

\begin{tabular}{|c|c|c|c|c|c|}
\hline Animals & Treatment & Model & Behavioral Tests & Main Outcomes & Ref. \\
\hline Long-Evans rats & $\begin{array}{l}10 \mathrm{mg} / \mathrm{kg} \text { of caffeine and } 5 \% \text { or } \\
10 \% \text { ethanol }(0.325 \text { or } 0.65 \mathrm{~g} / \mathrm{kg} \text {, } \\
\text { respectively) acute or chronic } \\
\text { ( } 3 \text { weeks) (p.o.) }\end{array}$ & $\begin{array}{l}\text { Carotid/middle cerebral } \\
\text { artery occlusion model of } \\
\text { ischemia }\end{array}$ & - & $\begin{array}{l}\text { Caffeine plus ethanol treatment (1) almost } \\
\text { entirely eliminated the ischemic injury, (2) } \\
\text { initiated at 30-, } 60-, 90-\text {, and } 120-\text { min } \\
\text { post-ischemia significantly reduced the } \\
\text { infarct volume; (3) for } 3 \text { weeks prior to } \\
\text { ischemia eliminates the neuroprotection } \\
\text { seen after acute treatment }\end{array}$ & [273] \\
\hline Long-Evans rats & $\begin{array}{l}2.5 \mathrm{~h} \text { infusion at doses ranging } \\
\text { from } 2 \text { to } 10 \mathrm{mg} / \mathrm{kg} \text { for caffeine and } \\
\text { from } 0.2 \text { to } 0.65 \mathrm{~g} / \mathrm{kg} \text { for ethanol }\end{array}$ & $\begin{array}{l}\text { Carotid/middle cerebral } \\
\text { artery occlusion model of } \\
\text { ischemia }\end{array}$ & $\begin{array}{l}\text { Sensorimotor tests: } \\
\text { measurement of forelimb } \\
\text { placing and foot-fault } \\
\text { asymmetry }\end{array}$ & $\begin{array}{l}\text { Caffeinol }(0.2 \mathrm{~g} / \mathrm{kg} \text { of ethanol and } 6 \mathrm{mg} / \mathrm{kg} \\
\text { of caffeine) treatment (1) reduced cortical } \\
\text { infarct volume and (2) decreased behavioral } \\
\text { dysfunction after transient carotid / middle } \\
\text { cerebral artery occlusion }\end{array}$ & [274] \\
\hline Sprague-Dawley rats & $\begin{array}{l}10 \mathrm{mg} / \mathrm{kg} \text { caffeine and/or ethanol } \\
0.32 \mathrm{~g} / \mathrm{kg} \text { infusion via the left } \\
\text { femoral vein }\end{array}$ & $\begin{array}{l}\text { Carotid/middle cerebral } \\
\text { artery occlusion model of } \\
\text { ischemia }\end{array}$ & $\begin{array}{l}\text { Sensorimotor tests: } \\
\text { measurement of forelimb } \\
\text { placing and foot-fault } \\
\text { asymmetry, postural reflex }\end{array}$ & $\begin{array}{l}\text { Caffeinol treatment reduced size of } \\
\text { excitotoxic lesion and caffeine may } \\
\text { augmented the anti-ischemic effect of } \\
\text { NMDA receptor blockers }\end{array}$ & [277] \\
\hline
\end{tabular}


Although caffeine is a widely used psychoactive substance around the world, its potential therapeutic value has only recently been seriously explored in Alzheimer's disease, dementia, Parkinson's disease as well as other cognitive impairments. Animal and human studies showed significantly positive effects of caffeine intake with dose-dependent improvement.

\subsection{Neuroprotective Effects of Chlorogenic Acid}

Chlorogenic acid is a polyphenol that can be found in fruit, vegetables, spices, olive oil, wine, tea, and especially in coffee. Both caffeinated and decaffeinated coffee contains a large amount of chlorogenic acid (70-350 mg per cup of coffee), which makes it one of the most abundant polyphenols in a diet of coffee-consuming populations [278]. Due to a wide distribution in the human diet, chlorogenic acid has gained much research attention. Numerous studies have shown that it exerts multiple health-beneficial effects such as antiinflammatory, hepatoprotective, cardioprotective, chemopreventive, antidiabetic, and antiobesity activities. There is also mounting evidence that chlorogenic acid has neuroprotective properties and it appears that its regular intake may reduce risk of neurodegenerative diseases and improve cognition $[73,278,279]$.

Preclinical studies. The neuroprotective effects of chlorogenic acid are linked mainly with its ability to reduce oxidative stress. Like other polyphenols, it has free radical scavenging activity and metal-chelating properties [280], and there is considerable in vitro evidence demonstrating protective effects of chlorogenic acid against neuronal damage caused by oxidative stress. For instance, Cho et al. [281] showed that chlorogenic acid suppressed the $\mathrm{H}_{2} \mathrm{O}_{2}$-induced PC12 cell death. The protective effect was related to the attenuation of intracellular ROS accumulation and the inhibition of JNK and p38 MAPK activation. In the study by Kim et al. [282], chlorogenic acid reduced apoptosis in primary cortical neurons by inhibiting the $\mathrm{H}_{2} \mathrm{O}_{2}$-induced downregulation of anti-apoptotic proteins Bcl-2 and $\mathrm{Bcl}-\mathrm{XL}$ as well as by blocking the $\mathrm{H}_{2} \mathrm{O}_{2}$-induced pro-apoptotic cleavage of caspase-3 and pro-poly(ADP-ribose) polymerase (pro-PARP). In addition, it increased the expression of the antioxidant enzyme-NAD(P)H quinone oxidoreductase (NQO-1). In this study, it was also demonstrated that the neuroprotective effects of caffeinated and decaffeinated coffee were similar, which suggests that other compounds than caffeine (e.g., chlorogenic acids) may be responsible for the neuroprotective properties of coffee [282]. Similar results were obtained by $\mathrm{Chu}$ et al. [283] who reported that green and roasted coffees (regular and decaffeinated) protected primary neuronal cells against the $\mathrm{H}_{2} \mathrm{O}_{2}$-induced oxidative damage and improved their survival by inhibiting the extracellular signal-regulated kinase-1 and -2 (ERK1/2) activation. Of note, there was a significant correlation between chlorogenic acid content and the neuroprotective efficacy of the tested samples [283]. In other studies, chlorogenic acid attenuated the $\mathrm{H}_{2} \mathrm{O}_{2}$-induced neurotoxicity, scavenged hydroxyl radical, decreased ROS production in neuro-2A cells [284], and attenuated the $\mathrm{H}_{2} \mathrm{O}_{2}$-induced increases in malondialdehyde (MDA) and ROS levels in rat brain slices [285]. A protective effect against the $\mathrm{H}_{2} \mathrm{O}_{2}$-mediated oxidative insult was also reported in rat pheochromocytoma cells. In this study, chlorogenic acid provided neuroprotection via directly neutralizing free radicals and indirectly inducing the endogenous antioxidant enzymes by activation of nuclear factor erythroid 2-related factor 2 (Nrf2) [286]. Similarly, chlorogenic acid protected against the aluminum-induced cytotoxicity in primary hippocampal neuronal cells by decreasing ROS production and by increasing the expression of Nrf2 and its target phase 2 enzymes [287].

The antioxidant properties of chlorogenic acid also contributed to its neuroprotective effects against the L-buthionine-(S,R)-sulfoximine-induced damage in cultured retinal ganglion cells [288], methylmercury-induced apoptosis in PC12 cells [289], and $\mathrm{FeSO}_{4}$-evoked oxidative stress in rat whole brain homogenates [290]. Furthermore, chlorogenic acid protected cultured cerebellar granule neurons from death induced by sodium nitroprusside (SNP) - a NO donor [291] and reduced the SNP-induced increase in MDA content in rat brain homogenates [290]. It also decreased NO level in cerebral neurons exposed to SNP, 
suggesting that its protective effects against the NO-induced neurotoxicity is likely due to direct free radical scavenging activity [291].

It is widely known that chronic neuroinflammation is closely associated with the pathogenesis of neurodegenerative diseases. Chlorogenic acid was found to reduce neuroinflammation and neurotoxicity in SH-SY5Y cells caused by toxic factors released from activated microglia and astrocytes. Moreover, it decreased production of pro-inflammatory cytokines (TNF $\alpha$ and IL-6) from lipopolysaccharide (LPS)/interferon- $\gamma$-stimulated microglia and THP-1 cells, as well as from interferon $\gamma$-stimulated astrocytes and U373 cells [292].

Chlorogenic acid was also reported to protect neurons from excitotoxic insults. These are important observations as the glutamate-mediated neurotoxicity is considered to play a crucial role in several neurodegenerative conditions, especially in Alzheimer's disease, Parkinson's disease, ischemic stroke, and epilepsy [293]. Oboh et al. [290] showed that it significantly reduced lipid peroxidation in quinolinic acid-treated rat brain homogenates. Quinolinic acid acts through the NMDA subtype of glutamate receptors, and it evokes glutamate-type excitotoxicity [294]. In further studies, chlorogenic acid protected primary cortical neurons from glutamate-induced injury. Importantly, glutamate-induced excitotoxic insult causes an elevation in the concentration of cytosolic $\mathrm{Ca}^{2+}$ and chlorogenic acid attenuated the increase in the intracellular $\mathrm{Ca}^{2+}$ level $[295,296]$. In the study by Rebai et al. [296], the neuroprotective effect of chlorogenic acid was mediated by suppressing the accumulation of ROS, restoring the mitochondrial membrane potential, and increasing superoxide dismutase (SOD) activity. Chlorogenic acid also reduced apoptosis by suppressing activation of pro-caspases (i.e., caspase 1, 8, and 9) and calpain. Moreover, it has been proposed that the protein kinase $C$ signaling pathways may be involved in the protective effect of chlorogenic against glutamate-induced neurotoxicity [296]. In another study, chlorogenic acid prevented the AMPA-mediated excitotoxicity in optic nerve oligodendrocytes by inhibiting ROS formation and activation of the antioxidant enzymatic system through the protein kinase C-dependent pathway as well as by the anti-apoptotic caspase and calpain-dependent targets [297].

Several studies focused on the protective effects of chlorogenic acid against the neurotoxicity caused by exposure to $A \beta$ peptide. For example, it displayed significant protective effects towards $\mathrm{A} \beta_{25-35}$-induced neuronal damage in PC12 cells as well as in neuroblastoma SH-SY5Y cells [298,299]. In addition, chlorogenic acid suppressed the $A \beta_{1-42}$ self-induced aggregation in PC12 cells [300]. It was also a potent inhibitor of $A \beta_{1-40}$ fibrillization in the ThT assay but it did not inhibit the oligomerization of $A \beta_{1-42}$, which suggests that its interaction with monomeric/oligomeric $A \beta$ proteins differs from the interaction with larger $A \beta$ aggregates [301]. Importantly, chlorogenic acid significantly inhibited $A \beta_{25-35}$-induced autophagy in SH-SY5Y cells by modulating lysosomal function. In the same study, it elevated protein levels of p-mTOR, p-p70s6k and nuclear transcription factor EB (TFEB) indicating that it may enhance the autophagic flux in A $32_{5-35}$-treated SH-SY5Y cells via the regulation of the mTOR/TFEB signaling pathway [299].

The cholinergic deficit in Alzheimer's disease is a well-known phenomenon, and the restoration of cholinergic function by inhibiting the (acetylcholinesterase) AChE and butyrylcholinesterase (BChE) activity is an effective treatment strategy for Alzheimer's disease. Given that chlorogenic acid has emerged as a promising neuroprotective agent, its ability to inhibit $\mathrm{AChE}$ and $\mathrm{BChE}$ activity has also been evaluated. In in vitro studies, it significantly inhibited AChE activity in mouse brain homogenates [302] and in primary hippocampal neuronal cells [287] as well as both AChE and BChE activities in rat brain homogenates [290]. Its inhibitory activity towards AChE and BChE was also demonstrated by using the spectrophotometric Ellman assay [303,304]. Importantly, the anti-AChE [302,304] and anti-BChE [304] activity of chlorogenic was also confirmed in in vivo models of scopolamine-induced amnesia in mice.

In in vitro model of Parkinson's disease, the impaired viability and enhanced apoptosis of 6-OHDA-damaged SH-SY5Y cells were significantly attenuated by chlorogenic 
acid pretreatment [305,306]. Chlorogenic acid also suppressed the 6-OHDA-induced ROS production and endoplasmic reticulum (ER) stress in SH-SY5Y cells [305]. Its protective effects against the 6-OHDA-induced toxicity were also reported in the mouse nerve growth factor (mNGF)-differentiated PC12 cells. It prevented cell damage by reducing the 6-OHDA-induced increase in intracellular $\mathrm{Ca}^{2+}$ level, suppressing ROS production and inhibiting caspase 3 and 9 activities [307]. Additionally, chlorogenic acid produced a cytoprotective effect against $\alpha$-synuclein-induced toxicity in catecholaminergic PC12 cells [308] and inhibited $\alpha$-synuclein fibril assembly [309].

In vivo preclinical studies also provide substantial evidence on the neuroprotective effects of chlorogenic acid. For instance, Vardi et al. [310] demonstrated that chlorogenic acid protected the rat brain cerebellum from oxidative damage induced by methotrexate-a chemotherapeutic agent with severe neurotoxic effects. A 24-day treatment with chlorogenic acid significantly reduced Purkinje cell injury, prevented the methotrexate-induced increase in MDA level as well as decrease in SOD and catalase activity, and reduced glutathione (GSH) content in the cerebellum. In rats with cadmium-induced oxidative brain damage, chlorogenic acid inhibited lipid peroxidation, augmented the antioxidant defense system, and prevented mitochondrial dysfunction and DNA fragmentation [311]. The antioxidant activity of chlorogenic acid also contributed to its protective effect against scopolamine-induced amnesia in mice [302,304]. Acute administration of chlorogenic acid significantly attenuated learning and short-term and long-term memory impairments caused by scopolamine injection in mice. The effect was accompanied by decreased MDA level and increased AChE activity in the hippocampus and frontal cortex [302]. Likewise, repeated administration of chlorogenic acid attenuated the scopolamine-induced learning and memory decline. It also decreased $\mathrm{AChE}$ and $\mathrm{BChE}$ activities as well as free radical production in the cortex and hippocampus of scopolamine-treated mice [304]. An interesting observation was made by Guo and Li [312] who reported the protective effect of chlorogenic acid against alcohol-induced brain damage in neonatal rats. Treatment with chlorogenic acid attenuated the altered cognitive function in ethanol-exposed pups. In the cerebral cortex and hippocampus, it decreased $\mathrm{AChE}$ and caspase-3 activity, reduced MDA and nitrite levels, increased SOD and catalase activity, reduced TNF- $\alpha$ and IL- $1 \beta$ levels, and decreased the level of transcription factor p 65 of NF-kB. Thus, the chlorogenic acid protected neonatal rats from ethanol-induced brain damage by decreasing oxidative stress, inflammation, and apoptosis of neuronal cells. In the study by Alarcón-Herrera et al. [313], chlorogenic acid ameliorated the 3-nitropropionic acid-induced toxicity and genotoxicity in mice suggesting its potential protective effect in Huntington's disease.

Chlorogenic acid was also reported to ameliorate brain ischemia-induced injury in rodents. In models of cerebral ischemia/reperfusion injury, it significantly reduced mortality [314], improved neurological deficit scores [314,315], attenuated sensory-motor functional deficits [316], reduced infarct volume [314-317], suppressed CA1 pyramidal cell loss [318-320], decreased brain edema [315-317], and attenuated blood-brain barrier (BBB) damage [316,317]. Importantly, it was demonstrated that chlorogenic acid has a neuroprotective effect against ischemia-induced cognitive deficits. It attenuated learning and memory impairments in ischemic rats [315,319] and in Mongolian gerbils [320]. The protective effect of chlorogenic acid against ischemia-induced brain injury appears to be related with its ability to reduce oxidative stress, neuroinflammation, and cell apoptosis. In rats with cerebral ischemia/reperfusion injury, chlorogenic acid dose-dependently increased the activity of SOD and GSH and suppressed ROS production, lactate dehydrogenase (LDH) release, and MDA accumulation as well as promoted the expression of Nrf2, NQO-1 and heme oxygenase 1 (HO-1) [315]. Likewise, it reduced ROS production and increased SOD2 expression in the CA1 hippocampal region of gerbils with transient global cerebral ischemia [320]. Overexpression of SOD2 (but not SOD1) was also observed in ischemic rats treated with chlorogenic acid [319]. Furthermore, chlorogenic acid suppressed the ischemiainduced increase in pro-inflammatory cytokines, i.e., TNF- $\alpha[317,320]$ and IL-2 [320], as well as overexpression of anti-inflammatory cytokines IL-4 and IL-13 [320]. It also down- 
regulated the expression of an apoptotic marker-caspase-3 [315,317] and increased the expression of an anti-apoptotic protein-Bcl2 in ischemic animals [319]. Moreover, it promoted BDNF [315] and NGF [314,315] expression in the brain of rats subjected to cerebral ischemia/reperfusion. Interestingly, chlorogenic acid was shown to downregulate matrix metalloproteinases (i.e., MMP-2 and MMP-9) mRNA and protein expression in the brain of ischemic rats and to inhibit MMP-2 and MMP-9 activity in in vitro zymography assays. Since extracellular matrix is involved in maintaining the integrity of the BBB and MMP-2 and MMP-9 degrade the extracellular matrix, it seems that the protective effect of chlorogenic acid on BBB damage may result from its ability to reduce expression and activity of MMP-2 and MMP-9 [316]. Interestingly, chlorogenic acid also increased the expression of CD31 (an endothelial marker) and decreased the expression of endothelin-1 in rats with global ischemia, which suggests that it may improve the vascular response by repairing the ischemia-induced endothelial cell damage [319].

Only few studies aimed to evaluate the potential beneficial effects of chlorogenic acid in animal models of Parkinson's disease. Shan et al. [305] showed that chlorogenic acid attenuated the 6-OHDA-induced Parkinson's-like behavioral impairments in rats and suppressed the 6-OHDA-induced decrease in striatal dopamine concentration. It also prevented $\alpha$-synuclein accumulation, increased SOD and glutathione peroxidase (GSH-Px) activities, and restored Bcl-2/Bax expression in the striatum [305]. In rotenone-injected mice, chlorogenic acid ameliorated degeneration of dopaminergic neurons in the substantia nigra and upregulated the antioxidative molecules-metallothionein-1 and 2, in striatal astrocytes [321]. In the study by Singh et al. [322], chlorogenic acid improved motor coordination and neurobehavioral activity in the MPTP-induced model of Parkinson's disease in mice. Of note, the behavioral effects were accompanied by reduced degeneration of dopaminergic neurons in the substantia nigra. Moreover, chlorogenic acid improved mitochondrial function, suppressed ROS generation, increased SOD and mitochondrial GSH activity, inhibited activation of proapoptotic proteins (Bax and caspase-3), and elevated expression of the anti-apoptotic protein ( $\mathrm{Bcl} 2)$. Since it improved the phosphorylation state of Akt, ERK1/2, and GSK3 $\beta$, it appears that the neuroprotective effects of chlorogenic acid against MPTP-induced neurotoxicity are mediated, at least in part, by the GSK3 $\beta$ phosphorylation-associated Akt/ERK pathway [322]. It is also worth noticing that chlorogenic acid attenuated the extensive release of release of TNF- $\alpha$ and IL- $1 \beta$ in the substantia nigra of the LPS-injected mice suggesting that this compound may suppress inflammatory response or damage in neurodegenerative diseases including Parkinson's disease [323].

Two in vivo studies focused on neuroprotective effects of chlorogenic acid against excitotoxicity. In the kainic acid-induced neurotoxicity model in mice, repeated administration of chlorogenic alleviated learning and memory impairments and protected the nNOS-positive neurons in the hippocampal CA1-4 regions from kainic acid-induced injury [324]. Chlorogenic acid also attenuated neuronal loss in the hippocampal CA1 region and produced an anticonvulsant-like effect in the pilocarpine-induced seizure model in mice. In pilocarpine-injected mice, it restored glutamate and gamma-aminobutyric acid (GABA) levels, and decreased NMDA, mGluR1, and mGluR5 receptors expression, which could contribute to the anticonvulsant and neuroprotective effect. Chlorogenic acid also protected from the pilocarpine-induced oxidative stress [325].

Recently, chlorogenic acid has been reported to produce beneficial effects in the APP/PS2 transgenic mice [299]. These double transgenic mice overexpress mutant forms of human APP and human PS2. The APP/PS2 mice display Alzheimer's-like impairments, e.g., cognitive dysfunction, amyloidosis, inflammation, and impaired synaptic plasticity [326]. Prolonged (180 days) treatment with chlorogenic acid significantly improved spatial memory, decreased neuronal damage in the hippocampus, and suppressed the excessive autophagy in the APP/PS2 mice. It was suggested that neuroprotective effect was likely related with modulation of the mTOR/TFEB signaling pathway [299]. It is noteworthy that cognitive dysfunctions in APP/PS2 mice were also prevented by chronic 
treatment with coffee polyphenols (including chlorogenic acid). The polyphenols also reduced $A \beta$ plaque deposition in the hippocampus [326].

Summary of in vivo studies on the neuroprotective effects of chlorogenic acid is introduced in Table 4.

Clinical studies. While numerous preclinical in vitro and in vivo experiments have been designed to evaluate the neuroprotective effects of chlorogenic acid, only few studies on this matter have been performed in human subjects. Cropley et al. [327] investigated the acute effects of caffeinated coffee, decaffeinated coffee with regular chlorogenic acid content $(224 \mathrm{mg})$, and decaffeinated coffee with higher chlorogenic acid content $(521 \mathrm{mg} / \mathrm{kg}$ ) on cognitive processes and mood in a randomized, double-blind, crossover study with 39 healthy older volunteers. Compared to regular decaffeinated coffee, the chlorogenic acid-rich coffee produced positive effects on mood and mood-related processes. Specifically, it increased alertness, decreased mental fatigue, and alleviated headaches. However, it did not produce substantial pro-cognitive effects. In another randomized placebo-controlled trial, 60 healthy older participants received $6 \mathrm{~g}$ of a decaffeinated green coffee blend or $540 \mathrm{mg}$ pure chlorogenic acids or placebo. Cognitive measures were made at 40 and $120 \mathrm{~min}$ post-intake. Pure chlorogenic acid did not produce any significant improvement in cognition function when compared to placebo. On the contrary, there was a trend towards chlorogenic acid consumption being associated with slower reaction time and slower information processing speed in comparison to placebo. Decaffeinated green coffee blend improved sustained attention, decision time, and alertness. In addition, both pure chlorogenic acid and the decaffeinated green coffee blend significantly improved symptoms of headache [328]. Despite the lack of significant pro-cognitive effects after single administration $[327,328]$, chlorogenic acid was reported to increase cognitive function following regular prolonged intake [329,330]. Saitou et al. [330] investigated the effects of a 16-week intake of chlorogenic acid-added beverage or placebo on cognitive functions in 38 healthy volunteers (aged 50-69 years) with subjective memory complaints. The obtained results showed that chlorogenic acid improves some cognitive functions (i.e., motor speed, executive function, psychomotor speed, and attention shifting) suggesting that its regular intake may increase individuals' ability to perform complex tasks by improving both motor activity and cognitive functions. Importantly, blood analysis showed increased levels of apolipoprotein A1 and transthyretin, which are considered biomarkers for the early-stage cognitive decline [330]. Similar effects were observed in the pilot study by Kato et al. [331], who reported that a 6-month intake of chlorogenic acid $(330 \mathrm{mg})$ improved composite and verbal memory, cognitive flexibility, complex attention, executive function, and motor speed in 8 participants with complaints of subjective memory loss. Moreover, biochemical studies revealed decreased plasma $A \beta_{42}$ and $A \beta_{42} / A \beta_{40}$ levels and elevated dehydroepiandrosterone sulfate level [331]. In a recent randomized controlled crossover trial, the effect of prolonged chlorogenic acids intake on cognitive function in mild cognitive impairment was investigated [329]. The study was performed on 34 individuals and comprised two 12-week chlorogenic acids intake periods (553.6 mg of chlorogenic acids or placebo twice daily) with a 4 -week washout period between them. The cognitive function tests showed that the continuous intake of chlorogenic acids improved cognitive functions in patients with mild cognitive impairment, especially attention and executive function. Taken together, clinical data on the neuroprotective properties of chlorogenic acid are limited. However, some initial evidence suggests that its regular intake may have beneficial effects on cognition function. 
Table 4. Summary of in vivo studies on the neuroprotective effects of chlorogenic acid.

\begin{tabular}{|c|c|c|c|c|c|}
\hline Animals & Treatment & Model & Behavioral Tests & Main Outcomes & Ref. \\
\hline Wistar rats & $100 \mathrm{mg} / \mathrm{kg}$ (i.p.) for 24 days & $\begin{array}{l}\text { Methotrexate-induced } \\
\text { cerebellar Purkinje cell } \\
\text { damage }\end{array}$ & - & $\begin{array}{l}\text { (1) Reduced Purkinje cell damage and the } \\
\text { expression of apoptotic cells, (2) decreased } \\
\text { production of MDA and increase in SOD and } \\
\text { catalase activity and GSH content in the } \\
\text { cerebellum }\end{array}$ & [310] \\
\hline Wistar rats & $60 \mathrm{mg} / \mathrm{kg}$ (p.o.) for 30 days & $\begin{array}{l}\text { Cadmium-induced brain } \\
\text { damage }\end{array}$ & - & $\begin{array}{l}\text { (1) Restored AChE, SOD, catalase, GSH-Px, and } \\
\text { GST activity; (2) restored GSH, vitamins C and } \\
\text { E, and lipid peroxidation level; ( } 3 \text { ) increased } \\
\text { membrane-bound ATPase activity; (4) } \\
\text { attenuated mitochondrial dysfunction and DNA } \\
\text { fragmentation }\end{array}$ & [311] \\
\hline ICR mice & $\begin{array}{l}3-9 \mathrm{mg} / \mathrm{kg} \text { (p.o.) } 30 \mathrm{~min} \\
\text { before scopolamine injection }\end{array}$ & $\begin{array}{l}\text { Scopolamine-induced } \\
\text { amnesia }\end{array}$ & $\begin{array}{l}\text { Y-maze test, passive } \\
\text { avoidance test, Morris water } \\
\text { maze test }\end{array}$ & $\begin{array}{l}\text { (1) Attenuation of the scopolamine-induced } \\
\text { learning and memory impairment, (2) decreased } \\
\text { AChE activity and MDA level in the } \\
\text { hippocampus and frontal cortex. }\end{array}$ & [302] \\
\hline Swiss Albino mice & $\begin{array}{l}1-10 \mathrm{mg} / \mathrm{kg} \text { (p.o.) for } 8 \text { days } \\
\text { before scopolamine injection }\end{array}$ & $\begin{array}{l}\text { Scopolamine-induced } \\
\text { amnesia }\end{array}$ & $\begin{array}{l}\text { Y-maze test, novel object } \\
\text { recognition test }\end{array}$ & $\begin{array}{l}\text { (1) Attenuation of the scopolamine-induced } \\
\text { learning and memory impairments, ( } 2 \text { ) } \\
\text { decreased AChE and BChE activities in the } \\
\text { cortex and hippocampus, (3) increased free } \\
\text { radical scavenging activity }\end{array}$ & [304] \\
\hline Wistar rats (5 days old pups) & $\begin{array}{l}100 \text { and } 200 \mathrm{mg} / \mathrm{kg} \text { (p.o.) } \\
\text { from PD } 6 \text { to } 28 \text { (with } \\
\text { ethanol) }\end{array}$ & $\begin{array}{l}\text { Alcohol-induced brain } \\
\text { damage }\end{array}$ & Morris water maze test & $\begin{array}{l}\text { (1) Attenuation of the altered cognitive function } \\
\text { in ethanol-exposed pups, decreased AChE and } \\
\text { caspase- } 3 \text { activity, (2) reduced MDA and nitrite } \\
\text { levels, (3) increased SOD and catalase activity, } \\
\text { (4) decreased TNF- } \alpha \text { and IL- } 1 \beta \text { levels, as well as } \\
\text { decreased level of p } 65 \text { of NF- } \mathrm{KB} \text { in the cerebral } \\
\text { cortex and hippocampus }\end{array}$ & [312] \\
\hline C57BL/6 mice & $100 \mathrm{mg} / \mathrm{kg}$ (i.p.) for 5 days & $\begin{array}{l}\text { 3-Nitropropionic acid } \\
\text { induced neurotoxicity }\end{array}$ & - & $\begin{array}{l}\text { Reduction of the 3-nitropropionic acid induced } \\
\text { toxicity and genotoxicity }\end{array}$ & [313] \\
\hline
\end{tabular}


Table 4. Cont.

\section{Animals} Treatment

15-60 mg/kg (p.o.) for 7 days
Focal cerebral

ischemia/reperfusion injury Neurological deficit scoring before ischemia induction

Wistar rats

\section{Model}

\section{Behavioral Tests}

neurological deficit scores, (2) decreased cerebral infarction area, (3) reduced ICAM-1 and

VCAM-1 levels, (4) increased erythropoietin and HIF- $1 \alpha$ levels, and (5) increased expression of NGF in the brain

(1) Attenuation of the learning and memory impairments; (2) improved neurological deficit scores; (3) decreased cerebral infarction volume, cerebral water content and cerebral index; (4) promoted BDNF and NGF expression; (5)

$20-500 \mathrm{mg} / \mathrm{kg}$ (p.o) for Sprague-Dawley rats 7 days before ischemia induction
Cerebral

ischemia/reperfusion injury
Neurological deficit scoring, step-down test, Y maze test

activity and GSH levels; (6)

decreased production of ROS, $\mathrm{LDH}$, and MDA;

(7) inhibited expression of caspase 3 and 9; and

(8) promoted Nrf2, NQO-1, and HO-1

expression

3-30 mg/ $\mathrm{kg}$ (i.p.) twice at $0 \mathrm{~h}$ and $2 \mathrm{~h}$ after ischemia induction

Focal cerebral ischemia/reperfusion injury

Balance-beam test

Sprague-Dawley rats

$10 \mathrm{mg} / \mathrm{kg}$ (i.n.) after $2 \mathrm{~h}$ of occlusion
Global cerebral

ischemia/reperfusion injury

(1) Reduced sensory-motor functional deficits, infarct volume, BBB damage, and brain edema and (2) decreased lipid peroxidation and the expressions of matrix metalloproteinases

(1) Reduced cerebral infarction volume and BBB damage; (2) restored the brain water content; (3) reduced calcium, nitrate, and glutamate levels in the cortex, hippocampus, cerebellum, and cerebrospinal fluid, and (4) decreased expression of TNF- $\alpha$, iNOS, and caspase- 3

Enhanced neuroprotective activity of

PEP-1-rpS3 against the ischemia-induced hippocampal damage

(1) Attenuation of the spatial memory impairment; (2) decreased CA1 pyramidal cell loss; (3) increased Bcl-2, SOD2, and CD31 expressions; and (4) decreased endothelin-1

Transient global after ischemia induction ischemia/reperfusion injury
Morris water maze test 
Table 4. Cont.

\begin{tabular}{|c|c|c|c|c|c|}
\hline Animals & Treatment & Model & Behavioral Tests & Main Outcomes & Ref. \\
\hline Mongolian gerbils & $\begin{array}{l}7.5-30 \mathrm{mg} / \mathrm{kg} \text { (i.p.) for } 5 \text { days } \\
\text { before ischemia induction }\end{array}$ & $\begin{array}{l}\text { Transient global cerebral } \\
\text { ischemia injury }\end{array}$ & $\begin{array}{l}8 \text { Arm radial maze test, } \\
\text { passive avoidance task }\end{array}$ & $\begin{array}{l}\text { (1) Attenuation of cognitive impairment; (2) } \\
\text { decreased CA1 pyramidal cell loss; (3) increased } \\
\text { SOD2 expression; (4) reduced production of } \\
\text { ROS, TNF- } \alpha \text {, and IL-2 and elevated expression } \\
\text { of IL-4 and IL-13 }\end{array}$ & [320] \\
\hline Sprague-Dawley rats & $\begin{array}{l}20-60 \mathrm{mg} / \mathrm{kg} \text { (i.p.) } 60 \mathrm{~min} \\
\text { before 6-OHDA injection, for } \\
7 \text { days }\end{array}$ & $\begin{array}{l}\text { 6-OHDA-induced } \\
\text { neurotoxicity }\end{array}$ & $\begin{array}{l}\text { Rotarod test, } \\
\text { apomorphine-induced } \\
\text { rotational test }\end{array}$ & $\begin{array}{l}\text { (1) Reversed motor deficits, (2) attenuated } \\
\text { decrease in striatal dopamine concentration, (3) } \\
\text { reduced } \alpha \text {-synuclein accumulation, (4) } \\
\text { increased SOD and GSH-Px activities, and (5) } \\
\text { restored Bcl-2/Bax expression in the striatum }\end{array}$ & [305] \\
\hline C57BL/6J mice & $\begin{array}{l}50 \mathrm{mg} / \mathrm{kg} \text { (p.o.) for } 1 \text { week } \\
\text { before rotenone exposure, } \\
\text { and then } 5 \text { days/week during } \\
\text { the } 4 \text { weeks of rotenone } \\
\text { treatment }\end{array}$ & $\begin{array}{l}\text { Rotenone-induced } \\
\text { neurotoxicity }\end{array}$ & - & $\begin{array}{l}\text { (1) Prevented degeneration of dopaminergic } \\
\text { neurons in the substantia nigra, (2) upregulated } \\
\text { metallothionein- } 1 \text { and } 2 \text { in striatal astrocytes }\end{array}$ & [321] \\
\hline Swiss Albino mice & $50 \mathrm{mg} / \mathrm{kg}$ (p.o.) for 24 days & MPTP-induced neurotoxicity & $\begin{array}{l}\text { Rotarod test, } \\
\text { pole test, } \\
\text { traction test, catalepsy test }\end{array}$ & $\begin{array}{l}\text { (1) Improved motor coordination and } \\
\text { neurobehavioral activity; (2) improved } \\
\text { mitochondria function; (3) reduced ROS } \\
\text { generation; (4) increased SOD and } \\
\text { mitochondrial GSH activity; (5) inhibited } \\
\text { activation of proapoptotic proteins (Bax and } \\
\text { caspase-3); (6) elevated expression of Bcl-2; (7) } \\
\text { improved phosphorylation state of Akt, } \\
\text { ERK1/2, and GSK3 } \beta\end{array}$ & [322] \\
\hline C57BL/6J mice & $\begin{array}{l}100 \mathrm{mg} / \mathrm{kg} \text { (i.p.) for } 7 \text { days } \\
\text { before LPS injection }\end{array}$ & LPS-induced neurotoxicity & - & $\begin{array}{l}\text { Attenuation of the LPS-induced IL- } 1 \beta \text { and } \\
\text { TNF- } \alpha \text { release in the substantia nigra }\end{array}$ & [323] \\
\hline Kunming mice & $\begin{array}{l}1 \mathrm{ml} \text { (p.o.) twice daily for } \\
35 \text { days }\end{array}$ & $\begin{array}{l}\text { Kainic acid-induced } \\
\text { neurotoxicity }\end{array}$ & Y maze test & $\begin{array}{l}\text { (1) Attenuation of learning and memory } \\
\text { impairment, (2) increased number of } \\
\text { nNOS-positive neurons in the hippocampal } \\
\text { CA1-4 regions }\end{array}$ & [324] \\
\hline
\end{tabular}


Table 4. Cont.

\section{Animals} Treatment

$5 \mathrm{mg} / \mathrm{kg}$ (p.o.) for 15 days, last injection $30 \mathrm{~min}$ before pilocarpine
Pilocarpine-induced seizures of clonic and tonic seizure)

Behavioral Tests

\section{Main Outcomes}

Ref.

(1) Anticonvulsant-like effect; (2) attenuated

neuronal loss in the hippocampal CA1 region

(3) restored glutamate and GABA levels; (4)

Genetic model of Alzheimer's disease
Morris water maze test decreased NMDA, mGluR1, and mGluR5

receptor expression; (5) decreased lipid

peroxidation and nitrite content; (6) increased

SOD, catalase, and GSH activity; (7) restored

$\mathrm{AChE}$ and monoamine oxidase activity

(1) Improved spatial memory, (2) decreased

neuronal damage in the hippocampus, (3)

inhibited autophagy, and (4) activation of the

mTOR/TFEB signaling pathway 
Taken together, emerging evidence, from both in vitro and in vivo studies, demonstrates neuroprotective effects of chlorogenic acid. It protects neurons from a wide range of stressors and cell death-inducing agents by ameliorating oxidative stress and neuroinflammation as well as by inhibiting apoptosis and autophagy. In addition, it possesses anti-amyloidogenic effects and inhibits AChE activity. Several signaling pathways, many of which are interdependent, have been proposed to be involved in the neuroprotective effects of chlorogenic acid. No differences between neuroprotective effects of caffeinated and decaffeinated coffee suggest that chlorogenic acid, the most abundant active coffee compound, may significantly contribute to the beneficial effects of coffee on some neurodegenerative disease and cognitive decline. A few preliminary clinical trials [327,329-331] showed that regular, but not acute, chlorogenic acid intake improves cognitive function in humans. Therefore, large-scale longitudinal clinical studies are highly warranted to provide more insight into the beneficial effects of chlorogenic acid in neurodegenerative diseases. Further studies are also required to better characterize the pharmacokinetics and metabolism of chlorogenic acid in humans and to identify its potential adverse effects.

\subsection{Neuroprotective Effects of Caffeic Acid}

Caffeic acid is produced by many plant species, not only by Coffea sp. Like many other polyphenols, caffeic acid exerts potent antioxidant and free radical scavenging properties [332]. Its antioxidant activity appears to be greater than the antioxidant activity of many other important coffee components including chlorogenic acid [333]. Moreover, numerous studies showed that caffeic acid has anti-inflammatory, anti-mutagenic, antibacterial, and anti-carcinogenic properties, which could be linked to its high antioxidant activity [334,335]. There is also a growing body of evidence showing possible neuroprotective effects of caffeic acid. It is noteworthy that its naturally occurring derivative-caffeic acid phenyl ester (CAPE) has also been extensively studied for neuroprotective properties. Chemical versatility and modifiability of caffeic acid caused its phenylpropanoid scaffold to become a commonly used template for the development of new derivatives with enhanced pharmacokinetic properties, increased bioactivity, and better safety profile [336].

Preclinical studies. Numerous in vitro studies have demonstrated that caffeic acid displays a broad-spectrum neuroprotective profile. Several reports showed that caffeic acid is protective against the $\mathrm{H}_{2} \mathrm{O}_{2}$-induced oxidative stress. For example, it attenuated the $\mathrm{H}_{2} \mathrm{O}_{2}$-induced cell injury in cultured cerebellar granule neurons [291], PC12 cells [337-339], neuroblastoma SH-SY5Y cells [340], and rat cortical slices [285]. Caffeic acid also suppressed intracellular ROS accumulation as well as the release of LDH from PC12 cells exposed to $\mathrm{H}_{2} \mathrm{O}_{2}$ [337,338]. Oboh et al. [290] reported that caffeic acid dose-dependently inhibited the excessive MDA production in rat brain homogenates following incubation with another pro-oxidant agents- $-\mathrm{FeSO}_{4}$ and SNP (a NO donor). Its beneficial effects against the NOinduced neurotoxicity were also reported by Taram et al. [291] who showed that caffeic acid protects cerebellar granule neurons from the SNP-induced death. The effect was accompanied by reduced NO production indicating that caffeic acid protects neurons against nitrosative stress via free radical scavenging activity. In the same study, caffeic acid provided significant protection against the glutamate/glycine-induced neurotoxicity, which is in line with previous reports showing that this compound protects primary cultures of rat cortical neurons from the excitoxicity induced by glutamate [296,341,342]. It is noteworthy that the neuroprotective effect was mediated by inhibition of the glutamateinduced intracellular $\mathrm{Ca}^{2+}$ influx and subsequent reduction in ROS formation [342]. Caffeic acid also exhibited anti-apoptotic properties by suppressing the glutamate-induced caspase activation [296]. Moreover, it ameliorated (via inhibiting 5-LOX activation) the NMDAinduced early and delayed injuries in PC12 cells [343] and the quinolinic acid-induced oxidative stress in rat brain homogenates [290] and rat striatal slices [344]. Interestingly, caffeic acid also attenuated cerebellar granule neurons death induced by brefeldin A-an ER stressor [291]. In contrast, it did not inhibit SH-SY5Y cell death induced by another ER stressor-tunicamycin [345]. This could have been due to the fact that these two 
agents have distinct mechanisms of action. Brefeldin A inhibits transport between the ER and Golgi apparatus, whereas tunicamycin suppresses protein glycosylation in the Golgi apparatus [291,345]. Furthermore, caffeic acid displayed protective activity against caspase-dependent intrinsic apoptosis in cerebellar granule neurons [291]. It seems that the anti-apoptotic effect of caffeic acid may result from its ability to modulate the anti-apoptotic and pro-survival pathways in neuronal cells. For instance, it upregulated anti-apoptotic proteins (Bcl2 and Bcl-XL) and downregulated pro-apoptotic proteins (Bad, PARP, and cleaved caspase 3) in mouse retinal ganglion cells subjected to the hypoxia-induced damage. In HT22 mouse hippocampal cells, caffeic acid reduced the acrolein-induced neurotoxicity by activation of the pro-survival Akt/GSK3 $\beta$ signaling pathway [346]. It is noteworthy that it also protected cerebellar granule neurons from death evoked by PS-341—a proteasome inhibitor. Inhibition of proteasome activity induces cell apoptosis by accumulation of c-Jun and a pro-apoptotic Bim protein [291]. Since caffeic acid was shown to activate the AKT signaling that promotes cellular survival via inhibition of Bim protein [346], it seems that this compound confers neuroprotection against PS-341 by inhibition of the pro-apoptotic Bim protein. Finally, caffeic acid ameliorated the levodopa-induced toxicity in neuroblastoma SH-SY5Y cells [347] and the A $\beta$-induced neurotoxicity, by the inhibition of calcium influx and tau phosphorylation, in PC12 cells [348].

Animal studies have provided further support for neuroprotective effects of caffeic acid. Yang et al. [349] showed that repeated administration of caffeic acid protected mouse brain from the aluminum-induced damage. It reversed the learning and memory impairments caused by aluminum overload and antagonized the aluminum-induced increase in brain MDA levels and decrease in the expression of choline acetyltransferase. It also decreased overexpression of APP, A $\beta$, and 5-LOX. Likewise, caffeic acid improved the learning and memory deficits in the aluminum-treated rats and reduced the aluminum-induced increase in AChE, catalase, and glutathione-S-transferase activity (GST) as well as GSH and nitrate levels in the brain [350]. Similar results were obtained by Deshmukh et al. [351] who reported that caffeic acid ameliorated the streptozotocin-induced neurocognitive deficits. It improved non-spatial memory performance in the object recognition task and spatial memory performance in the Morris water maze test. Moreover, it attenuated streptozotocin-induced oxidative stress and produced dose dependent decrease in $\mathrm{AChE}$ activity. Decreased brain AChE activity was also observed in the $\mathrm{A} \beta_{1-40}$-induced neurotoxicity in rats [352]. Interestingly, a 30-day treatment with caffeic acid improved the learning and memory abilities in naïve rats and inhibited significantly the AChE activity in the cerebral cortex and the striatum but increased the AChE activity in the hippocampus, hypothalamus, and pons [353]. However, data from in vitro studies on the possible anti-AChE activity of caffeic acid are inconsistent. Oboh et al. [290] reported that this compound inhibited both the $\mathrm{AChE}$ and $\mathrm{BChE}$ activity in rat whole brain homogenates. In other studies, caffeic acid exhibited AChE inhibitory effect in the cerebral cortex of rat brain, whole brain without the cerebral cortex [354], and whole brain with the cerebral cortex [350]. In contrast, Anwar et al. [353] reported that caffeic acid significantly increased the AChE activity in the cerebral cortex, cerebellum, and hypothalamus, while in the striatum, hippocampus, and pons, it did not alter the enzyme activity. This suggests that caffeic acid may have the specific selectivity in relation to the AChE from different brain regions [353].

Neurodegeneration is also a hallmark feature of epilepsy. There are only few reports on the neuroprotective effects of caffeic acid in animal models of seizure and epilepsy. It produced an anticonvulsant-like effect in the pilocarpine-induced seizure model in rats and decreased hippocampal damage caused by seizures. Moreover, it decreased lipid peroxidation level and nitrite content and increased SOD and catalase activity in the hippocampus following seizures [355]. In addition, caffeic acid prevented the quinolinic acid-induced behavioral alterations in rats $[344,356]$ and restored the redox status in rat striatum by increasing the levels of GSH and GSH/GSSG, reversing the rise in oxidized glutathione level in quinolinic acid-treated animals [356], which add support to the neuroprotective 
properties of this coffee compound against the excitotoxic damage. In the kainic acidinduced excitotoxicity model in rats, caffeic acid prolonged the latency to seizures and reduced neuronal loss in the CA3 hippocampal field [357]. Further studies, however, did not confirm the anticonvulsant-like properties of caffeic acid. It was not effective against the pentylenetetrazole- and pilocarpine-induced seizures in mice [358] and did not produce antiepileptogenic effect in the kindling model of epilepsy [359]. Nonetheless, caffeic acid presented neuroprotective effect against the pilocarpine-induced genotoxic damage in the mouse hippocampus [358]. It also showed neuroprotective action against DNA damage and oxidative stress in the cerebral cortex caused by the pentylenetetrazole-induced kindling in mice [359].

Several reports demonstrated that caffeic acid has protective effects on focal [360-363] and global [364] cerebral ischemia/reperfusion injury in rodents. Caffeic acid significantly reduced infarct volume and improved neurological deficit scores in mice [361] and rats [362,363] after induction of focal cerebral ischemia. It also decreased cell damage in the ischemic hippocampal CA1 region of Mongolian gerbils [360] and attenuated hippocampal neurons injury induced by global cerebral ischemia-reperfusion in rats [364]. Moreover, Pinheiro Fernandes et al. [361] showed that caffeic acid protects against ischemia-induced cognitive impairments. It attenuated working, spatial, and long-term aversive memory deficits in mice with focal cerebral ischemia. A beneficial effect of caffeic acid on cognitive decline following ischemia was also reported by Liang et al. [364]. In rats with global cerebral ischemia, it attenuated learning and memory deficits. There is evidence of microglia activation in ischemic stroke, and it appears that the neuroprotective effects of caffeic acid against ischemic injury may result, at least in part, from its ability to attenuate astrocyte proliferation and microglia activation. It was demonstrated that caffeic acid inhibited astrocyte proliferation 14 days after focal cerebral ischemia in rats [363] and decreased microglia activation and its protein level in ischemic gerbils [360]. The protective effects of caffeic acid in ischemia models may be also related to its ability to inhibit 5-LOX activity as it suppressed the production of leukotrienes (i.e., 5-LOX metabolites) in the rat brain after focal ischemia induction [363] as well as in the PC12 cells exposed to oxygen-glucose deprivation/reperfusion (OGD/OGD-R) insult - an in vitro model of ischemia/reperfusion [362]. Furthermore, caffeic acid downregulated the 5-LOX mRNA and protein overexpression in rats with global cerebral ischemia-reperfusion injury [364]. A declined expression of 5-LOX after caffeic acid treatment was also observed in rats with focal cerebral ischemia [362]. In OGD/OGD-R PC12 cells, caffeic acid suppressed the production of arachidonic acid by lipoxygenase metabolism, maintained the ultrastructure and integrated function of mitochondria, decreased ROS generation, and finally protects the cells from ischemia [362]. It is also worth mentioning that caffeic acid decreased caspase 3 immunoreactivity [361], reduced NF- $\mathrm{kBp} 65$ overexpression, decreased the brain MDA level and increased SOD activity [364], which further suggests that it may also ameliorate inflammation and oxidative stress following global cerebral ischemia-reperfusion injury. Interestingly, caffeic acid was also shown to inhibit the reduction of synaptophysin expression after ischemic insult in mice. Of note, synaptophysin is a membrane-associated protein that is an important marker of synaptogenesis, synaptic density, and neural development. Its expression decreases following ischemia, which is correlated with memory deficits [361].

Caffeic acid attenuated the lesion and neuron loss after cryoinjury in mice, which suggests its neuroprotective effect against traumatic brain injury. It inhibited astrocytes activation and thereby attenuating their proliferation and glial scar formation in the late phase of cryoinjury. Moreover, it inhibited the decrease in SOD activity and the increase in MDA content in the brain after cryoinjury [365]. In an in vivo model of Alzheimer's disease, it ameliorated the $\mathrm{A} \beta_{1-40}$-induced learning and memory impairment, increased synaptophysin expression and weakened the cerebral damage in rats. The effect was accompanied by inhibition of AChE activity, suppression of oxidative stress and reduced inflammation [352]. 
It was showed that caffeic acid may be also a preventive agent against the progression of Parkinson's disease. In vitro, caffeic acid provided protection against the 5-S-cysteinyldopamine-induced neurotoxicity in mouse cortical neurons [366]. Li et al. [367] showed that this compound protects against dopaminergic neurodegeneration in in vivo model. In the LPS-treated rats, it attenuated the loss of nigral dopaminergic neurons and microglia activation [367]. Next studies showed that caffeic acid reversed the paraquat-induced movement impairment (i.e., climbing capability) in Drosophila melanogaster-a valid model of Parkinson's disease [368]. In the same model, caffeic acid reduced fly mortality, restored mitochondrial activity, and attenuated the paraquat-induced oxidative stress [369]. Moreover, Tsai et al. [370] reported the neuroprotective effect of this compound in the MPTP mouse model of Parkinson's disease. It decreased the MPTP-caused inflammatory stress by suppressing the production of inflammatory cytokines (i.e., IL-1 $\beta$, IL-6, TNF $\alpha$, IL-4 and IL-10), lowering the production of $\mathrm{NO}$ and prostaglandin E2, and the activity of total NOS and COX-2. Caffeic acid intake also declined the expression of iNOS, nNOS, and COX-2 as well as retained the expression and production of BDNF, GDNF, and tyrosine hydroxylase in the striatum of the MPTP-treated mice. Although caffeic acid failed to affect dopamine transporter expression, it restored dopamine, DOPAC and HVA levels [370]. In rotenone-injected mice, chlorogenic acid attenuated degeneration of dopaminergic neurons in the substantia nigra and increased the expression of metallothionein- 1 and 2 in striatal astrocytes [321]. In another study, caffeic acid produced neuroprotective effects in the $\alpha$-synuclein-induced models of Parkinson's disease. $\alpha$-Synuclein is a presynaptic neuronal protein that is implicated in the pathophysiology of this disease. In SH-SY5Y cells overexpressing A53T $\alpha$-synuclein, caffeic acid alleviated the cell damage caused by overexpression of A53T $\alpha$-synuclein, suppressed the accumulation of A53T $\alpha$-synuclein, and induced the JNK/Bcl-2-mediated cell autophagy to degrade A53T $\alpha$-synuclein. In next experiments, caffeic acid administered for 8 weeks alleviated motor deficits, induced autophagy, decreased the accumulation of A53T $\alpha$-synuclein, and ameliorated the loss of dopaminergic neurons in the substantia nigra of A53T transgenic mice (i.e., mice expressing the human A53T mutant of $\alpha$-synuclein) [371]. Recently, caffeic acid was also reported to improve survival and motor performance in wild type Caenorhabditis elegans exposed to dopaminergic toxin 6-OHDA, which was in line with data obtained from in vitro studies. Specifically, caffeic acid prevented the loss of reductive capacity, cell damage, and the oxidative damage induced by 6-OHDA in rat cortical slices. Additionally, similar neuroprotective effects of caffeic acid were observed in both Caenorhabditis elegans and rat cortical slices treated with $\mathrm{FeSO}_{4}$ and quinolinic acid. Based on further molecular studies, it was concluded that caffeic acid confers neuroprotection against different toxic insults via the Nrf2/ARE pathway in the mammalian cortical tissue and the orthologous skn-1 pathway in the worms [372].

CAPE, a caffeic acid derivative, was also reported to exhibit neuroprotective effects in numerous in vitro studies. For example, it prevented the glutamate-induced excitotoxicity by inhibiting phosphorylation of p38 and caspase- 3 activation in cerebellar granule neurons [373]. CAPE also protected T22 mouse hippocampal cells from acrolein-induced neurodegeneration through modulating MAPKs and Akt/GSK3b signaling pathways [346]. Moreover, it was shown to be a potent inducer of HO-1 in astroglial cells and neurons [374]. Interestingly, inhibition of NF-kB by CAPE downregulated the release of pro-inflammatory miRNAs from primary human neuronal-glial cells stressed with the brain tissue-derived extracellular fluid from patients with Alzheimer's disease [375]. In an animal model of Alzheimer's disease, CAPE decreased $\mathrm{A} \beta_{1-42}$-induced neuronal apoptosis and neuroinflammation and improved learning and memory [376]. Furthermore, CAPE was effective against the $\mathrm{MPP}^{+}-[377,378]$ and 6-OHDA-induced $[379,380]$ neurotoxicity in vitro and attenuated the dopaminergic neuronal loss induced by 6-OHDA in mice [381] and rats [382] as well as by MPTP in mice [378], which makes it a potential therapeutic candidate for the prevention and/or treatment of Parkinson's disease. CAPE was also reported to produce neuroprotective effects in animal models of ischemia. It reduced focal cerebral ischemia 
injury in both mice and rats possibly through its antioxidant and anti-inflammatory effects and/or via the upregulation of NO production [383-385]. In addition, it inhibited apoptotic cell death in ischemic rats by downregulating caspase 3 and upregulating anti-apoptotic protein Bcl-xL [385]. CAPE also exhibited a preventive effect on early brain injury after subarachnoid hemorrhage in rats [386]. In other studies, this compound reversed cognitive impairment induced by streptozotocin [387], D-galactose [388], and cadmium [389].

Taken together, in vitro studies show that caffeic acid protects neurons from a wide range of cell death-inducing agents. Moreover, data from animal studies (Table 5) indicate that this compound may prevent neuronal damage/death caused by different stressors suggesting that caffeic acid is a promising neuroprotective compound for the prevention and treatment of neurodegenerative diseases. Unfortunately, there are no human intervention studies or clinical trials on this matter. Nevertheless, based on the above-mentioned reports, it appears that the neuroprotective properties of coffee may be largely attributed to the presence of caffeic acid.

\subsection{Neuroprotective Effects of Trigonelline}

Trigonelline, the second most abundant alkaloid in coffee beans, exerts a wide range of pharmacological effects including an anti-hyperglycemic, anti-hyperlipidemic, antibacterial, antiviral, and anti-tumor activity [390,391]. In contrast to caffeine or chlorogenic acid, neuroprotective effects of trigonelline have not been so extensively studied. However, there are several preliminary in vitro and in vivo studies showing that trigonelline provides neuroprotection and may be beneficial in the management of some neurodegenerative conditions. Few reports focused on the possible protective effects of trigonelline against Alzheimer's disease. Molecular docking study showed that it has high affinity to the $A \beta_{1-42}$ peptide altering its structure and thereby inhibiting its aggregation [392]. In rat cortical neurons, trigonelline prevented dendritic and axonal atrophy induced by administration of $\mathrm{A} \beta_{25-35}$. It also reversed the $\mathrm{A} \beta_{25-35}$-induced impairment of spatial memory in mice [393]. Moreover, trigonelline produced neuroprotective effect in a rat model of Alzheimer's disease induced by administration of $A \beta_{1-40}$. Pretreatment of $A \beta_{1-40}$-microinjected rats with trigonelline significantly improved spatial recognition memory in the $Y$ maze test and performance in the novel object recognition task. Importantly, histological analysis showed that trigonelline prevented $A \beta_{1-40}$-induced loss of hippocampal CA1 neurons. Furthermore, it decreased oxidative stress parameters; augmented antioxidant defensive system; reduced hippocampal levels of glial fibrillary acidic protein (GFAP), S100b, COX-2, TNF- $\alpha$, and IL-6; and improved mitochondrial membrane potential. Thus, it appears that the neuroprotective effect could be mediated by the reduction of oxidative stress, neuroinflammation, astrocyte activity, and preservation of mitochondrial integrity [394]. In another study, trigonelline ameliorated LPS-induced cognitive decline in mice in the Morris water maze task and $\mathrm{Y}$ maze test, which suggests that it can improve both spatial and working memory. The behavioral effects were accompanied with reduced oxidative stress parameters, decreased level of pro-inflammatory cytokines, decreased AChE activity, and upregulated BDNF level in both the hippocampus and cortex [395]. Similar results were obtained by Khalili et al. [396] who reported that trigonelline diminished the LPS-induced learning and memory disturbances via suppression of hippocampal oxidative stress, neuroinflammation, and $\mathrm{AChE}$ activity. In addition, they showed that the anti-inflammatory effect of trigonelline could be mediated by the NF- $\mathrm{KB}$ and TLR4 signaling pathways. 
Table 5. Summary of in vivo studies on the neuroprotective effects of caffeic acid.

\begin{tabular}{|c|c|c|c|c|c|}
\hline Animals & Treatment & Model & Behavioral Tests & Main Outcomes & Ref. \\
\hline Mice (KM strain) & $\begin{array}{l}10 \text { and } 30 \mathrm{mg} / \mathrm{kg} \text { (p.o.) } 30 \mathrm{~min} \\
\text { before aluminum injection and } \\
\text { then for } 10 \text { consecutive days }\end{array}$ & $\begin{array}{l}\text { Aluminum-induced } \\
\text { neurotoxicity }\end{array}$ & $\begin{array}{l}\text { Passive avoidance task, } \\
\text { water maze test }\end{array}$ & $\begin{array}{l}\text { (1) Attenuation of the aluminum-induced } \\
\text { impairment of learning and memory, (2) } \\
\text { decreased MDA level, (3) increased choline } \\
\text { acetyltransferase expression, (4) decreased } \\
\text { expression of amyloid precursor protein of } A \beta \text {, } \\
\text { and 5-LOX }\end{array}$ & [349] \\
\hline Male Wistar rats & $100 \mathrm{mg} / \mathrm{kg}$ (p.o.) for 11 days & $\begin{array}{l}\text { Aluminum-induced } \\
\text { neurotoxicity }\end{array}$ & Morris water maze test & $\begin{array}{l}\text { (1) Improved memory; (2) reduced AChE, } \\
\text { catalase, and GST activity; (3) reduced GSH and } \\
\text { nitrite levels }\end{array}$ & [350] \\
\hline Wistar rats & $10-40 \mathrm{mg} / \mathrm{kg}$ (p.o.) for 21 days & $\begin{array}{l}\text { Streptozotocin- induced } \\
\text { dementia }\end{array}$ & $\begin{array}{l}\text { Object recognition test, } \\
\text { Morris water maze test, } \\
\text { locomotor activity test }\end{array}$ & $\begin{array}{l}\text { (1) Attenuation of the streptozotocin -induced } \\
\text { learning and memory impairments; (2) increase } \\
\text { in AChE activity; (3) increase in MDA, nitrite, } \\
\text { and protein carbonyl levels; and (4) decrease in } \\
\text { GSH level }\end{array}$ & [351] \\
\hline Sprague-Dawley rats & $100 \mathrm{mg} / \mathrm{kg}$ (i.p.) for 2 weeks & $\mathrm{A} \beta_{1-40}$-induced neurotoxicity & Morris water maze test & $\begin{array}{l}\text { (1) Improved cognitive deficits, (2) decreased } \\
\text { AChE activity and nitrite generation, (3) } \\
\text { increased activity of catalase and GSH, (4) } \\
\text { reduced IL-6 and TNF- } \alpha \text { levels, (5) decreased } \\
\text { NF-KB-p65 protein expression and caspase-3 } \\
\text { activity, and (6) decreased p53 and p-p38 MAPK } \\
\text { protein expression }\end{array}$ & [352] \\
\hline Wistar rats & $10-100 \mathrm{mg} / \mathrm{kg}$ (p.o.) for 30 days & - & $\begin{array}{l}\text { Step-down inhibitory } \\
\text { avoidance test, open field test }\end{array}$ & $\begin{array}{l}\text { (1) Improved learning and memory; (2) } \\
\text { decreased AChE activity in the cerebral cortex } \\
\text { and striatum; and (3) increased AChE activity in } \\
\text { the cerebellum, hippocampus, hypothalamus, } \\
\text { and pons }\end{array}$ & [353] \\
\hline Wistar rats & $\begin{array}{l}4 \mathrm{mg} / \mathrm{kg} \text { (i.p.) } 30 \mathrm{~min} \text { before } \\
\text { pilocarpine injection }\end{array}$ & Pilocarpine-induced seizures & $\begin{array}{l}\text { Seizure assessment (latency } \\
\text { to the first seizure, \% } \\
\text { seizures) }\end{array}$ & $\begin{array}{l}\text { (1) Anticonvulsant-like effect, (2) decreased } \\
\text { lipid peroxidation level and nitrite content, (3) } \\
\text { increased SOD and catalase activity }\end{array}$ & [355] \\
\hline Wistar rats & $\begin{array}{l}20 \mathrm{mg} / \mathrm{kg} \text { (i.p.) for } 5 \text { days before } \\
\text { quinolinic acid administration }\end{array}$ & $\begin{array}{l}\text { Quinolinic acid-induced } \\
\text { neurotoxicity }\end{array}$ & $\begin{array}{l}\text { Circling behavior test, } \\
\text { cylinder test }\end{array}$ & $\begin{array}{l}\text { Attenuation of the quinolinic acid-induced } \\
\text { behavioral alterations }\end{array}$ & [344] \\
\hline
\end{tabular}


Table 5. Cont.

\begin{tabular}{|c|c|c|c|c|c|}
\hline Animals & Treatment & Model & Behavioral Tests & Main Outcomes & Ref. \\
\hline Male Wistar rats & 5 and $10 \mathrm{mg} / \mathrm{kg}$ (p.o.) for 21 days & $\begin{array}{l}\text { Quinolinic acid-induced } \\
\text { neurotoxicity }\end{array}$ & $\begin{array}{l}\text { Locomotor activity test, } \\
\text { rotarod test }\end{array}$ & $\begin{array}{l}\text { (1) Improvement of locomotor activity and } \\
\text { motor coordination, (2) restored redox status in } \\
\text { striatum }\end{array}$ & [356] \\
\hline Fisher rats & $50 \mathrm{mg} / \mathrm{kg}$ (i.p.) 4 injections & $\begin{array}{l}\text { Kainic acid-induced } \\
\text { neurotoxicity }\end{array}$ & $\begin{array}{l}\text { Seizure assessment (latency } \\
\text { to seizures, seizure severity) }\end{array}$ & $\begin{array}{l}\text { (1) Prolonged latency to seizures, (2) reduced } \\
\text { neuronal loss in the CA3 hippocampal field }\end{array}$ & [357] \\
\hline CF1 mice & $\begin{array}{l}4 \text { and } 8 \mathrm{mg} / \mathrm{kg} \text { (i.p.) } 30 \mathrm{~min} \\
\text { before seizure induction }\end{array}$ & $\begin{array}{l}\text { Pilocarpine- and } \\
\text { pentylenetetrazole-induced } \\
\text { seizures }\end{array}$ & $\begin{array}{l}\text { Seizure assessment (latency } \\
\text { to the first seizure, } \% \\
\text { seizures) }\end{array}$ & $\begin{array}{l}\text { (1) No anticonvulsant-like effect, (2) protection } \\
\text { against pilocarpine-induced genotoxic damage } \\
\text { in the hippocampus }\end{array}$ & [358] \\
\hline CF1 mice & $\begin{array}{l}1-8 \mathrm{mg} / \mathrm{kg} \text { (i.p.) } 30 \mathrm{~min} \text { before } \\
\text { pentylenetetrazole injection, once } \\
\text { every three day, for a total of } \\
6 \text { injections }\end{array}$ & $\begin{array}{l}\text { Pentylenetetrazole -induced } \\
\text { kindling }\end{array}$ & $\begin{array}{l}\text { Seizure assessment (latency } \\
\text { to the first seizure and the } \\
\text { occurrence of clonic forelimb } \\
\text { seizures) }\end{array}$ & $\begin{array}{l}\text { (1) No antiepileptogenic-like effect, (2) } \\
\text { protection against kindling-induced genotoxic } \\
\text { damage in cerebral cortex, (3) decreased ROS } \\
\text { production }\end{array}$ & [359] \\
\hline Mongolian gerbils & $\begin{array}{l}10 \text { and } 20 \mathrm{mg} / \mathrm{kg} \text { (p.o.) for } 3 \text { days } \\
\text { before ischemia induction }\end{array}$ & $\begin{array}{l}\text { Transient cerebral ischemia } \\
\text { injury }\end{array}$ & & $\begin{array}{l}\text { (1) Decreased cell damage in the ischemic } \\
\text { hippocampal CA1 region, (2) inhibition of } \\
\text { microglia activation }\end{array}$ & [360] \\
\hline Swiss mice & 2-60 mg/kg (i.p.) for 5 days & Focal cerebral ischemia injury & $\begin{array}{l}\text { Neurological deficit scoring, } \\
\text { passive avoidance test, } \\
\text { Y-maze test, water maze test, } \\
\text { open field test }\end{array}$ & $\begin{array}{l}\text { (1) Reduced infarcted area and improved } \\
\text { neurological deficit scores, (2) improvement of } \\
\text { working, spatial, and long-term aversive } \\
\text { memory deficits, (3) attenuation of the } \\
\text { ischemia-induced reduction in synaptophysin } \\
\text { expression, and (4) increase in caspase } \\
3 \text { expression }\end{array}$ & [361] \\
\hline Sprague-Dawley rats & $\begin{array}{l}50 \mathrm{mg} / \mathrm{kg} \text { (i.p.) immediately after } \\
\text { ischemia induction and then } \\
\text { repeatedly for } 12 \mathrm{~h}\end{array}$ & $\begin{array}{l}\text { Cerebral } \\
\text { ischemia/reperfusion injury }\end{array}$ & Neurological deficit scoring & $\begin{array}{l}\text { (1) Improved neurological deficit scores, (2) } \\
\text { reduced infraction volume, (3) decreased 5-LOX } \\
\text { expression }\end{array}$ & [362] \\
\hline Sprague-Dawley rats & $\begin{array}{l}50 \mathrm{mg} / \mathrm{kg} \text { (i.p.) } 30 \mathrm{~min} \text { before } \\
\text { ischemia induction and } 0,1,2 \mathrm{~h} \\
\text { after reperfusion in } 1 \mathrm{st} \text { day, and } \\
\text { twice daily in the } 2 \text { nd to } 5 \text { th day }\end{array}$ & $\begin{array}{l}\text { Focal cerebral } \\
\text { ischemia/reperfusion injury }\end{array}$ & $\begin{array}{l}\text { Neurological deficit scoring, } \\
\text { inclined board test }\end{array}$ & $\begin{array}{l}\text { (1) Reduction of neurological deficits, (2) } \\
\text { decreased neuron loss, infarct volume, brain } \\
\text { atrophy, and astrocyte proliferation, ( } 3 \text { ) } \\
\text { inhibition of leukotriene production }\end{array}$ & [363] \\
\hline
\end{tabular}


Table 5. Cont.

\begin{tabular}{|c|c|c|c|c|c|}
\hline Animals & Treatment & Model & Behavioral Tests & Main Outcomes & Ref. \\
\hline Sprague-Dawley rats & $\begin{array}{l}10-50 \mathrm{mg} / \mathrm{kg} \text { (i.p.) } 30 \mathrm{~min} \text { before } \\
\text { ischemia induction }\end{array}$ & $\begin{array}{l}\text { Global cerebral } \\
\text { ischemia-reperfusion injury }\end{array}$ & Morris water maze test & $\begin{array}{l}\text { (1) Attenuation of the ischemia-induced spatial } \\
\text { learning and memory deficits, (2) reduced } \\
\text { hippocampal neurons injury, (3) decreased } \\
\text { MDA level, (4) increased SOD activity, and (5) } \\
\text { suppressed 5-LOX overexpression }\end{array}$ & {$[364]$} \\
\hline ICR mice & $\begin{array}{l}10 \text { and } 50 \mathrm{mg} / \mathrm{kg} \text { (i.p.) } 30 \mathrm{~min}, 2 \\
\text { and } 6 \mathrm{~h} \text { after cryoinjury on the } \\
1 \text { st day and twice daily on days } 2 \\
\text { to } 7\end{array}$ & Brain cryoinjury & - & $\begin{array}{l}\text { (1) Reduced astrocyte proliferation and glial scar } \\
\text { wall formation, (2) decreased expression of } \\
\text { GFAP protein, (3) decreased SOD activity and } \\
\text { (4) increased MDA level }\end{array}$ & [365] \\
\hline Sprague-Dawley rats & $\begin{array}{l}50 \mathrm{mg} / \mathrm{kg} \text { (p.o.) 10.5, 5.5, and } 0.5 \\
\mathrm{~h} \text { before LPS injection }\end{array}$ & LPS-induced neurotoxicity & - & $\begin{array}{l}\text { Attenuation of the LPS-induced loss of } \\
\text { dopaminergic neurons and microglial activation } \\
\text { in the substantia nigra }\end{array}$ & {$[367]$} \\
\hline C57BL/6 mice & $0.5-2 \%$ in diet, for 4 weeks & MPTP-induced neurotoxicity & - & $\begin{array}{l}\text { (1) Decreased inflammatory cytokines levels; (2) } \\
\text { suppressed NO, prostaglandin E2, and GFAP } \\
\text { production; (3) reserved BDNF, GDNF, and } \\
\text { tyrosine hydroxylase levels; (4) improved } \\
\text { synthesis of dopamine }\end{array}$ & [370] \\
\hline C57BL/6J mice & $\begin{array}{l}50 \mathrm{mg} / \mathrm{kg} \text { (p.o.) for } 1 \text { week } \\
\text { before rotenone exposure, and } \\
\text { then } 5 \text { days / week during the } \\
4 \text { weeks of rotenone treatment }\end{array}$ & $\begin{array}{l}\text { Rotenone-induced } \\
\text { neurotoxicity }\end{array}$ & - & $\begin{array}{l}\text { (1) Prevented degeneration of dopaminergic } \\
\text { neurons in the substantia nigra, (2) upregulated } \\
\text { metallothionein- } 1 \text { and } 2 \text { in striatal astrocytes }\end{array}$ & [321] \\
\hline
\end{tabular}


It appears that trigonelline may also produce neuroprotective effects due to its antiglycating properties. In in vitro experiments, it suppressed formation of advanced glycation end products (AGEs), pentosidine compounds, and Amadori compounds (i.e., early markers of protein glycation). This is an important observation as AGEs contribute to amyloidosis in Alzheimer's disease suggesting that glycoxidation plays a crucial role in the pathogenesis of this disease. It was demonstrated that chronic administration of Dgalactose impairs learning and memory, induces oxidative damage, elevates the AGEs levels, and increases AChE activity in mice. It is noteworthy that trigonelline treatment significantly improved cognitive performance in the Morris water maze and Y-maze tests, reduced oxidative stress, and decreased AGEs and AChE levels in D-galactose-treated animals [397].

Neuroprotective properties of trigonelline were also reported in experimental models of Parkinson's disease. In unilaterally 6-OHDA-lesioned rats, it reduced apomorphineinduced rotations, increased the viability of neurons in the substantia nigra pars compacta, prevented apoptosis, and restored the MDA level [398]. Gaur et al. [399] showed however that trigonelline (but only at low doses) increased the number of ipsilateral rotations in the 6-OHDA-lesioned rats, indicating dopamine releasing action. In the same study, trigonelline pretreatment also reversed the MPTP-induced motor dysfunctions in mice. Additionally, it was demonstrated that this coffee compound is devoid of anticholinergic effects and does not inhibit MAO-B activity [399].

It is also worth mentioning that trigonelline was neuroprotective in ischemic stroke [400] and oxygen-glucose deprivation-induced neural injury [391]. Trigonelline injected immediately following ischemia induction produced neuroprotection in rats by reducing cerebral infarct, which was accompanied with improvement in motor and neurodeficit scores. Moreover, it reduced the glutathione-mediated expression of myeloperoxidase in the cortical brain region and augmented the antioxidant status. Consistent with in vivo findings, trigonelline increased the PC12 cell viability following hypoxia induction in in vitro experiments [400]. Qiu et al. [391] demonstrated that trigonelline protected hippocampal neurons from the oxygen-glucose deprivation/reperfusion-induced injury. It also ameliorated oxidative stress, attenuated inflammatory response, and inhibited cell apoptosis in hippocampal neurons. Of note, the neuroprotective effect was probably mediated by the activation of PI3K/Akt signaling pathway.

Taken together, the above-mentioned reports (Table 6) consistently demonstrated that trigonelline may be a promising neuroprotective agent mainly due to its antioxidant, antiinflammatory, and anti-apoptotic properties. However, the exact molecular mechanisms underlying the neuroprotective effects of trigonelline need to be established. Some studies showed possible involvement of the TLR4/NF-KB [396] and PI3K/Akt [391] signaling pathways, but these are preliminary findings only. It is noteworthy that a recent study showed trigonelline exerts an antidepressant-like effect in mice via reduction of NMDA receptor activity [401], which deserves further investigation as the NMDA-mediated glutamatergic transmission is also implicated in the pathophysiology of neurodegenerative disorders. It has been postulated that coffee may exert health promoting effects, including neuroprotective ones, via dampening inflammation-induced NF- $\mathrm{KB}$ activity and activation of the Nrf2 system with subsequent enhancement of the cell defense response [402,403]. Indeed, several coffee constituents (i.e., chlorogenic acids, caffeic acid, kahweol, and cafestol) have been reported to act as inducers of the Nrf2 pathway. In contrast, trigonelline is a potent inhibitor of the Nrf2 transcription factor and the inhibitory effect is observed at physiologically relevant concentrations. Importantly, roasting of coffee beans increases their ability to activate the Nrf2/ARE pathway. This is related to the formation of new potent activators of the Nrf2 transcription factor during roasting process (e.g., $\mathrm{N}$-methylpyridinium ion). A lower content of trigonelline in roasted coffee may also contribute to the stronger activation of Nrf2/ARE pathway [402-404]. Thus, the question also arises whether trigonelline significantly contributes to the beneficial effects of coffee beverages consumption in neurodegenerative diseases. 
Table 6. Summary of in vivo studies on the neuroprotective effects of trigonelline

\begin{tabular}{|c|c|c|c|c|c|}
\hline Animals & Treatment & Model & Behavioral Tests & Main Outcomes & Ref. \\
\hline ddY mice & $500 \mathrm{mg} / \mathrm{kg}$ (p.o.) for 15 days & $\begin{array}{l}\mathrm{A} \beta_{25-35} \text {-induced memory } \\
\text { impairment }\end{array}$ & Morris water maze test & Attenuated memory impairment & [393] \\
\hline Wistar rats & $100 \mathrm{mg} / \mathrm{kg}$ (p.o.) for 3 days & $\begin{array}{l}\mathrm{A} \beta_{25-35} \text { induced } \\
\text { neurotoxicity }\end{array}$ & $\begin{array}{l}\text { Y maze test, } \\
\text { novel object recognition task }\end{array}$ & $\begin{array}{l}\text { (1) Attenuated learning and memory } \\
\text { impairment; (2) alleviated hippocampal } \\
\text { neuronal loss; (3) improved mitochondrial } \\
\text { membrane potential; (4) restored MDA, protein } \\
\text { carbonyl, and GSH levels; (5) reduced SOD and } \\
\text { LDH activity; (6) reduced GFAP, S100b, COX-2, } \\
\text { TNF- } \alpha \text {, and IL-6 level in the hippocampus }\end{array}$ & [394] \\
\hline Swiss Albino mice & $\begin{array}{l}50 \text { and } 100 \mathrm{mg} / \mathrm{kg} \text { (p.o.) for } \\
28 \text { days }\end{array}$ & LPS-induced neurotoxicity & $\begin{array}{l}\text { Morris water maze test, } \\
\text { Y maze test }\end{array}$ & $\begin{array}{l}\text { (1) Attenuated learning and memory } \\
\text { disturbances, (2) decreased AChE activity, (3) } \\
\text { restored SOD activity, (4) restored GSH and } \\
\text { lipid peroxidation levels, (5) decreased TNF- } \alpha \\
\text { and IL-6 levels, and (6) increased BDNF level }\end{array}$ & [395] \\
\hline Wistar rats & 20-80 mg/kg (p.o.) for 7 days & LPS-induced neurotoxicity & $\begin{array}{l}\text { Y maze test, } \\
\text { Novel object discrimination } \\
\text { test, passive avoidance test }\end{array}$ & $\begin{array}{l}\text { (1) Attenuated learning and memory } \\
\text { disturbances; (2) decreased MDA level and } \\
\text { AChE activity; (3) increased SOD and catalase } \\
\text { activity; (4) reduced GSH level; and (5) } \\
\text { decreased NF- } \kappa B \text {, TLR4, and TNF- } \alpha \text { levels }\end{array}$ & [396] \\
\hline Swiss Albino mice & $20-80 \mathrm{mg} / \mathrm{kg}$ (p.o.) for 6 weeks & $\begin{array}{l}\text { D-Galactose induced } \\
\text { cognitive impairment }\end{array}$ & $\begin{array}{l}\text { Morris water maze test, } \\
\text { Y maze test }\end{array}$ & $\begin{array}{l}\text { (1) Attenuated learning and memory } \\
\text { disturbances, (2) decreased AChE activity, (3) } \\
\text { decreased AGEs and MDA levels, (4) increased } \\
\text { SOD activity and GSH level }\end{array}$ & [397] \\
\hline Wistar rats & $\begin{array}{l}50 \text { and } 100 \mathrm{mg} / \mathrm{kg} \text { (i.p.) for } \\
3 \text { days }\end{array}$ & $\begin{array}{l}\text { 6-OHDA-induced } \\
\text { neurotoxicity }\end{array}$ & $\begin{array}{l}\text { Apomorphine-induced } \\
\text { rotation test }\end{array}$ & $\begin{array}{l}\text { (1) Reduced rotational behavior, (2) increased } \\
\text { viability of neurons in substantia nigra, (3) } \\
\text { prevented apoptosis, (4) reduced MDA and } \\
\text { nitrite levels, and (5) increased GSH level }\end{array}$ & [398] \\
\hline Wistar rats & $\begin{array}{l}\text { Trigonella foenum-graecum extract } \\
\text { (82\% trigonelline) } 30-100 \mathrm{mg} / \mathrm{kg} \\
\text { (p.o.), } 2 \text { weeks after 6-OHDA } \\
\text { injection }\end{array}$ & $\begin{array}{l}\text { 6-OHDA-induced } \\
\text { neurotoxicity }\end{array}$ & $\begin{array}{l}\text { Apomorphine-induced } \\
\text { rotation test }\end{array}$ & Increased number of ipsilateral rotations & [399] \\
\hline
\end{tabular}


Table 6. Cont

\begin{tabular}{|c|c|c|c|c|c|}
\hline Animals & Treatment & Model & Behavioral Tests & Main Outcomes & Ref. \\
\hline C57BL/6 mice & $\begin{array}{l}\text { Trigonella foenum-graecum extract } \\
\text { (82\% trigonelline) } 30 \mathrm{mg} / \mathrm{kg} \\
\text { (p.o.), } 60 \text { min before or after } \\
\text { MPTP }\end{array}$ & MPTP-induced neurotoxicity & Open field test & $\begin{array}{l}\text { Improved spontaneous locomotor activity in the } \\
\text { pre-treatment schedule }\end{array}$ & [399] \\
\hline Sprague-Dawley rats & $\begin{array}{l}25-100 \mathrm{mg} / \mathrm{kg} \text { (i.p.) twice } \\
\text { ( } 30 \mathrm{~min} \text { before and immediately } \\
\text { after ischemia induction) }\end{array}$ & $\begin{array}{l}\text { Cerebral } \\
\text { ischemia/reperfusion injury }\end{array}$ & $\begin{array}{l}\text { Neurological deficit scoring, } \\
\text { rotarod test }\end{array}$ & $\begin{array}{l}\text { (1) Improved motor coordination and } \\
\text { neurodeficit scores, (2) decreased cerebral } \\
\text { infarction volume, (3) reduced nitrite and MDA } \\
\text { levels, (4) increased GSH level, and (5) } \\
\text { decreased expression of myeloperoxidase }\end{array}$ & [400] \\
\hline
\end{tabular}




\subsection{Neuroprotective Effects of Kahweol and Cafestol}

Kahweol and cafestol are two coffee-specific diterpenes present in unfiltered coffees such as Scandinavian-style boiled coffee, Turkish-style coffee, French press coffee, and espresso. Although these two compounds are known mainly from their hypercholesterolemic effects, a growing body of evidence shows that kahweol and cafestol also have many beneficial effects such as anti-inflammatory, antioxidant, hepatoprotective, antidiabetic, and anti-carcinogenic activities $[405,406]$. However, data on the neuroprotective properties of these two compounds are quite limited.

Kahweol is a potent antioxidant agent with cytoprotective properties [407,408], which suggests that it should also produce neuroprotection. Indeed, Hwang and Jeong [409] demonstrated the protective effect of kahweol against the 6-OHDA-induced oxidative stress in the dopaminergic SH-SY5Y neuronal cells indicating its possible neuroprotective effects in Parkinson's disease. They showed that kahweol significantly increased cell survival following 6-OHDA treatment and reduced 6-OHDA-induced ROS production. It also induced heme oxygenase-1 expression and Nrf2 nuclear translocation in dopaminergic neuronal cells. Next experiments demonstrated the involvement of PI3K/Akt and p38 signaling in kahweol-induced heme oxygenase-1 upregulation [409]. Kahweol was also protective in the human neuroblastoma SH-SY5Y cells exposed to methylglyoxal. It decreased the methylglyoxal-induced loss of mitochondrial membrane potential, prevented the mitochondria-related bioenergetics decline, and suppressed production of ROS and RNS [407]. Likewise, kahweol promoted mitochondrial protection in SH-SY5Y cells exposed to $\mathrm{H}_{2} \mathrm{O}_{2}$, decreased the level of oxidative stress markers, and reduced the production of ROS [410]. In both of the aforementioned studies, the protective effect of kahweol was mediated via activation of the PI3K/Akt and p38 MAPK/Nrf2 signaling pathways [407,410], which is in line with previous findings by Hwang and Jeong [409]. It is also worth mentioning that kahweol was protective against the $\mathrm{H}_{2} \mathrm{O}_{2}$-induced DNA damage [408]. This is an important observation in view of the fact that oxidative DNA damage is one of the earliest changes in neurodegenerative diseases.

It is noteworthy that there is one in vivo study showing a possible protective effect of kahweol on brain neurons. In mice, acute systemic administration of kahweol ameliorated the traumatic brain injury-induced brain parenchymal damage and reversed short- and long-term functional outcomes. These effects were accompanied by reduced production of cytokines (IL-1 $\beta$, MIP- $1 \alpha$, MIP-2, and TIMP-1) in the brain, decreased microglia/macrophage activation, and reduced neutrophil and leukocyte infiltration. In addition, continuous administration of kahweol potentiated the protective effects of a single-dosage treatment [411]. This is an important finding as the traumatic brain injury is associated with an increased risk of neurodegenerative diseases, though the mechanism underlying this association is not clear [412].

To date, only one study focused on the possible neuroprotective properties of cafestol. Trinh et al. [413] studied its protective effect in Drosophila models of Parkinson's disease. They showed that cafestol conferred neuroprotection in both $\alpha$-synuclein transgenic and parkin null mutant flies. Moreover, it was demonstrated that the effect was mediated through the Nrf2-dependent mechanism [413]. Similarly to kahweol, cafestol was also demonstrated to produce antioxidant and anti-inflammatory effects. Other studies showed that cafestol may activate the Nrf2 / ARE signaling pathway, increase the expression of HO-1, eliminate excessive ROS production, and protect against oxidative DNA damage $[406,408]$. All these effects may contribute to its potential neuroprotective action.

Summarizing, there are some initial evidence suggesting neuroprotective effects of kahweol and cafestol. However, the possible protective effects of the two coffee diterpenes have to be confirmed in animal models of neurodegenerative diseases. More insight into the absorption and metabolism of kahweol and cafestolis also needed. A special attention should be given to the ability of kahweol and cafestol (and/or their active metabolites) to cross the BBB as their brain penetration has not been studied so far. Moreover, since 
the coffee diterpenes are known to raise serum cholesterol level, it will be necessary to carefully evaluate the risk/benefit ratio of using them for neuroprotection.

\section{Summary and Conclusions}

Extensive in vitro and in vivo studies have demonstrated that coffee and its bioactive compounds exert neuroprotective effects suggesting their preventive and/or therapeutic potential for different neurodegenerative conditions (Figure 3). Among them, caffeine has been the most extensively investigated and the beneficial effects of coffee consumption can be largely (but not solely) attributed to caffeine. However, numerous reports show that other coffee compounds may independently produce neuroprotective effects indicating that decaffeinated coffee could be also very effective in neurodegenerative conditions. Polyphenolic acids (i.e., chlorogenic acids and caffeic acid) and trigonelline appear to be the most promising, but in contrast to caffeine, there is a lack of epidemiological studies or clinical reports on their protective effects in neurodegenerative diseases. There are only preliminary data on the possible beneficial effects of chlorogenic acid on cognitive function in humans. Thus, large-scale observational and clinical studies are highly warranted to provide more insight into the neuroprotective effects of caffeine, coffee polyphenols, and trigonelline. Each compound should be studied separately as each one has its own unique properties and can have different effects depending on the disease. Moreover, the exact mechanism(s) by which each component confers neuroprotection should be elucidated. Their bioavailability and long-term adverse effects also warrant further investigation.
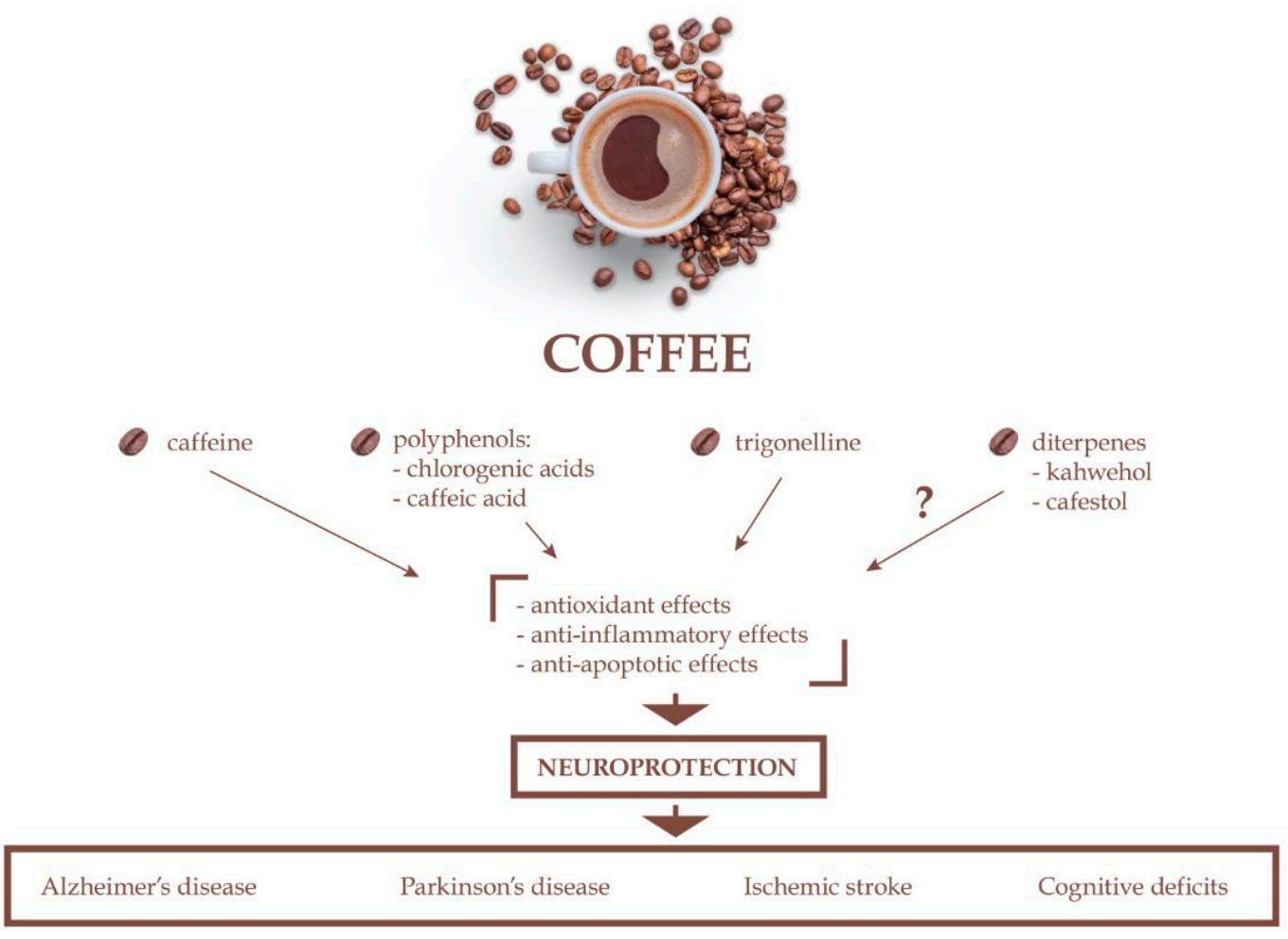

Figure 3. Summary of the neuroprotective effects of coffee.

On the other hand, the effects of coffee in neurodegenerative diseases may result from a synergistic action of many active compounds. Therefore, epidemiological and clinical studies should be continued to fully evaluate the association between regular coffee beverage consumption and the risk of neurodegenerative diseases. It should be, however, emphasized that such studies face a variety of challenges, and one of the most important is a high variability in the final composition of coffee beverage that depends on many factors such as coffee beans origin, roasting level, and brewing techniques [182]. In addition, since 
bioavailability of ingredients may depend on each individual's metabolism, the response to coffee intake can vary substantially across individuals [183], which should also be taken into account when studying the effect of coffee intake in neurodegenerative diseases.

Funding: This research received no external funding.

Institutional Review Board Statement: Not applicable.

Informed Consent Statement: Not applicable.

Conflicts of Interest: The authors declare no conflict of interest.

\begin{tabular}{|c|c|}
\hline \multicolumn{2}{|c|}{ Abbreviations } \\
\hline$A \beta$ & Amyloid beta \\
\hline $\mathrm{AChE}$ & Acetylcholinesterase \\
\hline AGEs & Advanced glycation end products \\
\hline Akt & Protein kinase B \\
\hline APP & Amyloid precursor protein \\
\hline APPsw & Swedish mutation mice, mice carrying the mutant APPK670N, M671L gene \\
\hline ATP & Adenosine- $5^{\prime}$-triphosphate \\
\hline Bax & Bcl-2-associated X protein \\
\hline $\mathrm{BBB}$ & Blood brain barrier \\
\hline $\mathrm{BChE}$ & Butyrylcholinesterase \\
\hline $\mathrm{Bcl} 2$ & B-cell lymphoma protein 2 \\
\hline BDNF & Brain-derived neurotrophic factor \\
\hline CAPE & Caffeic acid phenyl ester \\
\hline CBF & Cerebral blood flow \\
\hline CD31 & Platelet/endothelial cell adhesion molecule-1 \\
\hline CNS & Central nervous system \\
\hline COX-2 & Cyclooxygenase 2 \\
\hline CSF & Cerebrospinal fluid \\
\hline CYP & Cytochrome P450 \\
\hline DAT & Dopamine transporter \\
\hline ER & Endoplasmic reticulum \\
\hline ERK1/2 & Extracellular signal-regulated kinase-1 and -2 \\
\hline GABA & Gamma-aminobutyric acid \\
\hline GDNF & Glial cell line-derived neurotrophic factor \\
\hline GFAP & Glial fibrillary acidic protein \\
\hline GSK3 $\beta$ & Glycogen synthase kinase 3 beta \\
\hline GSH & Reduced glutathione \\
\hline GSH-Px & Glutathione peroxidase \\
\hline GST & Glutathione-S-transferase \\
\hline $\mathrm{HI}$ & Hypoxia-ischemia \\
\hline HIF1 $\alpha$ & Hypoxia-inducible factor 1 alpha \\
\hline $\mathrm{HO}-1$ & Heme oxygenase 1 \\
\hline ICAM-1 & Intercellular adhesion molecule 1 \\
\hline IL-1 $\beta$ & Interleukin 1 beta \\
\hline IL-2 & Interleukin 2 \\
\hline IL-4 & Interleukin 4 \\
\hline IL-6 & Interleukin 6 \\
\hline IL-13 & Interleukin 13 \\
\hline i.n. & Intranasal \\
\hline iNOS & Inducible nitric oxide synthase \\
\hline i.p. & Intraperitoneally \\
\hline i.v. & Intravenously \\
\hline $\mathrm{LDH}$ & Lactate dehydrogenase \\
\hline 5-LOX & 5-Lipoxygenase \\
\hline LPS & Lipopolysaccharide \\
\hline
\end{tabular}




$\begin{array}{ll}\text { MAPK } & \text { Mitogen-activated protein kinase } \\ \text { MB } & \text { Manganese bisethylenedithiocarbamate } \\ \text { MDA } & \text { Malondialdehyde } \\ \text { mGluR1 } & \text { Metabotropic glutamate receptor type 1 } \\ \text { mGluR5 } & \text { Metabotropic glutamate receptor type 5 } \\ \text { MMP-2, -9 } & \text { Metallomatrixprotease-2,-9 } \\ \text { MPTP } & \text { 1-Methyl-4-phenyl-1,2,3,6-tetrahydropyridine } \\ \text { MRI } & \text { Magnetic resonance imaging } \\ \text { mTOR } & \text { Mammalian target of rapamycin } \\ \text { NF-kB } & \text { Nuclear factor kappa-light-chain-enhancer of activated B cells } \\ \text { NGF } & \text { Nerve growth factor } \\ \text { NMDA } & \text { N-methyl-D-aspartate } \\ \text { nNOS } & \text { Neuronal nitric oxide synthase } \\ \text { NO } & \text { Nitric oxide } \\ \text { NOS-2 } & \text { Nitric oxide synthase-2 } \\ \text { NQO-1 } & \text { NAD(P)H quinone oxidoreductase } \\ \text { Nrf2 } & \text { Nuclear factor erythroid 2-related factor 2 } \\ \text { 6-OHDA } & \text { 6-Hydroxydopamine } \\ \text { p53 } & \text { Tumor protein p53 } \\ \text { p65 } & \text { Transcription factor p65 } \\ \text { PARP-1 } & \text { Poly [ADP-ribose] polymerase 1 } \\ \text { p-JNK } & \text { C-Jun N-terminal kinases } \\ \text { p.o. } & \text { Orally } \\ \text { PQ } & \text { 1,1'-Dimethyl-4,4'-bipyridinium dichloride hydrate } \\ \text { RNS } & \text { Nitrogen reactive species } \\ \text { ROS } & \text { Reactive oxygen species } \\ \text { rpS3 } & \text { Ribosomal protein } \\ \text { S100b } & \text { S100 calcium-binding protein B } \\ \text { SNP } & \text { Sodium nitroprusside } \\ \text { SOD } & \text { Superoxide dismutase } \\ \text { SOD2 } & \text { Superoxide dismutase 2 } \\ \text { TFEB } & \text { Transcription factor EB } \\ \text { TH+ } & \text { Tyrosine hydroxylase immunoreactivity } \\ \text { TLR4 } & \text { Toll-like receptor 4 } \\ \text { TNF- } \alpha & \text { Tumor necrosis factor } \alpha \\ \text { TrkB } & \text { Tirosine kinase receptor } \\ \text { UDP } & \text { Uridine 5'-diphosphate } \\ \text { VCAM-1 } & \text { Vascular cell adhesion protein 1 } \\ & \end{array}$

\section{References}

1. Clifford, M.N.; Gibson, C.L.; Rakotomalala, J.-J.R.; Cross, E.; Charrier, A. Caffeine from green beans of Mascarocoffea. Phytochemistry 1991, 30, 4039-4040. [CrossRef]

2. Cheek, M.; Csiba, L.; Bridson, D.M. A new species of Coffea (Rubiaceae) from western Cameroon. Kew Bull. 2002, 57, 675-680. [CrossRef]

3. Davis, A.P.; Rakotonasolo, F. New species of Coffea L. (Rubiaceae) from Madagascar. Bot. J. Linn. Soc. 2003, 142, 111-118. [CrossRef]

4. Davis, A.P.; Mvungi, E.F. Two new and endangered species of Coffea (Rubiaceae) from the Eastern Arc Mountains (Tanzania) and notes on associated conservation issues. Bot. J. Linn. Soc. 2004, 146, 111-118. [CrossRef]

5. Davis, A.P.; Govaerts, R.; Bridson, D.M.; Stoffelen, P. An annotated taxonomic conspectus of the genus Coffea (Rubiaceae). Bot. J. Linn. Soc. 2006, 152, 465-512. [CrossRef]

6. Sonké, B.; Nguembou, C.K.; Davis, A.P. A new dwarf Coffea (Rubiaceae) from southern Cameroon. Bot. J. Linn. Soc. 2006, 151, 425-430. [CrossRef]

7. Higdon, J.V.; Frei, B. Coffee and health: A review of recent human research. Crit. Rev. Food Sci. Nutr. 2006, 46, 101-123. [CrossRef]

8. Lee, D.R.; Lee, J.; Rota, M.; Lee, J.; Ahn, H.S.; Park, S.M.; Shin, D. Coffee consumption and risk of fractures: A systematic review and dose-response meta-analysis. Bone 2014, 63, 20-28. [CrossRef]

9. Bae, J.H.; Park, J.H.; Im, S.S.; Song, D.K. Coffee and health. Integr. Med. Res. 2014, 3, 189-191. [CrossRef]

10. International Coffee Organization. Coffee Trade Statistics; International Coffee Organization: London, UK, 2020.

11. Bizzo, M.L.G.; Farah, A.; Kempa, J.A.; Scancetti, L.B. Highlight in the history of coffee science related to health. In Coffee in Health and Disease Prevention; Preedy, V.R., Ed.; Elsevier: London, UK, 2015; pp. 11-17. 
12. Butt, M.S.; Sultan, M.T. Coffee and its consumption: Benefits and risks. Crit. Rev. Food Sci. Nutr. 2011, 51, 363-373. [CrossRef]

13. Ciaramelli, C.; Palmioli, A.; Airoldi, C. Coffee variety, origin and extraction procedure: Implications for coffee beneficial effects on human health. Food Chem. 2019, 278, 47-55. [CrossRef] [PubMed]

14. Han, K.; Hwang, E.; Park, J.B. Association between consumption of coffee and the prevalence of periodontitis: The 2008-2010 Korea National Health and Nutrition Examination Survey. PLoS ONE 2016, 11, e0158845. [CrossRef] [PubMed]

15. Horrigan, L.A.; Kelly, J.P.; Connor, T.J. Immunomodulatory effects of caffeine: Friend or foe? Pharmacol. Ther. 2006, 111, 877-892. [CrossRef] [PubMed]

16. Lee, J.K.; Kim, K.; Ahn, Y.; Yang, M.; Lee, J.E. Habitual coffee intake, genetic polymorphisms, and type 2 diabetes. Eur. J. Endocrinol. 2015, 172, 595-601. [CrossRef]

17. Ludwig, I.A.; Clifford, M.N.; Lean, M.E.; Ashihara, H.; Crozier, A. Coffee: Biochemistry and potential impact on health. Food Funct. 2014, 5, 1695-1717. [CrossRef]

18. Poole, R.; Kennedy, O.J.; Roderick, P.; Fallowfield, J.A.; Hayes, P.C.; Parkes, J. Coffee consumption and health: Umbrella review of meta-analyses of multiple health outcomes. BMJ 2017, 359, j5024. [CrossRef]

19. Santos, R.M.; Lima, D.R. Coffee consumption, obesity and type 2 diabetes: A mini-review. Eur. J. Nutr. 2016, 55, 1345-1358. [CrossRef]

20. Dórea, J.G.; da Costa, T.H. Is coffee a functional food? Br. J. Nutr. 2005, 93, 773-782. [CrossRef]

21. Cornelis, M.C.; El-Sohemy, A. Coffee, caffeine, and coronary heart disease. Curr. Opin. Lipidol. 2007, 18, 13-19. [CrossRef]

22. Gökcen, B.B.; Sanlier, N. Coffee consumption and disease correlations. Crit. Rev. Food Sci. Nutr. 2019, 59, 336-348. [CrossRef]

23. Nieber, K. The impact of coffee on health. Planta Med. 2017, 83, 1256-1263. [CrossRef] [PubMed]

24. Cano-Marquina, A.; Tarín, J.J.; Cano, A. The impact of coffee on health. Maturitas 2013, 75, 7-21. [CrossRef] [PubMed]

25. Oleaga, C.; Ciudad, C.J.; Noé, V.; Izquierdo-Pulido, M. Coffee polyphenols change the expression of STAT5B and ATF-2 modifying cyclin D1 levels in cancer cells. Oxid. Med. Cell Longev. 2012, 2012, 390385. [CrossRef] [PubMed]

26. Mineharu, Y.; Koizumi, A.; Wada, Y.; Iso, H.; Watanabe, Y.; Date, C.; Yamamoto, A.; Kikuchi, S.; Inaba, Y.; Toyoshima, H.; et al. Coffee, green tea, black tea and oolong tea consumption and risk of mortality from cardiovascular disease in Japanese men and women. J. Epidemiol. Community Health 2011, 65, 230-240. [CrossRef] [PubMed]

27. Sääksjärvi, K.; Knekt, P.; Rissanen, H.; Laaksonen, M.A.; Reunanen, A.; Männistö, S. Prospective study of coffee consumption and risk of Parkinson's disease. Eur. J. Clin. Nutr. 2008, 62, 908-915. [CrossRef]

28. Trevitt, J.; Kawa, K.; Jalali, A.; Larsen, C. Differential effects of adenosine antagonists in two models of parkinsonian tremor. Pharmacol. Biochem. Behav. 2009, 94, 24-29. [CrossRef]

29. Arendash, G.W.; Cao, C. Caffeine and coffee as therapeutics against Alzheimer's disease. J. Alzheimers. Dis. 2010, 20 (Suppl. 1), S117-S126. [CrossRef]

30. de Mendonça, A.; Cunha, R.A. Therapeutic opportunities for caffeine in Alzheimer's disease and other neurodegenerative disorders. J. Alzheimers. Dis. 2010, 20 (Suppl. 1), S1-S2. [CrossRef]

31. Hermansen, K.; Krogholm, K.S.; Bech, B.H.; Dragsted, L.O.; Hyldstrup, L.; Jorgensen, K.; Larsen, M.L.; Tjonneland, A.M. Coffee can protect against disease. Ugeskr. Laeger 2012, 174, 2293-2297.

32. Kawachi, I.; Willett, W.C.; Colditz, G.A.; Stampfer, M.J.; Speizer, F.E. A prospective study of coffee drinking and suicide in women. Arch. Intern. Med. 1996, 156, 521-525. [CrossRef]

33. Homan, D.J.; Mobarhan, S. Coffee: Good, bad, or just fun? A critical review of coffee's effects on liver enzymes. Nutr. Rev. 2006, 64, 43-46. [CrossRef] [PubMed]

34. Jee, S.H.; He, J.; Appel, L.J.; Whelton, P.K.; Suh, I.; Klag, M.J. Coffee consumption and serum lipids: A meta-analysis of randomized controlled clinical trials. Am. J. Epidemiol. 2001, 153, 353-362. [CrossRef] [PubMed]

35. Farah, A. Nutritional and health effects of coffee. In Achieving Sustainable Cultivaiton of Coffee, 1st ed.; Lashermes, P., Ed.; Burleigh Dodds Science Publishing: Cambridge, UK, 2018; pp. 259-290.

36. Diviš, P.; Pořízka, J.; Kř́ḱkala, J. The effect of coffee beans roasting on its chemical composition. Potr. S. J. F. Sci 2019, 13, 344-350. [CrossRef]

37. Farah, A.; Duarte, G. Bioavailability and metabolism of chlorogenic acids from coffee. In Coffee in Health and Disease Prevention; Preedy, V.R., Ed.; Elsevier: London, UK, 2015; pp. 789-801.

38. Moreira, A.S.; Nunes, F.M.; Domingues, M.R.; Coimbra, M.A. Coffee melanoidins: Structures, mechanisms of formation and potential health impacts. Food Funct. 2012, 3, 903-915. [CrossRef] [PubMed]

39. Nunes, F.M.; Coimbra, M.A. Role of hydroxycinnamates in coffee melanoidin formation. Phytochem. Rev. 2010, 9, 171-185. [CrossRef]

40. Arnaud, M.J. Metabolism of caffeine and other components of coffee. In Caffeine, Coffee and Health; Garattini, S., Ed.; Raven: New York, NY, USA, 1993; pp. 43-95.

41. Callahan, M.M.; Robertson, R.S.; Arnaud, M.J.; Branfman, A.R.; McComish, M.F.; Yesair, D.W. Human metabolism of [1-methyl14C]- and [2-14C]caffeine after oral administration. Drug Metab. Dispos. 1982, 10, 417-423.

42. Grosso, L.M.; Triche, E.; Benowitz, N.L.; Bracken, M.B. Prenatal caffeine assessment: Fetal and maternal biomarkers or selfreported intake? Ann. Epidemiol. 2008, 18, 172-178. [CrossRef] 
43. Sachse, K.T.; Jackson, E.K.; Wisniewski, S.R.; Gillespie, D.G.; Puccio, A.M.; Clark, R.S.; Dixon, C.E.; Kochanek, P.M. Increases in cerebrospinal fluid caffeine concentration are associated with favorable outcome after severe traumatic brain injury in humans. $J$. Cereb. Blood Flow Metab. 2008, 28, 395-401. [CrossRef]

44. Scott, N.R.; Chakraborty, J.; Marks, V. Determination of caffeine, theophylline and theobromine in serum and saliva using high-performance liquid chromatography. Ann. Clin. Biochem. 1984, 21 Pt 2, 120-124. [CrossRef]

45. Blanchard, J.; Sawers, S.J. The absolute bioavailability of caffeine in man. Eur. J. Clin. Pharmacol. 1983, 24, 93-98. [CrossRef]

46. Bonati, M.; Latini, R.; Galletti, F.; Young, J.F.; Tognoni, G.; Garattini, S. Caffeine disposition after oral doses. Clin. Pharmacol. Ther. 1982, 32, 98-106. [CrossRef] [PubMed]

47. Newton, R.; Broughton, L.J.; Lind, M.J.; Morrison, P.J.; Rogers, H.J.; Bradbrook, I.D. Plasma and salivary pharmacokinetics of caffeine in man. Eur. J. Clin. Pharmacol. 1981, 21, 45-52. [CrossRef] [PubMed]

48. Brachtel, D.; Richter, E. Effect of altered gastric emptying on caffeine absorption. Z. Gastroenterol. 1988, 26, 245-251. [PubMed]

49. Trang, J.M.; Blanchard, J.; Conrad, K.A.; Harrison, G.G. Relationship between total body clearance of caffeine and urine flow rate in elderly men. Biopharm. Drug Dispos. 1985, 6, 51-56. [CrossRef] [PubMed]

50. Nagel, R.A.; Dirix, L.Y.; Hayllar, K.M.; Preisig, R.; Tredger, J.M.; Williams, R. Use of quantitative liver function tests-Caffeine clearance and galactose elimination capacity-After orthotopic liver transplantation. J. Hepatol. 1990, 10, 149-157. [CrossRef]

51. Levy, M.; Granit, L.; Zylber-Katz, E. Chronopharmacokinetics of caffeine in healthy volunteers. Annu. Rev. Chronopharmacol. 1984, $1,97-100$.

52. Grant, D.M.; Tang, B.K.; Kalow, W. Polymorphic N-acetylation of a caffeine metabolite. Clin. Pharmacol. Ther. 1983, 33, 355-359. [CrossRef]

53. Ha, H.R.; Chen, J.; Krahenbuhl, S.; Follath, F. Biotransformation of caffeine by cDNA-expressed human cytochromes P-450. Eur. J. Clin. Pharmacol. 1996, 49, 309-315. [CrossRef]

54. Rasmussen, B.B.; Brix, T.H.; Kyvik, K.O.; Brøsen, K. The interindividual differences in the 3-demthylation of caffeine alias CYP1A2 is determined by both genetic and environmental factors. Pharmacogenetics 2002, 12, 473-478. [CrossRef]

55. Vistisen, K.; Loft, S.; Poulsen, H.E. Cytochrome P450 IA2 activity in man measured by caffeine metabolism: Effect of smoking, broccoli and exercise. Adv. Exp. Med. Biol. 1991, 283, 407-411.

56. Sasaki, S.; Limpar, M.; Sata, F.; Kobayashi, S.; Kishi, R. Interaction between maternal caffeine intake during pregnancy and CYP1A2 C164A polymorphism affects infant birth size in the Hokkaido study. Pediatr. Res. 2017, 82, 19-28. [CrossRef] [PubMed]

57. Chen, Y.; Liu, W.H.; Chen, B.L.; Fan, L.; Han, Y.; Wang, G.; Hu, D.L.; Tan, Z.R.; Zhou, G.; Cao, S.; et al. Plant polyphenol curcumin significantly affects CYP1A2 and CYP2A6 activity in healthy, male Chinese volunteers. Ann. Pharmacother. 2010, 44, 1038-1045 [CrossRef] [PubMed]

58. Chen, Y.; Xiao, P.; Ou-Yang, D.S.; Fan, L.; Guo, D.; Wang, Y.N.; Han, Y.; Tu, J.H.; Zhou, G.; Huang, Y.F.; et al. Simultaneous action of the flavonoid quercetin on cytochrome P450 (CYP) 1A2, CYP2A6, N-acetyltransferase and xanthine oxidase activity in healthy volunteers. Clin. Exp. Pharmacol. Physiol. 2009, 36, 828-833. [CrossRef] [PubMed]

59. Fuhr, U.; Klittich, K.; Staib, A.H. Inhibitory effect of grapefruit juice and its bitter principal, naringenin, on CYP1A2 dependent metabolism of caffeine in man. Br. J. Clin. Pharmacol. 1993, 35, 431-436. [CrossRef] [PubMed]

60. Fuhr, U.; Maier, A.; Keller, A.; Steinijans, V.W.; Sauter, R.; Staib, A.H. Lacking effect of grapefruit juice on theophylline pharmacokinetics. Int. J. Clin. Pharmacol. Ther. 1995, 33, 311-314.

61. Lampe, J.W.; King, I.B.; Li, S.; Grate, M.T.; Barale, K.V.; Chen, C.; Feng, Z.; Potter, J.D. Brassica vegetables increase and apiaceous vegetables decrease cytochrome P450 1A2 activity in humans: Changes in caffeine metabolite ratios in response to controlled vegetable diets. Carcinogenesis 2000, 21, 1157-1162. [CrossRef]

62. Faber, M.S.; Fuhr, U. Time response of cytochrome P450 1A2 activity on cessation of heavy smoking. Clin. Pharmacol. Ther. 2004, 76, 178-184. [CrossRef]

63. Jodynis-Liebert, J.; Flieger, J.; Matuszewska, A.; Juszczyk, J. Serum metabolite/caffeine ratios as a test for liver function. J. Clin. Pharmacol. 2004, 44, 338-347. [CrossRef]

64. Park, G.J.; Katelaris, P.H.; Jones, D.B.; Seow, F.; Le Couteur, D.G.; Ngu, M.C. Validity of the 13C-caffeine breath test as a noninvasive, quantitative test of liver function. Hepatology 2003, 38, 1227-1236. [CrossRef]

65. Backman, J.T.; Karjalainen, M.J.; Neuvonen, M.; Laitila, J.; Neuvonen, P.J. Rofecoxib is a potent inhibitor of cytochrome P450 1A2: Studies with tizanidine and caffeine in healthy subjects. Br. J. Clin. Pharmacol. 2006, 62, 345-357. [CrossRef]

66. Carrillo, J.A.; Benitez, J. Clinically significant pharmacokinetic interactions between dietary caffeine and medications. Clin Pharmacokinet. 2000, 39, 127-153. [CrossRef] [PubMed]

67. Doude van Troostwijk, L.J.; Koopmans, R.P.; Vermeulen, H.D.; Guchelaar, H.J. CYP1A2 activity is an important determinant of clozapine dosage in schizophrenic patients. Eur. J. Pharm. Sci. 2003, 20, 451-457. [CrossRef] [PubMed]

68. Fuhr, U.; Anders, E.M.; Mahr, G.; Sörgel, F.; Staib, A.H. Inhibitory potency of quinolone antibacterial agents against cytochrome P450IA2 activity in vivo and in vitro. Antimicrob. Agents Chemother. 1992, 36, 942-948. [CrossRef] [PubMed]

69. Blanchard, J.; Sawers, S.J. Comparative pharmacokinetics of caffeine in young and elderly men. J. Pharmacokinet. Biopharm. 1983, 11, 109-126. [CrossRef] [PubMed]

70. Blanchard, J.; Sawers, S.J. Relationship between urine flow rate and renal clearance of caffeine in man. J. Clin. Pharmacol. 1983, 23, 134-138. [CrossRef] [PubMed] 
71. Tang-Liu, D.D.; Williams, R.L.; Riegelman, S. Disposition of caffeine and its metabolites in man. J. Pharmacol. Exp. Ther. 1983, 224, 180-185.

72. Clifford, M.N. Chlorogenic acids and other cinnamates-nature, occurrence and dietary burden. J. Sci. Food Agric. 1999, 79, 362-372. [CrossRef]

73. Naveed, M.; Hejazi, V.; Abbas, M.; Kamboh, A.A.; Khan, G.J.; Shumzaid, M.; Ahmad, F.; Babazadeh, D.; FangFang, X.; ModarresiGhazani, F.; et al. Chlorogenic acid (CGA): A pharmacological review and call for further research. Biomed. Pharmacother. 2018, 97, 67-74. [CrossRef]

74. Clifford, M.N.; Jaganath, I.B.; Ludwig, I.A.; Crozier, A. Chlorogenic acids and the acyl-quinic acids: Discovery, biosynthesis, bioavailability and bioactivity. Nat. Prod. Rep. 2017, 34, 1391-1421. [CrossRef]

75. Renouf, M.; Guy, P.A.; Marmet, C.; Fraering, A.L.; Longet, K.; Moulin, J.; Enslen, M.; Barron, D.; Dionisi, F.; Cavin, C.; et al Measurement of caffeic and ferulic acid equivalents in plasma after coffee consumption: Small intestine and colon are key sites for coffee metabolism. Mol. Nutr. Food Res. 2010, 54, 760-766. [CrossRef]

76. Stalmach, A.; Mullen, W.; Barron, D.; Uchida, K.; Yokota, T.; Cavin, C.; Steiling, H.; Williamson, G.; Crozier, A. Metabolite profiling of hydroxycinnamate derivatives in plasma and urine after the ingestion of coffee by humans: Identification of biomarkers of coffee consumption. Drug Metab. Dispos. 2009, 37, 1749-1758. [CrossRef] [PubMed]

77. Farrell, T.L.; Dew, T.P.; Poquet, L.; Hanson, P.; Williamson, G. Absorption and metabolism of chlorogenic acids in cultured gastric epithelial monolayers. Drug Metab. Dispos. 2011, 39, 2338-2346. [CrossRef] [PubMed]

78. Konishi, Y.; Kobayashi, S. Transepithelial transport of chlorogenic acid, caffeic acid, and their colonic metabolites in intestinal caco-2 cell monolayers. J. Agric. Food Chem. 2004, 52, 2518-2526. [CrossRef] [PubMed]

79. Zhao, Z.; Moghadasian, M.H. Bioavailability of hydroxycinnamates: A brief review of in vivo and in vitro studies. Phytochem. Rev. Vol. 2010, 9, 133-145. [CrossRef]

80. Erk, T.; Williamson, G.; Renouf, M.; Marmet, C.; Steiling, H.; Dionisi, F.; Barron, D.; Melcher, R.; Richling, E. Dose-dependent absorption of chlorogenic acids in the small intestine assessed by coffee consumption in ileostomists. Mol. Nutr. Food Res. 2012, 56, 1488-1500. [CrossRef]

81. Clifford, M.N.; Kerimi, A.; Williamson, G. Bioavailability and metabolism of chlorogenic acids (acyl-quinic acids) in humans. Compr. Rev. Food Sci. Food Saf. 2020, 19, 1299-1352. [CrossRef]

82. Farah, A.; Monteiro, M.; Donangelo, C.M.; Lafay, S. Chlorogenic acids from green coffee extract are highly bioavailable in humans. J. Nutr. 2008, 138, 2309-2315. [CrossRef]

83. Matsui, Y.; Nakamura, S.; Kondou, N.; Takasu, Y.; Ochiai, R.; Masukawa, Y. Liquid chromatography-electrospray ionizationtandem mass spectrometry for simultaneous analysis of chlorogenic acids and their metabolites in human plasma. J. Chromatogr. B Analyt. Technol. Biomed. Life Sci. 2007, 858, 96-105. [CrossRef]

84. Stalmach, A.; Steiling, H.; Williamson, G.; Crozier, A. Bioavailability of chlorogenic acids following acute ingestion of coffee by humans with an ileostomy. Arch. Biochem. Biophys. 2010, 501, 98-105. [CrossRef]

85. Wong, C.C.; Meinl, W.; Glatt, H.R.; Barron, D.; Stalmach, A.; Steiling, H.; Crozier, A.; Williamson, G. In vitro and in vivo conjugation of dietary hydroxycinnamic acids by UDP-glucuronosyltransferases and sulfotransferases in humans. J. Nutr. Biochem. 2010, 21, 1060-1068. [CrossRef]

86. Olthof, M.R.; Hollman, P.C.; Katan, M.B. Chlorogenic acid and caffeic acid are absorbed in humans. J. Nutr. 2001, 131 , 66-71. [CrossRef]

87. Manach, C.; Scalbert, A.; Morand, C.; Rémésy, C.; Jiménez, L. Polyphenols: Food sources and bioavailability. Am. J. Clin. Nutr. 2004, 79, 727-747. [CrossRef] [PubMed]

88. Scalbert, A.; Williamson, G. Chocolate: Modern science investigates an ancient medicine. J. Med. Food. 2000, 3, 121-125.

89. Oliveira, D.M.; Bastos, D.H.M. Phenolic acids bioavailability. Quim. Nova 2011, 34, 1051-1056. [CrossRef]

90. Rechner, A.R.; Smith, M.A.; Kuhnle, G.; Gibson, G.R.; Debnam, E.S.; Srai, S.K.; Moore, K.P.; Rice-Evans, C.A. Colonic metabolism of dietary polyphenols: Influence of structure on microbial fermentation products. Free Radic. Biol. Med. 2004, 36, $212-225$. [CrossRef] [PubMed]

91. Bresciani, L.; Tassotti, M.; Rosi, A.; Martini, D.; Antonini, M.; Dei Cas, A.; Bonadonna, R.; Brighenti, F.; Del Rio, D.; Mena, P. Absorption, pharmacokinetics, and urinary excretion of pyridines after consumption of coffee and cocoa-based products containing coffee in a repeated dose, crossover human intervention study. Mol. Nutr. Food Res. 2020, 64, e2000489. [CrossRef] [PubMed]

92. Midttun, Ø.; Ulvik, A.; Nygård, O.; Ueland, P.M. Performance of plasma trigonelline as a marker of coffee consumption in an epidemiologic setting. Am. J. Clin. Nutr. 2018, 107, 941-947. [CrossRef]

93. Lang, R.; Wahl, A.; Skurk, T.; Yagar, E.F.; Schmiech, L.; Eggers, R.; Hauner, H.; Hofmann, T. Development of a hydrophilic liquid interaction chromatography-high-performance liquid chromatography-tandem mass spectrometry based stable isotope dilution analysis and pharmacokinetic studies on bioactive pyridines in human plasma and urine after coffee consumption. Anal. Chem. 2010, 82, 1486-1497.

94. Lang, R.; Dieminger, N.; Beusch, A.; Lee, Y.M.; Dunkel, A.; Suess, B.; Skurk, T.; Wahl, A.; Hauner, H.; Hofmann, T. Bioappearance and pharmacokinetics of bioactives upon coffee consumption. Anal. Bioanal. Chem. 2013, 405, 8487-8503. [CrossRef]

95. Yuyama, S.; Kawano, Y. Urinary excretion of N1-methyl-2-pyridone-5-carboxylic acid and the fate of remaining of trigonelline. Adv. Exp. Med. Biol. 1996, 398, 599-603. 
96. Yuyama, S.; Suzuki, T. The excretion of N1-methyl-2-pyridone-5-carboxylic acid and related compounds in human subjects after oral administration of nicotinic acid, trigonelline and N1-methyl-2-pyridone-5-carboxylic acid. Adv. Exp. Med. Biol. 1991, 294, 475-479. [PubMed]

97. De Roos, B.; Meyboom, S.; Kosmeijer-Schuil, T.G.; Katan, M.B. Absorption and urinary excretion of the coffee diterpenes cafestol and kahweol in healthy ileostomy volunteers. J. Intern. Med. 1998, 244, 451-460. [CrossRef] [PubMed]

98. Kovacs, G.G. Molecular pathology of neurodegenerative diseases: Principles and practice. J. Clin. Pathol. 2019, 72, 725-735. [CrossRef] [PubMed]

99. Prince, M. World Alzheimer Report 2015: The Global Impact of Dementia. Available online: https://www.alz.co.uk/research/ world-report-2015 (accessed on 8 April 2018).

100. Brookmeyer, R.; Johnson, E.; Ziegler-Graham, K.; Arrighi, H.M. Forecasting the global burden of Alzheimer's disease. Alzheimers Dement. 2007, 3, 186-191. [CrossRef]

101. Dening, T.; Sandilyan, M.B. Dementia: Definitions and types. Nurs. Stand. 2015, 29, 37-42. [CrossRef]

102. Bateman, R.J.; Aisen, P.S.; De Strooper, B.; Fox, N.C.; Lemere, C.A.; Ringman, J.M.; Salloway, S.; Sperling, R.A.; Windisch, M.; Xiong, C. Autosomal-dominant Alzheimer's disease: A review and proposal for the prevention of Alzheimer's disease. Alzheimers Res. Ther. 2011, 3, 1-13. [CrossRef]

103. Terry, R.D.; Peck, A.; DeTeresa, R.; Schechter, R.; Horoupian, D.S. Some morphometric aspects of the brain in senile dementia of the Alzheimer type. Ann. Neurol. 1981, 10, 184-192. [CrossRef]

104. Teipel, S.J.; Flatz, W.H.; Heinsen, H.; Bokde, A.L.; Schoenberg, S.O.; Stöckel, S.; Dietrich, O.; Reiser, M.F.; Möller, H.J.; Hampel, H. Measurement of basal forebrain atrophy in Alzheimer's disease using MRI. Brain 2005, 128 Pt 11, 2626-2644. [CrossRef]

105. Klucken, J.; McLean, P.J.; Gomez-Tortosa, E.; Ingelsson, M.; Hyman, B.T. Neuritic alterations and neural system dysfunction in Alzheimer's disease and dementia with Lewy bodies. Neurochem. Res. 2003, 28, 1683-1691. [CrossRef]

106. Crews, L.; Masliah, E. Molecular mechanisms of neurodegeneration in Alzheimer's disease. Hum. Mol. Genet. 2010, 19, R12-R20. [CrossRef]

107. Grutzendler, J.; Helmin, K.; Tsai, J.; Gan, W.B. Various dendritic abnormalities are associated with fibrillar amyloid deposits in Alzheimer's disease. Ann. N. Y. Acad. Sci. 2007, 1097, 30-39. [CrossRef] [PubMed]

108. Lippa, C.F.; Hamos, J.E.; Pulaski-Salo, D.; DeGennaro, L.J.; Drachman, D.A. Alzheimer's disease and aging: Effects on perforant pathway perikarya and synapses. Neurobiol. Aging 1992, 13, 405-411. [CrossRef]

109. Perlson, E.; Maday, S.; Fu, M.M.; Moughamian, A.J.; Holzbaur, E.L. Retrograde axonal transport: Pathways to cell death? Trends Neurosci. 2010, 33, 335-344. [CrossRef] [PubMed]

110. Serrano-Pozo, A.; Frosch, M.P.; Masliah, E.; Hyman, B.T. Neuropathological alterations in Alzheimer disease. Cold Spring Harb. Perspect. Med. 2011, 1, a006189. [CrossRef]

111. Ingelsson, M.; Fukumoto, H.; Newell, K.L.; Growdon, J.H.; Hedley-Whyte, E.T.; Frosch, M.P.; Albert, M.S.; Hyman, B.T.; Irizarry, M.C. Early Abeta accumulation and progressive synaptic loss, gliosis, and tangle formation in AD brain. Neurology 2004, 62, 925-931. [CrossRef]

112. Šimić, G.; Babić Leko, M.; Wray, S.; Harrington, C.; Delalle, I.; Jovanov-Milošević, N.; Bažadona, D.; Buée, L.; de Silva, R.; Di Giovanni, G.; et al. Tau protein hyperphosphorylation and aggregation in Alzheimer's disease and other tauopathies, and possible neuroprotective strategies. Biomolecules 2016, 6, 6. [CrossRef]

113. Hardy, J.; Selkoe, D.J. The amyloid hypothesis of Alzheimer's disease: Progress and problems on the road to therapeutics. Science 2002, 297, 353-356. [CrossRef]

114. Jonsson, T.; Atwal, J.K.; Steinberg, S.; Snaedal, J.; Jonsson, P.V.; Bjornsson, S.; Stefansson, H.; Sulem, P.; Gudbjartsson, D.; Maloney, J.; et al. A mutation in APP protects against Alzheimer's disease and age-related cognitive decline. Nature 2012, 488, 96-99. [CrossRef]

115. Lashley, T.; Rohrer, J.D.; Mead, S.; Revesz, T. Review: An update on clinical, genetic and pathological aspects of frontotemporal lobar degenerations. Neuropathol. Appl. Neurobiol. 2015, 41, 858-881. [CrossRef]

116. Contestabile, A. The history of the cholinergic hypothesis. Behav. Brain Res. 2011, 221, 334-340. [CrossRef]

117. Francis, P.T.; Palmer, A.M.; Snape, M.; Wilcock, G.K. The cholinergic hypothesis of Alzheimer's disease: A review of progress. J. Neurol. Neurosurg. Psychiatry 1999, 66, 137-147. [CrossRef] [PubMed]

118. Cervellati, C.; Wood, P.L.; Romani, A.; Valacchi, G.; Squerzanti, M.; Sanz, J.M.; Ortolani, B.; Zuliani, G. Oxidative challenge in Alzheimer's disease: State of knowledge and future needs. J. Investig. Med. 2016, 64, 21-32. [CrossRef] [PubMed]

119. Di Marco, L.Y.; Venneri, A.; Farkas, E.; Evans, P.C.; Marzo, A.; Frangi, A.F. Vascular dysfunction in the pathogenesis of Alzheimer's disease-A review of endothelium-mediated mechanisms and ensuing vicious circles. Neurobiol. Dis. 2015, 82, 593-606. [CrossRef] [PubMed]

120. Christensen, A.; Pike, C.J. Menopause, obesity and inflammation: Interactive risk factors for Alzheimer's disease. Front. Aging Neurosci. 2015, 7, 130. [CrossRef] [PubMed]

121. Folch, J.; Patraca, I.; Martínez, N.; Pedrós, I.; Petrov, D.; Ettcheto, M.; Abad, S.; Marin, M.; Beas-Zarate, C.; Camins, A. The role of leptin in the sporadic form of Alzheimer's disease. Interactions with the adipokines amylin, ghrelin and the pituitary hormone prolactin. Life Sci. 2015, 140, 19-28. [CrossRef] [PubMed]

122. Ben Haim, L.; Carrillo-de Sauvage, M.A.; Ceyzériat, K.; Escartin, C. Elusive roles for reactive astrocytes in neurodegenerative diseases. Front. Cell Neurosci. 2015, 9, 278. [CrossRef] 
123. Chen, Z.; Zhong, C. Oxidative stress in Alzheimer's disease. Neurosci. Bull. 2014, 30, 271-281. [CrossRef]

124. Yiannopoulou, K.G.; Papageorgiou, S.G. Current and future treatments for Alzheimer's disease. Ther. Adv. Neurol. Disord. 2013, 6, 19-33. [CrossRef]

125. Dorsey, E.R.; Elbaz, A.; Nichols, E.; Abd-Allah, F.; Abdelalim, A.; Adsuar, J.C.; Ansha, M.G.; Brayne, C.; Choi, J.Y.J.; Collado-Mateo, D.; et al. Global, regional, and national burden of Parkinson's disease, 1990-2016: A systematic analysis for the Global Burden of Disease Study 2016. Lancet Neurol. 2018, 17, 939-953. [CrossRef]

126. Bagheri, H.; Damase-Michel, C.; Lapeyre-Mestre, M.; Cismondo, S.; O'Connell, D.; Senard, J.M.; Rascol, O.; Montastruc, J.L. A study of salivary secretion in Parkinson's disease. Clin. Neuropharmacol. 1999, 22, 213-215.

127. Park, J.H.; Kang, Y.J.; Horak, F.B. What is wrong with balance in Parkinson's disease? J. Mov. Disord. 2015, 8, 109-114. [CrossRef] [PubMed]

128. Brown, R.G.; Landau, S.; Hindle, J.V.; Playfer, J.; Samuel, M.; Wilson, K.C.; Hurt, C.S.; Anderson, R.J.; Carnell, J.; Dickinson, L.; et al. Depression and anxiety related subtypes in Parkinson's disease. J. Neurol. Neurosurg. Psychiatry 2011, 82, 803-809. [CrossRef] [PubMed]

129. Hardoff, R.; Sula, M.; Tamir, A.; Soil, A.; Front, A.; Badarna, S.; Honigman, S.; Giladi, N. Gastric emptying time and gastric motility in patients with Parkinson's disease. Mov. Disord. 2001, 16, 1041-1047. [CrossRef] [PubMed]

130. Poewe, W. Non-motor symptoms in Parkinson's disease. Eur. J. Neurol. 2008, 15 (Suppl. 1), 14-20. [CrossRef]

131. Senard, J.M.; Raï, S.; Lapeyre-Mestre, M.; Brefel, C.; Rascol, O.; Rascol, A.; Montastruc, J.L. Prevalence of orthostatic hypotension in Parkinson's disease. J. Neurol. Neurosurg. Psychiatry 1997, 63, 584-589. [CrossRef]

132. Uchiyama, T.; Sakakibara, R.; Yamamoto, T.; Ito, T.; Yamaguchi, C.; Awa, Y.; Yanagisawa, M.; Higuchi, Y.; Sato, Y.; Ichikawa, T.; et al. Urinary dysfunction in early and untreated Parkinson's disease. J. Neurol. Neurosurg. Psychiatry 2011, 82, 1382-1386. [CrossRef]

133. Anglade, P.; Vyas, S.; Javoy-Agid, F.; Herrero, M.T.; Michel, P.P.; Marquez, J.; Mouatt-Prigent, A.; Ruberg, M.; Hirsch, E.C.; Agid, Y. Apoptosis and autophagy in nigral neurons of patients with Parkinson's disease. Histol. Histopathol. 1997, $12,25-31$.

134. Schapira, A.H.; Jenner, P. Etiology and pathogenesis of Parkinson's disease. Mov. Disord. 2011, 26, 1049-1055. [CrossRef]

135. Braak, H.; de Vos, R.A.; Bohl, J.; Del Tredici, K. Gastric alpha-synuclein immunoreactive inclusions in Meissner's and Auerbach's plexuses in cases staged for Parkinson's disease-related brain pathology. Neurosci. Lett. 2006, 396, 67-72. [CrossRef]

136. McGeer, P.L.; McGeer, E.G. The alpha-synuclein burden hypothesis of Parkinson disease and its relationship to Alzheimer disease. Exp. Neurol. 2008, 212, 235-238. [CrossRef]

137. Volpicelli-Daley, L.A.; Luk, K.C.; Patel, T.P.; Tanik, S.A.; Riddle, D.M.; Stieber, A.; Meaney, D.F.; Trojanowski, J.Q.; Lee, V.M. Exogenous $\alpha$-synuclein fibrils induce Lewy body pathology leading to synaptic dysfunction and neuron death. Neuron 2011, 72, 57-71. [CrossRef] [PubMed]

138. Kalia, L.V.; Lang, A.E. Parkinson disease in 2015: Evolving basic, pathological and clinical concepts in PD. Nat. Rev. Neurol. 2016, 12, 65-66. [CrossRef] [PubMed]

139. Mullin, S.; Schapira, A.H. Pathogenic mechanisms of neurodegeneration in Parkinson disease. Neurol. Clin. 2015, 33, 1-17. [CrossRef]

140. Hornykiewicz, O.; Kish, S.J. Biochemical pathophysiology of Parkinson's disease. Adv. Neurol. 1987, 45, 19-34. [PubMed]

141. Hayes, M.T. Parkinson's disease and parkinsonism. Am. J. Med. 2019, 132, 802-807. [CrossRef] [PubMed]

142. Reich, S.G.; Savitt, J.M. Parkinson's disease. Med. Clin. N. Am. 2019, 103, 337-350. [CrossRef] [PubMed]

143. Johnson, C.O.; Nguyen, M.; Roth, G.A.; Nichols, E.; Alam, T.; Abate, D.; Abd-Allah, F.; Abdelalim, A.; Abraha, H.N.; Abu-Rmeileh, N.M.; et al. Global, regional, and national burden of stroke, 1990-2016: A systematic analysis for the Global Burden of Disease Study 2016. Lancet Neurol. 2019, 18, 439-458. [CrossRef]

144. Cereda, C.; Carrera, E. Posterior cerebral artery territory infarctions. Front. Neurol. Neurosci. 2012, 30, 128-131.

145. Jensen, M.B.; St Louis, E.K. Management of acute cerebellar stroke. Arch. Neurol. 2005, 62, 537-544. [CrossRef]

146. Kumral, E.; Bayulkem, G.; Evyapan, D.; Yunten, N. Spectrum of anterior cerebral artery territory infarction: Clinical and MRI findings. Eur. J. Neurol. 2002, 9, 615-624. [CrossRef]

147. Wardlaw, J.M. What causes lacunar stroke? J. Neurol. Neurosurg. Psychiatry 2005, 76, 617-619. [CrossRef] [PubMed]

148. White, H.; Boden-Albala, B.; Wang, C.; Elkind, M.S.; Rundek, T.; Wright, C.B.; Sacco, R.L. Ischemic stroke subtype incidence among whites, blacks, and Hispanics: The Northern Manhattan Study. Circulation 2005, 111, 1327-1331. [CrossRef] [PubMed]

149. Nogueira, R.G.; Jadhav, A.P.; Haussen, D.C.; Bonafe, A.; Budzik, R.F.; Bhuva, P.; Yavagal, D.R.; Ribo, M.; Cognard, C.; Hanel, R.A.; et al. Thrombectomy 6 to $24 \mathrm{~h}$ after stroke with a mismatch between deficit and infarct. N. Engl. J. Med. 2018, 378, 11-21. [CrossRef] [PubMed]

150. Powers, W.J.; Rabinstein, A.A.; Ackerson, T.; Adeoye, O.M.; Bambakidis, N.C.; Becker, K.; Biller, J.; Brown, M.; Demaerschalk, B.M.; Hoh, B.; et al. 2018 Guidelines for the early management of patients with acute ischemic stroke: A guideline for healthcare professionals from the American Heart Association/American Stroke Association. Stroke 2018, 49, e46-e110. [CrossRef] [PubMed]

151. Sandercock, P.A.; Counsell, C.; Tseng, M.C.; Cecconi, E. Oral antiplatelet therapy for acute ischaemic stroke. Cochrane Database Syst. Rev. 2014, 2014, Cd000029. [CrossRef]

152. Choi, D.W. Glutamate neurotoxicity and diseases of the nervous system. Neuron 1988, 1, 623-634. [CrossRef]

153. Siesjö, B.K.; Katsura, K.I.; Kristián, T.; Li, P.A.; Siesjö, P. Molecular mechanisms of acidosis-mediated damage. Acta Neurochir. Suppl. 1996, 66, 8-14. 
154. Tombaugh, G.C.; Sapolsky, R.M. Evolving concepts about the role of acidosis in ischemic neuropathology. J. Neurochem. 1993, 61, 793-803. [CrossRef]

155. Xiong, Z.G.; Zhu, X.M.; Chu, X.P.; Minami, M.; Hey, J.; Wei, W.L.; MacDonald, J.F.; Wemmie, J.A.; Price, M.P.; Welsh, M.J.; et al. Neuroprotection in ischemia: Blocking calcium-permeable acid-sensing ion channels. Cell 2004, 118, 687-698. [CrossRef]

156. Jayaraj, R.L.; Azimullah, S.; Beiram, R.; Jalal, F.Y.; Rosenberg, G.A. Neuroinflammation: Friend and foe for ischemic stroke. J. NeuroInflamm. 2019, 16, 142. [CrossRef]

157. Hwang, J.Y.; Aromolaran, K.A.; Zukin, R.S. Epigenetic mechanisms in stroke and epilepsy. Neuropsychopharmacology 2013, 38, 167-182. [CrossRef] [PubMed]

158. Zhang, J.; Zhang, Y.; Xing, S.; Liang, Z.; Zeng, J. Secondary neurodegeneration in remote regions after focal cerebral infarction: A new target for stroke management? Stroke 2012, 43, 1700-1705. [CrossRef] [PubMed]

159. Levine, D.A.; Galecki, A.T.; Langa, K.M.; Unverzagt, F.W.; Kabeto, M.U.; Giordani, B.; Wadley, V.G. Trajectory of cognitive decline after incident stroke. JAMA 2015, 314, 41-51. [CrossRef]

160. Hervé, D.; Molko, N.; Pappata, S.; Buffon, F.; LeBihan, D.; Bousser, M.G.; Chabriat, H. Longitudinal thalamic diffusion changes after middle cerebral artery infarcts. J. Neurol. Neurosurg. Psychiatry 2005, 76, 200-205. [CrossRef] [PubMed]

161. Li, C.; Ling, X.; Liu, S.; Xu, A.; Zhang, Y.; Xing, S.; Pei, Z.; Zeng, J. Early detection of secondary damage in ipsilateral thalamus after acute infarction at unilateral corona radiata by diffusion tensor imaging and magnetic resonance spectroscopy. BMC Neurol. 2011, 11, 49. [CrossRef] [PubMed]

162. Nakane, M.; Tamura, A.; Sasaki, Y.; Teraoka, A. MRI of secondary changes in the thalamus following a cerebral infarct. Neuroradiology 2002, 44, 915-920. [PubMed]

163. Aho, L.; Jolkkonen, J.; Alafuzoff, I. Beta-amyloid aggregation in human brains with cerebrovascular lesions. Stroke 2006, 37, 2940-2945. [CrossRef] [PubMed]

164. Ong, L.K.; Zhao, Z.; Kluge, M.; Walker, F.R.; Nilsson, M. Chronic stress exposure following photothrombotic stroke is associated with increased levels of Amyloid beta accumulation and altered oligomerisation at sites of thalamic secondary neurodegeneration in mice. J. Cereb. Blood Flow Metab. 2017, 37, 1338-1348. [CrossRef] [PubMed]

165. Mitkari, B.; Kerkelä, E.; Nystedt, J.; Korhonen, M.; Jolkkonen, J. Unexpected complication in a rat stroke model: Exacerbation of secondary pathology in the thalamus by subacute intraarterial administration of human bone marrow-derived mesenchymal stem cells. J. Cereb. Blood Flow Metab. 2015, 35, 363-366. [CrossRef]

166. Zhang, Y.; Xing, S.; Zhang, J.; Li, J.; Li, C.; Pei, Z.; Zeng, J. Reduction of $\beta$-amyloid deposits by $\gamma$-secretase inhibitor is associated with the attenuation of secondary damage in the ipsilateral thalamus and sensory functional improvement after focal cortical infarction in hypertensive rats. J. Cereb. Blood Flow Metab. 2011, 31, 572-579. [CrossRef]

167. Zhang, J.; Zhang, Y.; Li, J.; Xing, S.; Li, C.; Li, Y.; Dang, C.; Fan, Y.; Yu, J.; Pei, Z.; et al. Autophagosomes accumulation is associated with $\beta$-amyloid deposits and secondary damage in the thalamus after focal cortical infarction in hypertensive rats. J. Neurochem. 2012, 120, 564-573. [CrossRef] [PubMed]

168. Sarajärvi, T.; Lipsanen, A.; Mäkinen, P.; Peräniemi, S.; Soininen, H.; Haapasalo, A.; Jolkkonen, J.; Hiltunen, M. Bepridil decreases $\mathrm{A} \beta$ and calcium levels in the thalamus after middle cerebral artery occlusion in rats. J. Cell Mol. Med. 2012, 16, 2754-2767. [CrossRef] [PubMed]

169. Beghi, E. The Epidemiology of Epilepsy. Neuroepidemiology 2020, 54, 185-191. [CrossRef] [PubMed]

170. Liu, G.; Slater, N.; Perkins, A. Epilepsy: Treatment options. Am. Fam. Physician 2017, 96, 87-96. [PubMed]

171. Blümcke, I.; Thom, M.; Aronica, E.; Armstrong, D.D.; Bartolomei, F.; Bernasconi, A.; Bernasconi, N.; Bien, C.G.; Cendes, F.; Coras, R.; et al. International consensus classification of hippocampal sclerosis in temporal lobe epilepsy: A Task Force report from the ILAE Commission on Diagnostic Methods. Epilepsia 2013, 54, 1315-1329. [CrossRef] [PubMed]

172. De Lanerolle, N.C.; Lee, T.S.; Spencer, D.D. Histopathology of human epilepsy. In Jasper's Basic Mechanisms of the Epilepsies, 4th ed.; Noebels, J.L., Avoli, M., Rogawski, M.A., Olsen, R.W., Delgado-Escueta, A.V., Eds.; National Center for Biotechnology: Bethesda, MD, USA, 2010.

173. Thom, M. Review: Hippocampal sclerosis in epilepsy: A neuropathology review. Neuropathol. Appl. Neurobiol. 2014, 40, 520-543. [CrossRef] [PubMed]

174. Briellmann, R.S.; Berkovic, S.F.; Syngeniotis, A.; King, M.A.; Jackson, G.D. Seizure-associated hippocampal volume loss: A longitudinal magnetic resonance study of temporal lobe epilepsy. Ann. Neurol. 2002, 51, 641-644. [CrossRef]

175. Jackson, G.D.; Berkovic, S.F.; Tress, B.M.; Kalnins, R.M.; Fabinyi, G.C.; Bladin, P.F. Hippocampal sclerosis can be reliably detected by magnetic resonance imaging. Neurology 1990, 40, 1869-1875. [CrossRef]

176. Henshall, D.C. Apoptosis signalling pathways in seizure-induced neuronal death and epilepsy. Biochem. Soc. Trans. 2007, 35 Pt 2, 421-423. [CrossRef]

177. Peltola, J.; Palmio, J.; Korhonen, L.; Suhonen, J.; Miettinen, A.; Hurme, M.; Lindholm, D.; Keränen, T. Interleukin-6 and interleukin-1 receptor antagonist in cerebrospinal fluid from patients with recent tonic-clonic seizures. Epilepsy Res. 2000, 41, 205-211. [CrossRef]

178. Ravizza, T.; Gagliardi, B.; Noé, F.; Boer, K.; Aronica, E.; Vezzani, A. Innate and adaptive immunity during epileptogenesis and spontaneous seizures: Evidence from experimental models and human temporal lobe epilepsy. Neurobiol. Dis. 2008, 29, 142-160. [CrossRef] 
179. De Lanerolle, N.C.; Lee, T.S. New facets of the neuropathology and molecular profile of human temporal lobe epilepsy. Epilepsy Behav. 2005, 7, 190-203. [CrossRef] [PubMed]

180. Van Vliet, E.A.; da Costa Araújo, S.; Redeker, S.; van Schaik, R.; Aronica, E.; Gorter, J.A. Blood-brain barrier leakage may lead to progression of temporal lobe epilepsy. Brain 2007, 130 Pt 2, 521-534. [CrossRef]

181. Bae, J.M. History of coffee consumption and risk of Alzheimer's disease: A meta-epidemiological study of population-based cohort studies. Dement. Neurocogn. Disord. 2020, 19, 108-113. [CrossRef] [PubMed]

182. Kolahdouzan, M.; Hamadeh, M.J. The neuroprotective effects of caffeine in neurodegenerative diseases. CNS Neurosci. Ther. 2017, 23, 272-290. [CrossRef] [PubMed]

183. Wasim, S.; Kukkar, V.; Awad, V.M.; Sakhamuru, S.; Malik, B.H. Neuroprotective and neurodegenerative aspects of coffee and its active ingredients in view of scientific literature. Cureus 2020, 12, e9578. [PubMed]

184. Colombo, R.; Papetti, A. An outlook on the role of decaffeinated coffee in neurodegenerative diseases. Crit. Rev. Food Sci. Nutr. 2020, 60, 760-779. [CrossRef] [PubMed]

185. Patil, H.; Lavie, C.J.; O'Keefe, J.H. Cuppa joe: Friend or foe? Effects of chronic coffee consumption on cardiovascular and brain health. Mo. Med. 2011, 108, 431-438.

186. Fredholm, B.B.; Bättig, K.; Holmén, J.; Nehlig, A.; Zvartau, E.E. Actions of caffeine in the brain with special reference to factors that contribute to its widespread use. Pharmacol. Rev. 1999, 51, 83-133.

187. McCusker, R.R.; Goldberger, B.A.; Cone, E.J. Caffeine content of specialty coffees. J. Anal. Toxicol. 2003, 27, 520-522. [CrossRef]

188. Smith, A. Effects of caffeine on human behavior. Food Chem. Toxicol. 2002, 40, 1243-1255. [CrossRef]

189. van Gelder, B.M.; Buijsse, B.; Tijhuis, M.; Kalmijn, S.; Giampaoli, S.; Nissinen, A.; Kromhout, D. Coffee consumption is inversely associated with cognitive decline in elderly European men: The FINE Study. Eur. J. Clin. Nutr. 2007, 61, 226-232. [CrossRef]

190. Devasagayam, T.P.; Kamat, J.P.; Mohan, H.; Kesavan, P.C. Caffeine as an antioxidant: Inhibition of lipid peroxidation induced by reactive oxygen species. Biochim. Biophys. Acta 1996, 1282, 63-70. [CrossRef]

191. Ullah, F.; Ali, T.; Ullah, N.; Kim, M.O. Caffeine prevents d-galactose-induced cognitive deficits, oxidative stress, neuroinflammation and neurodegeneration in the adult rat brain. Neurochem. Int. 2015, 90, 114-124. [CrossRef] [PubMed]

192. Molinengo, L.; Scordo, I.; Pastorello, B. Action of caffeine, L-PIA and their combination on memory retention in the rat. Life Sci. 1994, 54, 1247-1250. [CrossRef]

193. Costa, M.S.; Botton, P.H.; Mioranzza, S.; Souza, D.O.; Porciúncula, L.O. Caffeine prevents age-associated recognition memory decline and changes brain-derived neurotrophic factor and tirosine kinase receptor (TrkB) content in mice. Neuroscience 2008, 153, 1071-1078. [CrossRef] [PubMed]

194. Arendash, G.W.; Schleif, W.; Rezai-Zadeh, K.; Jackson, E.K.; Zacharia, L.C.; Cracchiolo, J.R.; Shippy, D.; Tan, J. Caffeine protects Alzheimer's mice against cognitive impairment and reduces brain beta-amyloid production. Neuroscience 2006, 142, 941-952. [CrossRef] [PubMed]

195. Arendash, G.W.; Mori, T.; Cao, C.; Mamcarz, M.; Runfeldt, M.; Dickson, A.; Rezai-Zadeh, K.; Tane, J.; Citron, B.A.; Lin, X.; et al. Caffeine reverses cognitive impairment and decreases brain amyloid-beta levels in aged Alzheimer's disease mice. J. Alzheimers Dis. 2009, 17, 661-680. [CrossRef]

196. Dall'Igna, O.P.; Porciúncula, L.O.; Souza, D.O.; Cunha, R.A.; Lara, D.R. Neuroprotection by caffeine and adenosine A2A receptor blockade of beta-amyloid neurotoxicity. Br. J. Pharmacol. 2003, 138, 1207-1209. [CrossRef] [PubMed]

197. Dall'Igna, O.P.; Fett, P.; Gomes, M.W.; Souza, D.O.; Cunha, R.A.; Lara, D.R. Caffeine and adenosine A(2a) receptor antagonists prevent beta-amyloid (25-35)-induced cognitive deficits in mice. Exp. Neurol. 2007, 203, 241-245. [CrossRef]

198. Giunta, S.; Andriolo, V.; Castorina, A. Dual blockade of the A1 and A2A adenosine receptor prevents amyloid beta toxicity in neuroblastoma cells exposed to aluminum chloride. Int. J. Biochem. Cell Biol. 2014, 54, 122-136. [CrossRef] [PubMed]

199. Leite, M.R.; Wilhelm, E.A.; Jesse, C.R.; Brandăo, R.; Nogueira, C.W. Protective effect of caffeine and a selective A2A receptor antagonist on impairment of memory and oxidative stress of aged rats. Exp. Gerontol. 2011, 46, 309-315. [CrossRef] [PubMed]

200. Laurent, C.; Eddarkaoui, S.; Derisbourg, M.; Leboucher, A.; Demeyer, D.; Carrier, S.; Schneider, M.; Hamdane, M.; Müller, C.E.; Buée, L.; et al. Beneficial effects of caffeine in a transgenic model of Alzheimer's disease-like tau pathology. Neurobiol. Aging 2014, 35, 2079-2090. [CrossRef] [PubMed]

201. Prasanthi, J.R.; Dasari, B.; Marwarha, G.; Larson, T.; Chen, X.; Geiger, J.D.; Ghribi, O. Caffeine protects against oxidative stress and Alzheimer's disease-like pathology in rabbit hippocampus induced by cholesterol-enriched diet. Free Radic. Biol. Med. 2010, 49, 1212-1220. [CrossRef]

202. Han, M.E.; Kim, H.J.; Lee, Y.S.; Kim, D.H.; Choi, J.T.; Pan, C.S.; Yoon, S.; Baek, S.Y.; Kim, B.S.; Kim, J.B.; et al. Regulation of cerebrospinal fluid production by caffeine consumption. BMC Neurosci. 2009, 10,1-12. [CrossRef]

203. Wostyn, P.; Van, D.D.; Audenaert, K.; De Deyn, P.P. Increased cerebrospinal fluid production as a possible mechanism underlying caffeine's protective effect against Alzheimer's disease. Int. J. Alzheimers Dis. 2011, 2011, 617420. [CrossRef]

204. Bagga, P.; Chugani, A.N.; Patel, A.B. Neuroprotective effects of caffeine in MPTP model of Parkinson's disease: A (13)C NMR study. Neurochem. Int. 2016, 92, 25-34. [CrossRef]

205. Chen, X.; Lan, X.; Roche, I.; Liu, R.; Geiger, J.D. Caffeine protects against MPTP-induced blood-brain barrier dysfunction in mouse striatum. J. Neurochem. 2008, 107, 1147-1157. [CrossRef]

206. Gevaerd, M.S.; Takahashi, R.N.; Silveira, R.; Da, C.C. Caffeine reverses the memory disruption induced by intra-nigral MPTPinjection in rats. Brain Res. Bull. 2001, 55, 101-106. [CrossRef] 
207. Singh, S.; Singh, K.; Gupta, S.P.; Patel, D.K.; Singh, V.K.; Singh, R.K.; Singh, M.P. Effect of caffeine on the expression of cytochrome P450 1A2, adenosine A2A receptor and dopamine transporter in control and 1-methyl 4-phenyl 1, 2, 3, 6-tetrahydropyridine treated mouse striatum. Brain Res. 2009, 1283, 115-126. [CrossRef]

208. Xu, K.; Xu, Y.; Brown-Jermyn, D.; Chen, J.F.; Ascherio, A.; Dluzen, D.E.; Schwarzschild, M.A. Estrogen prevents neuroprotection by caffeine in the mouse 1-methyl-4-phenyl-1,2,3,6-tetrahydropyridine model of Parkinson's disease. J. Neurosci. 2006, 26, 535-541. [CrossRef]

209. Xu, K.; Xu, Y.H.; Chen, J.F.; Schwarzschild, M.A. Neuroprotection by caffeine: Time course and role of its metabolites in the MPTP model of Parkinson's disease. Neuroscience 2010, 167, 475-481. [CrossRef] [PubMed]

210. Aguiar, L.M.; Nobre, H.V., Jr.; Macedo, D.S.; Oliveira, A.A.; Freitas, R.M.; Vasconcelos, S.M.; Cunha, G.M.; Sousa, F.C.; Viana, G.S. Neuroprotective effects of caffeine in the model of 6-hydroxydopamine lesion in rats. Pharmacol. Biochem. Behav. 2006, 84, 415-419. [CrossRef] [PubMed]

211. Joghataie, M.T.; Roghani, M.; Negahdar, F.; Hashemi, L. Protective effect of caffeine against neurodegeneration in a model of Parkinson's disease in rat: Behavioral and histochemical evidence. Parkinsonism. Relat. Disord. 2004, 10, 465-468. [CrossRef] [PubMed]

212. Kachroo, A.; Irizarry, M.C.; Schwarzschild, M.A. Caffeine protects against combined paraquat and maneb-induced dopaminergic neuron degeneration. Exp. Neurol. 2010, 223, 657-661. [CrossRef]

213. Sonsalla, P.K.; Wong, L.Y.; Harris, S.L.; Richardson, J.R.; Khobahy, I.; Li, W.; Gadad, B.S.; German, D.C. Delayed caffeine treatment prevents nigral dopamine neuron loss in a progressive rat model of Parkinson's disease. Exp. Neurol. 2012, 234, $482-487$. [CrossRef]

214. Machado-Filho, J.A.; Correia, A.O.; Montenegro, A.B.; Nobre, M.E.; Cerqueira, G.S.; Neves, K.R.; Naffah-Mazzacoratti, M.G.; Cavalheiro, E.A.; de Castro Brito, G.A.; de Barros Viana, G.S. Caffeine neuroprotective effects on 6-OHDA-lesioned rats are mediated by several factors, including pro-inflammatory cytokines and histone deacetylase inhibitions. Behav. Brain Res. 2014, 264, 116-125. [CrossRef]

215. Chen, J.F.; Xu, K.; Petzer, J.P.; Staal, R.; Xu, Y.H.; Beilstein, M.; Sonsalla, P.K.; Castagnoli, K.; Castagnoli, N., Jr.; Schwarzschild, M.A. Neuroprotection by caffeine and A(2A) adenosine receptor inactivation in a model of Parkinson's disease. J. Neurosci. 2001, 21, RC143. [CrossRef]

216. Ikeda, K.; Kurokawa, M.; Aoyama, S.; Kuwana, Y. Neuroprotection by adenosine A2A receptor blockade in experimental models of Parkinson's disease. J. Neurochem. 2002, 80, 262-270. [CrossRef]

217. Pierri, M.; Vaudano, E.; Sager, T.; Englund, U. KW-6002 protects from MPTP induced dopaminergic toxicity in the mouse. Neuropharmacology 2005, 48, 517-524. [CrossRef]

218. Xu, K.; Bastia, E.; Schwarzschild, M. Therapeutic potential of adenosine A(2A) receptor antagonists in Parkinson's disease. Pharmacol. Ther. 2005, 105, 267-310. [CrossRef] [PubMed]

219. Yu, L.; Shen, H.Y.; Coelho, J.E.; Araújo, I.M.; Huang, Q.Y.; Day, Y.J.; Rebola, N.; Canas, P.M.; Rapp, E.K.; Ferrara, J.; et al. Adenosine A2A receptor antagonists exert motor and neuroprotective effects by distinct cellular mechanisms. Ann. Neurol. 2008, 63, 338-346. [CrossRef] [PubMed]

220. Popoli, P.; Betto, P.; Reggio, R.; Ricciarello, G. Adenosine A2A receptor stimulation enhances striatal extracellular glutamate levels in rats. Eur. J. Pharmacol. 1995, 287, 215-217. [CrossRef]

221. Prediger, R.D. Effects of caffeine in Parkinson's disease: From neuroprotection to the management of motor and non-motor symptoms. J. Alzheimers. Dis. 2010, 20 (Suppl. 1), S205-S220. [CrossRef]

222. Morelli, M.; Carta, A.R.; Jenner, P. Adenosine A2A receptors and Parkinson's disease. In Handbook of Experimental Pharmacology; Springer: Berlin/Heidelberg, Germany, 2009; pp. 589-615.

223. Carta, A.R.; Kachroo, A.; Schintu, N.; Xu, K.; Schwarzschild, M.A.; Wardas, J.; Morelli, M. Inactivation of neuronal forebrain A receptors protects dopaminergic neurons in a mouse model of Parkinson's disease. J. Neurochem. 2009, 111, 1478-1489. [CrossRef]

224. Rudolphi, K.A.; Keil, M.; Fastbom, J.; Fredholm, B.B. Ischaemic damage in gerbil hippocampus is reduced following upregulation of adenosine (A1) receptors by caffeine treatment. Neurosci. Lett. 1989, 103, 275-280. [CrossRef]

225. Georgiev, V.; Johansson, B.; Fredholm, B.B. Long-term caffeine treatment leads to a decreased susceptibility to NMDA-induced clonic seizures in mice without changes in adenosine A1 receptor number. Brain Res. 1993, 612, 271-277. [CrossRef]

226. Evans, S.M.; Pinto Pereira, L.M.; Addae, J.I. Neuroprotection by caffeine and pentoxifylline during experimental cerebral ischaemia. West Indian Med. J. 1999, 48, 23-25.

227. Sutherland, G.R.; Peeling, J.; Lesiuk, H.J.; Brownstone, R.M.; Rydzy, M.; Saunders, J.K.; Geiger, J.D. The effects of caffeine on ischemic neuronal injury as determined by magnetic resonance imaging and histopathology. Neuroscience 1991, 42, 171-182. [CrossRef]

228. Alexander, M.; Smith, A.L.; Rosenkrantz, T.S.; Fitch, R.H. Therapeutic effect of caffeine treatment immediately following neonatal hypoxic-ischemic injury on spatial memory in male rats. Brain Sci. 2013, 3, 177-190. [CrossRef]

229. Kilicdag, H.; Daglioglu, Y.K.; Erdogan, S.; Zorludemir, S. Effects of caffeine on neuronal apoptosis in neonatal hypoxic-ischemic brain injury. J. Matern. Fetal Neonatal Med. 2014, 27, 1470-1475. [CrossRef]

230. Potter, M.; Rosenkrantz, T.; Fitch, R.H. Behavioral and neuroanatomical outcomes in a rat model of preterm hypoxic-ischemic brain Injury: Effects of caffeine and hypothermia. Int. J. Dev. Neurosci. 2018, 70, 46-55. [CrossRef] [PubMed]

231. Maia, L.; de Mendonça, A. Does caffeine intake protect from Alzheimer's disease? Eur. J. Neurol. 2002, 9, 377-382. [CrossRef] 
232. Lindsay, J.; Laurin, D.; Verreault, R.; Hébert, R.; Helliwell, B.; Hill, G.B.; McDowell, I. Risk factors for Alzheimer's disease: A prospective analysis from the Canadian Study of Health and Aging. Am. J. Epidemiol. 2002, 156, 445-453. [CrossRef] [PubMed]

233. Eskelinen, M.H.; Ngandu, T.; Tuomilehto, J.; Soininen, H.; Kivipelto, M. Midlife coffee and tea drinking and the risk of late-life dementia: A population-based CAIDE study. J. Alzheimers Dis. 2009, 16, 85-91. [CrossRef] [PubMed]

234. Eskelinen, M.H.; Kivipelto, M. Caffeine as a protective factor in dementia and Alzheimer's disease. J. Alzheimers Dis. 2010, 20 (Suppl. 1), S167-S174. [CrossRef] [PubMed]

235. Beydoun, M.A.; Beydoun, H.A.; Gamaldo, A.A.; Teel, A.; Zonderman, A.B.; Wang, Y. Epidemiologic studies of modifiable factors associated with cognition and dementia: Systematic review and meta-analysis. BMC. Public Health 2014, 14, 643. [CrossRef]

236. Santos, C.; Costa, J.; Santos, J.; Vaz-Carneiro, A.; Lunet, N. Caffeine intake and dementia: Systematic review and meta-analysis. J. Alzheimers. Dis. 2010, 20 (Suppl. 1), S187-S204. [CrossRef]

237. Barranco Quintana, J.L.; Allam, M.F.; Serrano Del Castillo, A.; Fernández-Crehuet Navajas, R. Alzheimer's disease and coffee: A quantitative review. Neurol. Res. 2007, 29, 91-95. [CrossRef]

238. Crichton, G.E.; Bryan, J.; Murphy, K.J. Dietary antioxidants, cognitive function and dementia-A systematic review. Plant. Foods Hum. Nutr. 2013, 68, 279-292. [CrossRef]

239. Di Marco, L.Y.; Marzo, A.; Munoz-Ruiz, M.; Ikram, M.A.; Kivipelto, M.; Ruefenacht, D.; Venneri, A.; Soininen, H.; Wanke, I.; Ventikos, Y.A.; et al. Modifiable lifestyle factors in dementia: A systematic review of longitudinal observational cohort studies. J. Alzheimers Dis. 2014, 42, 119-135. [CrossRef] [PubMed]

240. Ritchie, K.; Carriére, I.; de Mendonca, A.; Portet, F.; Dartigues, J.F.; Rouaud, O.; Barberger-Gateau, P.; Ancelin, M.L. The neuroprotective effects of caffeine: A prospective population study (the Three City Study). Neurology 2007, 69, 536-545. [CrossRef] [PubMed]

241. Kim, Y.S.; Kwak, S.M.; Myung, S.K. Caffeine intake from coffee or tea and cognitive disorders: A meta-analysis of observational studies. Neuroepidemiology 2015, 44, 51-63. [CrossRef] [PubMed]

242. Costa, J.; Lunet, N.; Santos, C.; Santos, J.; Vaz-Carneiro, A. Caffeine exposure and the risk of Parkinson's disease: A systematic review and meta-analysis of observational studies. J. Alzheimers. Dis. 2010, 20 (Suppl. 1), S221-S238. [CrossRef] [PubMed]

243. Hernán, M.A.; Takkouche, B.; Caamano-Isorna, F.; Gestal-Otero, J.J. A meta-analysis of coffee drinking, cigarette smoking, and the risk of Parkinson's disease. Ann. Neurol. 2002, 52, 276-284. [CrossRef]

244. Noyce, A.J.; Bestwick, J.P.; Silveira-Moriyama, L.; Hawkes, C.H.; Giovannoni, G.; Lees, A.J.; Schrag, A. Meta-analysis of early nonmotor features and risk factors for Parkinson disease. Ann. Neurol. 2012, 72, 893-901. [CrossRef]

245. Qi, H.; Li, S. Dose-response meta-analysis on coffee, tea and caffeine consumption with risk of Parkinson's disease. Geriatr. Gerontol. Int. 2014, 14, 430-439. [CrossRef]

246. Ross, G.W.; Abbott, R.D.; Petrovitch, H.; Morens, D.M.; Grandinetti, A.; Tung, K.H.; Tanner, C.M.; Masaki, K.H.; Blanchette, P.L.; Curb, J.D.; et al. Association of coffee and caffeine intake with the risk of Parkinson disease. JAMA 2000, 283, $2674-2679$. [CrossRef]

247. Hu, G.; Bidel, S.; Jousilahti, P.; Antikainen, R.; Tuomilehto, J. Coffee and tea consumption and the risk of Parkinson's disease. Mov. Disord. 2007, 22, 2242-2248. [CrossRef]

248. Liu, R.; Guo, X.; Park, Y.; Huang, X.; Sinha, R.; Freedman, N.D.; Hollenbeck, A.R.; Blair, A.; Chen, H. Caffeine intake, smoking, and risk of Parkinson disease in men and women. Am. J. Epidemiol. 2012, 175, 1200-1207. [CrossRef]

249. Palacios, N.; Gao, X.; McCullough, M.L.; Schwarzschild, M.A.; Shah, R.; Gapstur, S.; Ascherio, A. Caffeine and risk of Parkinson's disease in a large cohort of men and women. Mov. Disord. 2012, 27, 1276-1282. [CrossRef] [PubMed]

250. Altman, R.D.; Lang, A.E.; Postuma, R.B. Caffeine in Parkinson's disease: A pilot open-label, dose-escalation study. Mov. Disord. 2011, 26, 2427-2431. [CrossRef] [PubMed]

251. Postuma, R.B.; Lang, A.E.; Munhoz, R.P.; Charland, K.; Pelletier, A.; Moscovich, M.; Filla, L.; Zanatta, D.; Rios, R.S.; Altman, R.; et al. Caffeine for treatment of Parkinson disease: A randomized controlled trial. Neurology 2012, 79, 651-658. [CrossRef] [PubMed]

252. Postuma, R.B.; Anang, J.; Pelletier, A.; Joseph, L.; Moscovich, M.; Grimes, D.; Furtado, S.; Munhoz, R.P.; Appel-Cresswell, S.; Moro, A.; et al. Caffeine as symptomatic treatment for Parkinson disease (Café-PD): A randomized trial. Neurology 2017, 89, 1795-1803. [CrossRef]

253. Tan, E.K.; Chua, E.; Fook-Chong, S.M.; Teo, Y.Y.; Yuen, Y.; Tan, L.; Zhao, Y. Association between caffeine intake and risk of Parkinson's disease among fast and slow metabolizers. Pharmacogenet. Genom. 2007, 17, 1001-1005. [CrossRef]

254. Fondell, E.; O’Reilly, É.I.J.; Fitzgerald, K.C.; Falcone, G.J.; Kolonel, L.N.; Park, Y.; Gapstur, S.M.; Ascherio, A. Intakes of caffeine, coffee and tea and risk of amyotrophic lateral sclerosis: Results from five cohort studies. Amyotroph. Lateral. Scler. Front. Degener. 2015, 16, 366-371. [CrossRef]

255. Larsson, S.C. Coffee, tea, and cocoa and risk of stroke. Stroke 2014, 45, 309-314. [CrossRef]

256. Selb, S.J.; Selb, K. Coffee and alcohol consumption as triggering factors for sudden cardiac death: Case-crossover study. Croat. Med. J. 2004, 45, 775-780.

257. Tavani, A.; Bertuzzi, M.; Negri, E.; Sorbara, L.; La, V.C. Alcohol, smoking, coffee and risk of non-fatal acute myocardial infarction in Italy. Eur. J. Epidemiol. 2001, 17, 1131-1137. [CrossRef]

258. Smits, P.; Thien, T.; van't Laar, A. Circulatory effects of coffee in relation to the pharmacokinetics of caffeine. Am. J. Cardiol. 1985, 56, 958-963. [CrossRef] 
259. Prineas, R.J.; Jacobs, D.R., Jr.; Crow, R.S.; Blackburn, H. Coffee, tea and VPB. J. Chronic. Dis. 1980, 33, 67-72. [CrossRef]

260. Hartley, T.R.; Lovallo, W.R.; Whitsett, T.L. Cardiovascular effects of caffeine in men and women. Am. J. Cardiol. 2004, 93, 1022-1026. [CrossRef] [PubMed]

261. Lopez-Garcia, E.; Rodriguez-Artalejo, F.; Rexrode, K.M.; Logroscino, G.; Hu, F.B.; van Dam, R.M. Coffee consumption and risk of stroke in women. Circulation 2009, 119, 1116-1123. [CrossRef] [PubMed]

262. Silletta, M.G.; Marfisi, R.; Levantesi, G.; Boccanelli, A.; Chieffo, C.; Franzosi, M.; Geraci, E.; Maggioni, A.P.; Nicolosi, G.; Schweiger, C.; et al. Coffee consumption and risk of cardiovascular events after acute myocardial infarction: Results from the GISSI (Gruppo Italiano per lo Studio della Sopravvivenza nell'Infarto miocardico)-Prevenzione trial. Circulation 2007, 116, 2944-2951. [CrossRef] [PubMed]

263. Greenberg, J.A.; Chow, G.; Ziegelstein, R.C. Caffeinated coffee consumption, cardiovascular disease, and heart valve disease in the elderly (from the Framingham Study). Am. J. Cardiol. 2008, 102, 1502-1508. [CrossRef]

264. Zhang, W.; Lopez-Garcia, E.; Li, T.Y.; Hu, F.B.; van Dam, R.M. Coffee consumption and risk of cardiovascular diseases and all-cause mortality among men with type 2 diabetes. Diabetes Care 2009, 32, 1043-1045. [CrossRef]

265. Mukamal, K.J.; Hallqvist, J.; Hammar, N.; Ljung, R.; Gémes, K.; Ahlbom, A.; Ahnve, S.; Janszky, I. Coffee consumption and mortality after acute myocardial infarction: The Stockholm Heart Epidemiology Program. Am. Heart J. 2009, 157, 495-501. [CrossRef]

266. De Koning Gans, J.M.; Uiterwaal, C.S.; van der Schouw, Y.T.; Boer, J.M.; Grobbee, D.E.; Verschuren, W.M.; Beulens, J.W. Tea and coffee consumption and cardiovascular morbidity and mortality. Arterioscler. Thromb. Vasc. Biol. 2010, 30, 1665-1671. [CrossRef]

267. Ding, M.; Bhupathiraju, S.N.; Satija, A.; van Dam, R.M.; Hu, F.B. Long-term coffee consumption and risk of cardiovascular disease: A systematic review and a dose-response meta-analysis of prospective cohort studies. Circulation 2014, 129, 643-659. [CrossRef]

268. Larsson, S.C.; Männistö, S.; Virtanen, M.J.; Kontto, J.; Albanes, D.; Virtamo, J. Coffee and tea consumption and risk of stroke subtypes in male smokers. Stroke 2008, 39, 1681-1687. [CrossRef]

269. Kim, B.; Nam, Y.; Kim, J.; Choi, H.; Won, C. Coffee consumption and stroke risk: A meta-analysis of epidemiologic studies. Korean J. Fam. Med. 2012, 33, 356-365. [CrossRef] [PubMed]

270. Mostofsky, E.; Schlaug, G.; Mukamal, K.J.; Rosamond, W.D.; Mittleman, M.A. Coffee and acute ischemic stroke onset: The Stroke Onset Study. Neurology 2010, 75, 1583-1588. [CrossRef] [PubMed]

271. Washio, T.; Sasaki, H.; Ogoh, S. Acute impact of drinking coffee on the cerebral and systemic vasculature. Physiol. Rep. 2017, 5, e13288. [CrossRef] [PubMed]

272. Larsson, S.C.; Orsini, N. Coffee consumption and risk of stroke: A dose-response meta-analysis of prospective studies. Am. J. Epidemiol. 2011, 174, 993-1001. [CrossRef] [PubMed]

273. Strong, R.; Grotta, J.C.; Aronowski, J. Combination of low dose ethanol and caffeine protects brain from damage produced by focal ischemia in rats. Neuropharmacology 2000, 39, 515-522. [CrossRef]

274. Aronowski, J.; Strong, R.; Shirzadi, A.; Grotta, J.C. Ethanol plus caffeine (caffeinol) for treatment of ischemic stroke: Preclinical experience. Stroke 2003, 34, 1246-1251. [CrossRef]

275. Piriyawat, P.; Labiche, L.A.; Burgin, W.S.; Aronowski, J.A.; Grotta, J.C. Pilot dose-escalation study of caffeine plus ethanol (caffeinol) in acute ischemic stroke. Stroke 2003, 34, 1242-1245. [CrossRef]

276. Martin-Schild, S.; Hallevi, H.; Shaltoni, H.; Barreto, A.D.; Gonzales, N.R.; Aronowski, J.; Savitz, S.I.; Grotta, J.C. Combined neuroprotective modalities coupled with thrombolysis in acute ischemic stroke: A pilot study of caffeinol and mild hypothermia. J. Stroke Cerebrovasc. Dis. 2009, 18, 86-96. [CrossRef]

277. Zhao, X.; Strong, R.; Piriyawat, P.; Palusinski, R.; Grotta, J.C.; Aronowski, J. Caffeinol at the receptor level: Anti-ischemic effect of $\mathrm{N}$-methyl-D-aspartate receptor blockade is potentiated by caffeine. Stroke 2010, 41, 363-367. [CrossRef]

278. Heitman, E.; Ingram, D.K. Cognitive and neuroprotective effects of chlorogenic acid. Nutr. Neurosci. 2017, 20, 32-39. [CrossRef]

279. Tajik, N.; Tajik, M.; Mack, I.; Enck, P. The potential effects of chlorogenic acid, the main phenolic components in coffee, on health: A comprehensive review of the literature. Eur. J. Nutr. 2017, 56, 2215-2244. [CrossRef] [PubMed]

280. Nabavi, S.F.; Tejada, S.; Setzer, W.N.; Gortzi, O.; Sureda, A.; Braidy, N.; Daglia, M.; Manayi, A.; Nabavi, S.M. Chlorogenic acid and mental diseases: From hhemistry to medicine. Curr. Neuropharmacol. 2017, 15, 471-479. [CrossRef] [PubMed]

281. Cho, E.S.; Jang, Y.J.; Hwang, M.K.; Kang, N.J.; Lee, K.W.; Lee, H.J. Attenuation of oxidative neuronal cell death by coffee phenolic phytochemicals. Mutat. Res. 2009, 661, 18-24. [CrossRef] [PubMed]

282. Kim, J.; Lee, S.; Shim, J.; Kim, H.W.; Kim, J.; Jang, Y.J.; Yang, H.; Park, J.; Choi, S.H.; Yoon, J.H.; et al. Caffeinated coffee, decaffeinated coffee, and the phenolic phytochemical chlorogenic acid up-regulate NQO1 expression and prevent $\mathrm{H}_{2} \mathrm{O}_{2}$-induced apoptosis in primary cortical neurons. Neurochem. Int. 2012, 60, 466-474. [CrossRef] [PubMed]

283. Chu, Y.F.; Brown, P.H.; Lyle, B.J.; Chen, Y.; Black, R.M.; Williams, C.E.; Lin, Y.C.; Hsu, C.W.; Cheng, I.H. Roasted coffees high in lipophilic antioxidants and chlorogenic acid lactones are more neuroprotective than green coffees. J. Agric. Food Chem. 2009, 57, 9801-9808. [CrossRef] [PubMed]

284. Mira, A.; Yamashita, S.; Katakura, Y.; Shimizu, K. In vitro neuroprotective activities of compounds from Angelica shikokiana Makino. Molecules 2015, 20, 4813-4832. [CrossRef] [PubMed]

285. Gul, Z.; Demircan, C.; Bagdas, D.; Buyukuysal, R.L. Protective effects of chlorogenic acid and its metabolites on hydrogen peroxide-induced alterations in rat brain slices: A comparative study with resveratrol. Neurochem. Res. 2016, 41, 2075-2085. [CrossRef] 
286. Yao, J.; Peng, S.; Xu, J.; Fang, J. Reversing ROS-mediated neurotoxicity by chlorogenic acid involves its direct antioxidant activity and activation of Nrf2-ARE signaling pathway. Biofactors 2019, 45, 616-626. [CrossRef]

287. Wang, X.; Fan, X.; Yuan, S.; Jiao, W.; Liu, B.; Cao, J.; Jiang, W. Chlorogenic acid protects against aluminium-induced cytotoxicity through chelation and antioxidant actions in primary hippocampal neuronal cells. Food Funct. 2017, 8, 2924-2934. [CrossRef]

288. Nakajima, Y.; Shimazawa, M.; Mishima, S.; Hara, H. Water extract of propolis and its main constituents, caffeoylquinic acid derivatives, exert neuroprotective effects via antioxidant actions. Life Sci. 2007, 80, 370-377. [CrossRef]

289. Li, Y.; Shi, W.; Li, Y.; Zhou, Y.; Hu, X.; Song, C.; Ma, H.; Wang, C.; Li, Y. Neuroprotective effects of chlorogenic acid against apoptosis of PC12 cells induced by methylmercury. Environ. Toxicol. Pharmacol. 2008, 26, 13-21. [CrossRef] [PubMed]

290. Oboh, G.; Agunloye, O.M.; Akinyemi, A.J.; Ademiluyi, A.O.; Adefegha, S.A. Comparative study on the inhibitory effect of caffeic and chlorogenic acids on key enzymes linked to Alzheimer's disease and some pro-oxidant induced oxidative stress in rats' brain-in vitro. Neurochem. Res. 2013, 38, 413-419. [CrossRef] [PubMed]

291. Taram, F.; Winter, A.N.; Linseman, D.A. Neuroprotection comparison of chlorogenic acid and its metabolites against mechanistically distinct cell death-inducing agents in cultured cerebellar granule neurons. Brain Res. 2016, 1648 Pt A, 69-80. [CrossRef]

292. Lee, M.; McGeer, E.G.; McGeer, P.L. Quercetin, not caffeine, is a major neuroprotective component in coffee. Neurobiol. Aging 2016, 46, 113-123. [CrossRef] [PubMed]

293. Lewerenz, J.; Maher, P. Chronic glutamate toxicity in neurodegenerative diseases - What is the evidence? Front. Neurosci. 2015, 9 , 469. [CrossRef] [PubMed]

294. Lugo-Huitrón, R.; Ugalde Muñiz, P.; Pineda, B.; Pedraza-Chaverrí, J.; Ríos, C.; Pérez-de la Cruz, V. Quinolinic acid: An endogenous neurotoxin with multiple targets. Oxid. Med. Cell Longev. 2013, 2013, 104024. [CrossRef]

295. Mikami, Y.; Yamazawa, T. Chlorogenic acid, a polyphenol in coffee, protects neurons against glutamate neurotoxicity. Life Sci. 2015, 139, 69-74. [CrossRef]

296. Rebai, O.; Belkhir, M.; Sanchez-Gomez, M.V.; Matute, C.; Fattouch, S.; Amri, M. Differential molecular targets for neuroprotective effect of chlorogenic acid and its related compounds against glutamate induced excitotoxicity and oxidative stress in rat cortical neurons. Neurochem. Res. 2017, 42, 3559-3572. [CrossRef]

297. Rebai, O.; Amri, M. Chlorogenic Acid Prevents AMPA-mediated excitotoxicity in optic nerve oligodendrocytes through a PKC and caspase-dependent pathways. Neurotox. Res. 2018, 34, 559-573. [CrossRef]

298. Liu, Q.F.; Jeon, Y.; Sung, Y.W.; Lee, J.H.; Jeong, H.; Kim, Y.M.; Yun, H.S.; Chin, Y.W.; Jeon, S.; Cho, K.S.; et al. Nardostachys jatamansi ethanol extract ameliorates A $\beta 42$ cytotoxicity. Biol. Pharm. Bull. 2018, 41, 470-477. [CrossRef]

299. Gao, L.; Li, X.; Meng, S.; Ma, T.; Wan, L.; Xu, S. Chlorogenic acid alleviates A $\beta(25-35)$-induced autophagy and cognitive impairment via the mTOR/TFEB signaling pathway. Drug Des. Dev. Ther. 2020, 14, 1705-1716. [CrossRef] [PubMed]

300. Wei, M.; Chen, L.; Liu, J.; Zhao, J.; Liu, W.; Feng, F. Protective effects of a Chotosan Fraction and its active components on $\beta$-amyloid-induced neurotoxicity. Neurosci. Lett. 2016, 617, 143-149. [CrossRef] [PubMed]

301. Mancini, R.S.; Wang, Y.; Weaver, D.F. Phenylindanes in brewed coffee inhibit amyloid-beta and tau aggregation. Front. Neurosci. 2018, 12, 735. [CrossRef] [PubMed]

302. Kwon, S.H.; Lee, H.K.; Kim, J.A.; Hong, S.I.; Kim, H.C.; Jo, T.H.; Park, Y.I.; Lee, C.K.; Kim, Y.B.; Lee, S.Y.; et al. Neuroprotective effects of chlorogenic acid on scopolamine-induced amnesia via anti-acetylcholinesterase and anti-oxidative activities in mice. Eur. J. Pharmacol. 2010, 649, 210-217. [CrossRef]

303. Szwajgier, D. Anticholinesterase activity of selected phenolic acids and flavonoids-Interaction testing in model solutions. Ann. Agric. Environ. Med. 2015, 22, 690-694. [CrossRef]

304. Nazir, N.; Zahoor, M.; Nisar, M.; Karim, N.; Latif, A.; Ahmad, S.; Uddin, Z. Evaluation of neuroprotective and anti-amnesic effects of Elaeagnus umbellata Thunb. On scopolamine-induced memory impairment in mice. BMC Complementary Med. Ther. 2020, 20, 1-17. [CrossRef]

305. Shan, S.; Tian, L.; Fang, R. Chlorogenic acid exerts beneficial effects in 6-hydroxydopamine-induced neurotoxicity by inhibition of endoplasmic reticulum stress. Med. Sci. Monit. 2019, 25, 453-459. [CrossRef]

306. Kwon, S.H.; Ma, S.X.; Hong, S.I.; Kim, S.Y.; Lee, S.Y.; Jang, C.G. Eucommia ulmoides Oliv. bark. attenuates 6-hydroxydopamineinduced neuronal cell death through inhibition of oxidative stress in SH-SY5Y cells. J. Ethnopharmacol. 2014, 152, 173-182. [CrossRef]

307. Lin, C.M.; Lin, Y.T.; Lee, T.L.; Imtiyaz, Z.; Hou, W.C.; Lee, M.H. In vitro and in vivo evaluation of the neuroprotective activity of Uncaria hirsuta Haviland. J. Food Drug Anal. 2020, 28, 147-158. [CrossRef]

308. Teraoka, M.; Nakaso, K.; Kusumoto, C.; Katano, S.; Tajima, N.; Yamashita, A.; Zushi, T.; Ito, S.; Matsura, T. Cytoprotective effect of chlorogenic acid against $\alpha$-synuclein-related toxicity in catecholaminergic PC12 cells. J. Clin. Biochem. Nutr. 2012, $51,122-127$. [CrossRef] [PubMed]

309. Masuda, M.; Hasegawa, M.; Nonaka, T.; Oikawa, T.; Yonetani, M.; Yamaguchi, Y.; Kato, K.; Hisanaga, S.; Goedert, M. Inhibition of alpha-synuclein fibril assembly by small molecules: Analysis using epitope-specific antibodies. FEBS Lett. 2009, 583, 787-791. [CrossRef] [PubMed]

310. Vardi, N.; Parlakpinar, H.; Ates, B. Beneficial effects of chlorogenic acid on methotrexate-induced cerebellar Purkinje cell damage in rats. J. Chem. Neuroanat. 2012, 43, 43-47. [CrossRef] [PubMed]

311. Hao, M.L.; Pan, N.; Zhang, Q.H.; Wang, X.H. Therapeutic efficacy of chlorogenic acid on cadmium-induced oxidative neuropathy in a murine model. Exp. Ther. Med. 2015, 9, 1887-1894. [CrossRef] [PubMed] 
312. Guo, Z.; Li, J. Chlorogenic Acid Prevents Alcohol-induced Brain Damage in Neonatal Rat. Transl. Neurosci. 2017, 8, 176-181. [CrossRef]

313. Alarcón-Herrera, N.; Flores-Maya, S.; Bellido, B.; García-Bores, A.M.; Mendoza, E.; Ávila-Acevedo, G.; Hernández-Echeagaray, E. Protective effects of chlorogenic acid in 3-nitropropionic acid induced toxicity and genotoxicity. Food Chem. Toxicol. 2017, 109 Pt. 2, 1018-1025. [CrossRef]

314. Miao, M.; Cao, L.; Li, R.; Fang, X.; Miao, Y. Protective effect of chlorogenic acid on the focal cerebral ischemia reperfusion rat models. Saudi Pharm. J. 2017, 25, 556-563. [CrossRef]

315. Liu, D.; Wang, H.; Zhang, Y.; Zhang, Z. Protective effects of chlorogenic acid on cerebral ischemia/reperfusion injury rats by regulating oxidative stress-related Nrf2 pathway. Drug Des. Dev. Ther. 2020, 14, 51-60. [CrossRef]

316. Lee, K.; Lee, J.S.; Jang, H.J.; Kim, S.M.; Chang, M.S.; Park, S.H.; Kim, K.S.; Bae, J.; Park, J.W.; Lee, B.; et al. Chlorogenic acid ameliorates brain damage and edema by inhibiting matrix metalloproteinase- 2 and 9 in a rat model of focal cerebral ischemia. Eur. J. Pharmacol. 2012, 689, 89-95. [CrossRef]

317. Kumar, G.; Mukherjee, S.; Paliwal, P.; Singh, S.S.; Birla, H.; Singh, S.P.; Krishnamurthy, S.; Patnaik, R. Neuroprotective effect of chlorogenic acid in global cerebral ischemia-reperfusion rat model. Naunyn Schmiedebergs Arch. Pharmacol. 2019, 392, 1293-1309. [CrossRef]

318. Ahn, E.H.; Kim, D.W.; Shin, M.J.; Kwon, S.W.; Kim, Y.N.; Kim, D.S.; Lim, S.S.; Kim, J.; Park, J.; Eum, W.S.; et al. Chlorogenic acid improves neuroprotective effect of PEP-1-ribosomal protein S3 against ischemic insult. Exp. Neurobiol. 2011, 20,169-175. [CrossRef]

319. Hermawati, E.; Arfian, N.; Mustofa, M.; Partadiredja, G. Chlorogenic acid ameliorates memory loss and hippocampal cell death after transient global ischemia. Eur. J. Neurosci. 2020, 51, 651-669. [CrossRef]

320. Lee, T.K.; Kang, I.J.; Kim, B.; Sim, H.J.; Kim, D.W.; Ahn, J.H.; Lee, J.C.; Ryoo, S.; Shin, M.C.; Cho, J.H.; et al. Experimental pretreatment with chlorogenic acid prevents transient ischemia-induced cognitive decline and neuronal damage in the hippocampus through anti-oxidative and anti-inflammatory effects. Molecules 2020, 25, 3578. [CrossRef] [PubMed]

321. Miyazaki, I.; Isooka, N.; Wada, K.; Kikuoka, R.; Kitamura, Y.; Asanuma, M. Effects of enteric environmental modification by coffee components on neurodegeneration in rotenone-treated mice. Cells 2019, 8, 221. [CrossRef]

322. Singh, S.S.; Rai, S.N.; Birla, H.; Zahra, W.; Rathore, A.S.; Dilnashin, H.; Singh, R.; Singh, S.P. Neuroprotective effect of chlorogenic acid on mitochondrial dysfunction-mediated apoptotic death of DA neurons in a Parkinsonian mouse model. Oxid. Med. Cell Longev. 2020, 2020, 6571484. [CrossRef] [PubMed]

323. Shen, W.; Qi, R.; Zhang, J.; Wang, Z.; Wang, H.; Hu, C.; Zhao, Y.; Bie, M.; Wang, Y.; Fu, Y.; et al. Chlorogenic acid inhibits LPS-induced microglial activation and improves survival of dopaminergic neurons. Brain Res. Bull. 2012, 88, 487-494. [CrossRef]

324. Tu, Q.; Tang, X.; Hu, Z. Chlorogenic acid protection of neuronal nitric oxide synthase-positive neurons in the hippocampus of mice with impaired learning and memory. Neural Regen. Res. 2008, 3, 1218-1221.

325. Aseervatham, G.S.; Suryakala, U.; Sundaram, S.; Bose, P.C.; Sivasudha, T. Expression pattern of NMDA receptors reveals antiepileptic potential of apigenin 8-C-glucoside and chlorogenic acid in pilocarpine induced epileptic mice. Biomed. Pharmacother. 2016, 82, 54-64. [CrossRef] [PubMed]

326. Ishida, K.; Yamamoto, M.; Misawa, K.; Nishimura, H.; Misawa, K.; Ota, N.; Shimotoyodome, A. Coffee polyphenols prevent cognitive dysfunction and suppress amyloid $\beta$ plaques in APP/PS2 transgenic mouse. Neurosci. Res. 2020, 154, 35-44. [CrossRef]

327. Cropley, V.; Croft, R.; Silber, B.; Neale, C.; Scholey, A.; Stough, C.; Schmitt, J. Does coffee enriched with chlorogenic acids improve mood and cognition after acute administration in healthy elderly? A pilot study. Psychopharmacology 2012, 219, 737-749. [CrossRef]

328. Camfield, D.A.; Silber, B.Y.; Scholey, A.B.; Nolidin, K.; Goh, A.; Stough, C. A randomised placebo-controlled trial to differentiate the acute cognitive and mood effects of chlorogenic acid from decaffeinated coffee. PLoS ONE 2013, 8, e82897. [CrossRef]

329. Ochiai, R.; Saitou, K.; Suzukamo, C.; Osaki, N.; Asada, T. Effect of chlorogenic acids on cognitive function in mild cognitive impairment: A randomized controlled crossover trial. J. Alzheimers Dis. 2019, 72, 1209-1216. [CrossRef] [PubMed]

330. Saitou, K.; Ochiai, R.; Kozuma, K.; Sato, H.; Koikeda, T.; Osaki, N.; Katsuragi, Y. Effect of chlorogenic acids on cognitive function: A randomized, double-blind, placebo-controlled trial. Nutrients 2018, 10, 1337. [CrossRef] [PubMed]

331. Kato, M.; Ochiai, R.; Kozuma, K.; Sato, H.; Katsuragi, Y. Effect of chlorogenic acid intake on cognitive function in the elderly: A pilot study. Evid. Based Complementary Altern. Med. 2018, 2018, 8608497. [CrossRef] [PubMed]

332. Habtemariam, S. Protective effects of caffeic acid and the Alzheimer's brain: An update. Mini Rev. Med. Chem 2017, 17, 667-674. [CrossRef] [PubMed]

333. Sato, Y.; Itagaki, S.; Kurokawa, T.; Ogura, J.; Kobayashi, M.; Hirano, T.; Sugawara, M.; Iseki, K. In vitro and in vivo antioxidant properties of chlorogenic acid and caffeic acid. Int. J. Pharm. 2011, 403, 136-138. [CrossRef]

334. Espíndola, K.M.M.; Ferreira, R.G.; Narvaez, L.E.M.; Silva Rosario, A.C.R.; da Silva, A.H.M.; Silva, A.G.B.; Vieira, A.P.O.; Monteiro, M.C. Chemical and pharmacological aspects of caffeic acid and its activity in hepatocarcinoma. Front. Oncol. 2019, 9, 541. [CrossRef]

335. Pereira, P.; de Oliveira, P.A.; Ardenghi, P.; Rotta, L.; Henriques, J.A.; Picada, J.N. Neuropharmacological analysis of caffeic acid in rats. Basic Clin. Pharmacol. Toxicol. 2006, 99, 374-378. [CrossRef]

336. Silva, T.; Oliveira, C.; Borges, F. Caffeic acid derivatives, analogs and applications: A patent review (2009-2013). Expert Opin. Ther. Pat. 2014, 24, 1257-1270. [CrossRef] 
337. Im, S.E.; Yoon, H.; Nam, T.G.; Heo, H.J.; Lee, C.Y.; Kim, D.O. Antineurodegenerative effect of phenolic extracts and caffeic acid derivatives in romaine lettuce on neuron-like PC-12 cells. J. Med. Food 2010, 13, 779-784. [CrossRef]

338. Jeong, C.H.; Jeong, H.R.; Choi, G.N.; Kim, D.O.; Lee, U.; Heo, H.J. Neuroprotective and anti-oxidant effects of caffeic acid isolated from Erigeron annuus leaf. Chin. Med. 2011, 6, 1-9. [CrossRef]

339. Pavlica, S.; Gebhardt, R. Protective effects of ellagic and chlorogenic acids against oxidative stress in PC12 cells. Free Radic Res. 2005, 39, 1377-1390. [CrossRef] [PubMed]

340. Omar, S.H.; Kerr, P.G.; Scott, C.J.; Hamlin, A.S.; Obied, H.K. Olive (Olea europaea L.) Biophenols: A nutriceutical against oxidative stress in SH-SY5Y cells. Molecules 2017, 22, 1858. [CrossRef] [PubMed]

341. Kim, S.R.; Kim, Y.C. Neuroprotective phenylpropanoid esters of rhamnose isolated from roots of Scrophularia buergeriana Phytochemistry 2000, 54, 503-509. [CrossRef]

342. Koo, K.A.; Kim, S.H.; Oh, T.H.; Kim, Y.C. Acteoside and its aglycones protect primary cultures of rat cortical cells from glutamate-induced excitotoxicity. Life Sci. 2006, 79, 709-716. [CrossRef] [PubMed]

343. Song, Y.; Wei, E.Q.; Zhang, W.P.; Ge, Q.F.; Liu, J.R.; Wang, M.L.; Huang, X.J.; Hu, X.; Chen, Z. Minocycline protects PC12 cells against NMDA-induced injury via inhibiting 5-lipoxygenase activation. Brain Res. 2006, 1085, 57-67. [CrossRef]

344. Colín-González, A.L.; Sánchez-Hernández, S.; De Lima, M.E.; Ali, S.F.; Chavarría, A.; Villeda, J.; Santamaría, A. Protective effects of caffeic acid on quinolinic acid-induced behavioral and oxidative alterations in rats. J. Drug Alcohol Res. 2015, 4, 1-5. [CrossRef]

345. Izuta, H.; Shimazawa, M.; Tazawa, S.; Araki, Y.; Mishima, S.; Hara, H. Protective effects of Chinese propolis and its component, chrysin, against neuronal cell death via inhibition of mitochondrial apoptosis pathway in SH-SY5Y cells. J. Agric. Food Chem. 2008, 56, 8944-8953. [CrossRef]

346. Huang, Y.; Jin, M.; Pi, R.; Zhang, J.; Chen, M.; Ouyang, Y.; Liu, A.; Chao, X.; Liu, P.; Liu, J.; et al. Protective effects of caffeic acid and caffeic acid phenethyl ester against acrolein-induced neurotoxicity in HT22 mouse hippocampal cells. Neurosci. Lett. 2013, 535, 146-151. [CrossRef]

347. Omar, S.H.; Scott, C.J.; Hamlin, A.S.; Obied, H.K. Biophenols: Enzymes ( $\beta$-secretase, Cholinesterases, histone deacetylase and tyrosinase) inhibitors from olive (Olea europaea L.). Fitoterapia 2018, 128, 118-129. [CrossRef]

348. Sul, D.; Kim, H.S.; Lee, D.; Joo, S.S.; Hwang, K.W.; Park, S.Y. Protective effect of caffeic acid against beta-amyloid-induced neurotoxicity by the inhibition of calcium influx and tau phosphorylation. Life Sci. 2009, 84, 257-262. [CrossRef]

349. Yang, J.Q.; Zhou, Q.X.; Liu, B.Z.; He, B.C. Protection of mouse brain from aluminum-induced damage by caffeic acid. CNS Neurosci. Ther. 2008, 14, 10-16. [CrossRef]

350. Khan, K.A.; Kumar, N.; Nayak, P.G.; Nampoothiri, M.; Shenoy, R.R.; Krishnadas, N.; Rao, C.M.; Mudgal, J. Impact of caffeic acid on aluminium chloride-induced dementia in rats. J. Pharm. Pharmacol. 2013, 65, 1745-1752. [CrossRef] [PubMed]

351. Deshmukh, R.; Kaundal, M.; Bansal, V. Samardeep, Caffeic acid attenuates oxidative stress, learning and memory deficit in intra-cerebroventricular streptozotocin induced experimental dementia in rats. Biomed. Pharmacother. 2016, 81, 56-62. [CrossRef] [PubMed]

352. Wang, Y.; Wang, Y.; Li, J.; Hua, L.; Han, B.; Zhang, Y.; Yang, X.; Zeng, Z.; Bai, H.; Yin, H.; et al. Effects of caffeic acid on learning deficits in a model of Alzheimer's disease. Int. J. Mol. Med. 2016, 38, 869-875. [CrossRef] [PubMed]

353. Anwar, J.; Spanevello, R.M.; Thomé, G.; Stefanello, N.; Schmatz, R.; Gutierres, J.; Vieira, J.; Baldissarelli, J.; Carvalho, F.B.; da Rosa, M.M.; et al. Effects of caffeic acid on behavioral parameters and on the activity of acetylcholinesterase in different tissues from adult rats. Pharmacol. Biochem. Behav. 2012, 103, 386-394. [CrossRef] [PubMed]

354. Akomolafe, S.F.; Akinyemi, A.J.; Ogunsuyi, O.B.; Oyeleye, S.I.; Oboh, G.; Adeoyo, O.O.; Allismith, Y.R. Effect of caffeine, caffeic acid and their various combinations on enzymes of cholinergic, monoaminergic and purinergic systems critical to neurodegeneration in rat brain-In vitro. Neurotoxicology 2017, 62, 6-13. [CrossRef]

355. Dos Santos Sales, Í.M.; do Nascimento, K.G.; Feitosa, C.M.; Saldanha, G.B.; Feng, D.; de Freitas, R.M. Caffeic acid effects on oxidative stress in rat hippocampus after pilocarpine-induced seizures. Neurol. Sci. 2011, 32, 375-380. [CrossRef] [PubMed]

356. Kalonia, H.; Kumar, P.; Kumar, A.; Nehru, B. Effects of caffeic acid, rofecoxib, and their combination against quinolinic acidinduced behavioral alterations and disruption in glutathione redox status. Neurosci. Bull. 2009, 25, 343-352. [CrossRef]

357. Uz, T.; Pesold, C.; Longone, P.; Manev, H. Aging-associated up-regulation of neuronal 5-lipoxygenase expression: Putative role in neuronal vulnerability. FASEB J. 1998, 12, 439-449. [CrossRef]

358. Coelho, V.R.; Vieira, C.G.; de Souza, L.P.; da Silva, L.L.; Pflüger, P.; Regner, G.G.; Papke, D.K.; Picada, J.N.; Pereira, P. Behavioral and genotoxic evaluation of rosmarinic and caffeic acid in acute seizure models induced by pentylenetetrazole and pilocarpine in mice. Naunyn Schmiedebergs Arch. Pharmacol. 2016, 389, 1195-1203. [CrossRef]

359. Coelho, V.R.; Vieira, C.G.; de Souza, L.P.; Moysés, F.; Basso, C.; Papke, D.K.; Pires, T.R.; Siqueira, I.R.; Picada, J.N.; Pereira, P. Antiepileptogenic, antioxidant and genotoxic evaluation of rosmarinic acid and its metabolite caffeic acid in mice. Life Sci. 2015, 122, 65-71. [CrossRef] [PubMed]

360. Kim, I.H.; Yan, B.C.; Park, J.H.; Yeun, G.H.; Yim, Y.; Ahn, J.H.; Lee, J.C.; Hwang, I.K.; Cho, J.H.; Kim, Y.M.; et al. Neuroprotection of a novel synthetic caffeic acid-syringic acid hybrid compound against experimentally induced transient cerebral ischemic damage. Planta Med. 2013, 79, 313-321. [CrossRef] [PubMed]

361. Pinheiro Fernandes, F.D.; Fontenele Menezes, A.P.; de Sousa Neves, J.C.; Fonteles, A.A.; da Silva, A.T.; de Araújo Rodrigues, P.; Santos do Carmo, M.R.; de Souza, C.M.; de Andrade, G.M. Caffeic acid protects mice from memory deficits induced by focal cerebral ischemia. Behav. Pharmacol. 2014, 25, 637-647. [CrossRef] [PubMed] 
362. Song, Y.; Bei, Y.; Xiao, Y.; Tong, H.D.; Wu, X.Q.; Chen, M.T. Edaravone, a free radical scavenger, protects neuronal cells' mitochondria from ischemia by inactivating another new critical factor of the 5-lipoxygenase pathway affecting the arachidonic acid metabolism. Brain Res. 2018, 1690, 96-104. [CrossRef]

363. Zhou, Y.; Fang, S.H.; Ye, Y.L.; Chu, L.S.; Zhang, W.P.; Wang, M.L.; Wei, E.Q. Caffeic acid ameliorates early and delayed brain injuries after focal cerebral ischemia in rats. Acta Pharmacol. Sin. 2006, 27, 1103-1110. [CrossRef]

364. Liang, G.; Shi, B.; Luo, W.; Yang, J. The protective effect of caffeic acid on global cerebral ischemia-reperfusion injury in rats. Behav. Brain Funct. 2015, 11, 18. [CrossRef]

365. Zhang, L.; Zhang, W.P.; Chen, K.D.; Qian, X.D.; Fang, S.H.; Wei, E.Q. Caffeic acid attenuates neuronal damage, astrogliosis and glial scar formation in mouse brain with cryoinjury. Life Sci. 2007, 80, 530-537. [CrossRef]

366. Vauzour, D.; Corona, G.; Spencer, J.P. Caffeic acid, tyrosol and p-coumaric acid are potent inhibitors of 5-S-cysteinyl-dopamine induced neurotoxicity. Arch. Biochem. Biophys. 2010, 501, 106-111. [CrossRef]

367. Li, Z.; Choi, D.Y.; Shin, E.J.; Hunter, R.L.; Jin, C.H.; Wie, M.B.; Kim, M.S.; Park, S.J.; Bing, G.; Kim, H.C. Phenidone protects the nigral dopaminergic neurons from LPS-induced neurotoxicity. Neurosci. Lett. 2008, 445, 1-6. [CrossRef]

368. Jimenez-Del-Rio, M.; Guzman-Martinez, C.; Velez-Pardo, C. The effects of polyphenols on survival and locomotor activity in Drosophila melanogaster exposed to iron and paraquat. Neurochem. Res. 2010, 35, 227-238. [CrossRef]

369. Dos Santos Nunes, R.G.; Pereira, P.S.; Elekofehinti, O.O.; Fidelis, K.R.; da Silva, C.S.; Ibrahim, M.; Barros, L.M.; da Cunha, F.A.B.; Lukong, K.E.; de Menezes, I.R.A.; et al. Possible involvement of transcriptional activation of nuclear factor erythroid 2-related factor 2 (Nrf2) in the protective effect of caffeic acid on paraquat-induced oxidative damage in Drosophila melanogaster. Pestic Biochem. Physiol. 2019, 157, 161-168. [CrossRef]

370. Tsai, S.J.; Chao, C.Y.; Yin, M.C. Preventive and therapeutic effects of caffeic acid against inflammatory injury in striatum of MPTP-treated mice. Eur. J. Pharmacol. 2011, 670, 441-447. [CrossRef] [PubMed]

371. Zhang, Y.; Wu, Q.; Zhang, L.; Wang, Q.; Yang, Z.; Liu, J.; Feng, L. Caffeic acid reduces A53T $\alpha$-synuclein by activating JNK/Bcl2-mediated autophagy in vitro and improves behaviour and protects dopaminergic neurons in a mouse model of Parkinson's disease. Pharmacol. Res. 2019, 150, 104538. [CrossRef]

372. Colonnello, A.; Aguilera-Portillo, G.; Rubio-López, L.C.; Robles-Bañuelos, B.; Rangel-López, E.; Cortez-Núñez, S.; Evaristo-Priego, Y.; Silva-Palacios, A.; Galván-Arzate, S.; García-Contreras, R.; et al. Comparing the neuroprotective effects of caffeic acid in rat cortical slices and Caenorhabditis elegans: Involvement of Nrf2 and SKN-1 signaling pathways. Neurotox. Res. 2020, 37, 326-337. [CrossRef] [PubMed]

373. Wei, X.; Ma, Z.; Fontanilla, C.V.; Zhao, L.; Xu, Z.C.; Taggliabraci, V.; Johnstone, B.H.; Dodel, R.C.; Farlow, M.R.; Du, Y. Caffeic acid phenethyl ester prevents cerebellar granule neurons (CGNs) against glutamate-induced neurotoxicity. Neuroscience 2008, 155, 1098-1105. [CrossRef] [PubMed]

374. Scapagnini, G.; Vasto, S.; Abraham, N.G.; Caruso, C.; Zella, D.; Fabio, G. Modulation of Nrf2/ARE pathway by food polyphenols: A nutritional neuroprotective strategy for cognitive and neurodegenerative disorders. Mol. Neurobiol. 2011, 44, 192-201. [CrossRef]

375. Alexandrov, P.N.; Dua, P.; Hill, J.M.; Bhattacharjee, S.; Zhao, Y.; Lukiw, W.J. microRNA (miRNA) speciation in Alzheimer's disease (AD) cerebrospinal fluid (CSF) and extracellular fluid (ECF). Int. J. Biochem. Mol. Biol. 2012, 3, 365-373.

376. Morroni, F.; Sita, G.; Graziosi, A.; Turrini, E.; Fimognari, C.; Tarozzi, A.; Hrelia, P. Neuroprotective effect of caffeic acid phenethyl ester in a mouse model of Alzheimer's disease involves Nrf2/HO-1 pathway. Aging Dis. 2018, 9, 605-622. [CrossRef]

377. Dos Santos, N.A.; Martins, N.M.; Silva Rde, B.; Ferreira, R.S.; Sisti, F.M.; dos Santos, A.C. Caffeic acid phenethyl ester (CAPE) protects PC12 cells from MPP+ toxicity by inducing the expression of neuron-typical proteins. Neurotoxicology 2014, 45, 131-138. [CrossRef]

378. Fontanilla, C.V.; Ma, Z.; Wei, X.; Klotsche, J.; Zhao, L.; Wisniowski, P.; Dodel, R.C.; Farlow, M.R.; Oertel, W.H.; Du, Y. Caffeic acid phenethyl ester prevents 1-methyl-4-phenyl-1,2,3,6-tetrahydropyridine-induced neurodegeneration. Neuroscience 2011, 188, 135-141. [CrossRef]

379. Noelker, C.; Bacher, M.; Gocke, P.; Wei, X.; Klockgether, T.; Du, Y.; Dodel, R. The flavanoide caffeic acid phenethyl ester blocks 6-hydroxydopamine-induced neurotoxicity. Neurosci. Lett. 2005, 383, 39-43. [CrossRef] [PubMed]

380. Turan, D.; Abdik, H.; Sahin, F.; Avşar Abdik, E. Evaluation of the neuroprotective potential of caffeic acid phenethyl ester in a cellular model of Parkinson's disease. Eur. J. Pharmacol. 2020, 883, 173342. [CrossRef] [PubMed]

381. Kurauchi, Y.; Hisatsune, A.; Isohama, Y.; Mishima, S.; Katsuki, H. Caffeic acid phenethyl ester protects nigral dopaminergic neurons via dual mechanisms involving haem oxygenase-1 and brain-derived neurotrophic factor. Br. J. Pharmacol. 2012, 166, 1151-1168. [CrossRef]

382. Silva, R.B.; Santos, N.A.; Martins, N.M.; Ferreira, D.A.; Barbosa, F., Jr.; Oliveira Souza, V.C.; Kinoshita, A.; Baffa, O.; Del-Bel, E.; Santos, A.C. Caffeic acid phenethyl ester protects against the dopaminergic neuronal loss induced by 6-hydroxydopamine in rats. Neuroscience 2013, 233, 86-94. [CrossRef] [PubMed]

383. Tsai, S.K.; Lin, M.J.; Liao, P.H.; Yang, C.Y.; Lin, S.M.; Liu, S.M.; Lin, R.H.; Chih, C.L.; Huang, S.S. Caffeic acid phenethyl ester ameliorates cerebral infarction in rats subjected to focal cerebral ischemia. Life Sci. 2006, 78, 2758-2762. [CrossRef]

384. Hwang, S.A.; Kim, C.D.; Lee, W.S. Caffeic acid phenethyl ester protects against photothrombotic cortical ischemic injury in mice. Korean J. Physiol. Pharmacol. 2018, 22, 101-110. [CrossRef] 
385. Khan, M.; Elango, C.; Ansari, M.A.; Singh, I.; Singh, A.K. Caffeic acid phenethyl ester reduces neurovascular inflammation and protects rat brain following transient focal cerebral ischemia. J. Neurochem. 2007, 102, 365-377. [CrossRef]

386. Palaz, M.N.; Akcay, E. The impact of propolis factor caffeic acid phenethyl-ester on the cerebral vasospasm and early brain damage in the experimentally induced subarachnoid hemorrhage on rats. World Neurosurg. 2020, 138, e736-e742. [CrossRef]

387. Kumar, M.; Kaur, D.; Bansal, N. Caffeic Acid Phenethyl Ester (CAPE) Prevents development of STZ-ICV induced dementia in rats. Pharmacogn. Mag. 2017, 13 (Suppl. 1), S10-S15.

388. Fu, W.; Wang, H.; Ren, X.; Yu, H.; Lei, Y.; Chen, Q. Neuroprotective effect of three caffeic acid derivatives via ameliorate oxidative stress and enhance PKA/CREB signaling pathway. Behav. Brain Res. 2017, 328, 81-86. [CrossRef]

389. Hao, R.; Song, X.; Li, F.; Tan, X.; Sun-Waterhouse, D.; Li, D. Caffeic acid phenethyl ester reversed cadmium-induced cell death in hippocampus and cortex and subsequent cognitive disorders in mice: Involvements of AMPK/SIRT1 pathway and amyloid-tau-neuroinflammation axis. Food Chem. Toxicol. 2020, 144, 111636. [CrossRef] [PubMed]

390. Mohamadi, N.; Sharififar, F.; Pournamdari, M.; Ansari, M. A review on biosynthesis, analytical techniques, and pharmacological activities of trigonelline as a plant alkaloid. J. Diet. Suppl. 2018, 15, 207-222. [CrossRef]

391. Qiu, Z.; Wang, K.; Jiang, C.; Su, Y.; Fan, X.; Li, J.; Xue, S.; Yao, L. Trigonelline protects hippocampal neurons from oxygen-glucose deprivation-induced injury through activating the PI3K/Akt pathway. Chem. Biol. Interact. 2020, 317, 108946. [CrossRef]

392. Makowska, J.; Szczesny, D.; Lichucka, A.; Giełdoń, A.; Chmurzyński, L.; Kaliszan, R. Preliminary studies on trigonelline as potential anti-Alzheimer disease agent: Determination by hydrophilic interaction liquid chromatography and modeling of interactions with beta-amyloid. J. Chromatogr. B Analyt. Technol. Biomed. Life Sci. 2014, 968, 101-104. [CrossRef]

393. Tohda, C.; Kuboyama, T.; Komatsu, K. Search for natural products related to regeneration of the neuronal network. Neurosignals 2005, 14, 34-45. [CrossRef] [PubMed]

394. Fahanik-Babaei, J.; Baluchnejadmojarad, T.; Nikbakht, F.; Roghani, M. Trigonelline protects hippocampus against intracerebral $\mathrm{A} \beta(1-40)$ as a model of Alzheimer's disease in the rat: Insights into underlying mechanisms. Metab. Brain Dis. 2019, 34, 191-201. [CrossRef] [PubMed]

395. Chowdhury, A.A.; Gawali, N.B.; Munshi, R.; Juvekar, A.R. Trigonelline insulates against oxidative stress, proinflammatory cytokines and restores BDNF levels in lipopolysaccharide induced cognitive impairment in adult mice. Metab. Brain Dis. 2018, 33, 681-691. [CrossRef] [PubMed]

396. Khalili, M.; Alavi, M.; Esmaeil-Jamaat, E.; Baluchnejadmojarad, T.; Roghani, M. Trigonelline mitigates lipopolysaccharide-induced learning and memory impairment in the rat due to its anti-oxidative and anti-inflammatory effect. Int. Immunopharmacol. 2018, 61, 355-362. [CrossRef] [PubMed]

397. Chowdhury, A.A.; Gawali, N.B.; Bulani, V.D.; Kothavade, P.S.; Mestry, S.N.; Deshpande, P.S.; Juvekar, A.R. In vitro antiglycating effect and in vivo neuroprotective activity of Trigonelline in d-galactose induced cognitive impairment. Pharmacol. Rep. 2018, 70, 372-377. [CrossRef] [PubMed]

398. Mirzaie, M.; Khalili, M.; Kiasalari, Z.; Roghani, M. Neuroprotective and antiapoptotic potential of trigonelline in a striatal 6-hydroxydopamine rat model of parkinson's disease. Neurophysiology 2016, 48, 176-183. [CrossRef]

399. Gaur, V.; Bodhankar, S.L.; Mohan, V.; Thakurdesai, P.A. Neurobehavioral assessment of hydroalcoholic extract of Trigonella foenum-graecum seeds in rodent models of Parkinson's disease. Pharm. Biol. 2013, 51, 550-557. [CrossRef] [PubMed]

400. Pravalika, K.; Sarmah, D.; Kaur, H.; Vats, K.; Saraf, J.; Wanve, M.; Kalia, K.; Borah, A.; Yavagal, D.R.; Dave, K.R.; et al. Trigonelline therapy confers neuroprotection by reduced glutathione mediated myeloperoxidase expression in animal model of ischemic stroke. Life Sci. 2019, 216, 49-58. [CrossRef] [PubMed]

401. Anjomshoa, M.; Boroujeni, S.N.; Bagheri, E.; Lorigooini, Z.; Amini-Khoei, H. Possible involvement of N-methyl-D-aspartate receptor (NMDA-R) in the antidepressant-like effect of trigonelline in male mice. Curr. Pharm. Des. 2020, 26, 5067-5071. [CrossRef]

402. Kolb, H.; Kempf, K.; Martin, S. Health effects of coffee: Mechanism unraveled? Nutrients 2020, 12, 1842. [CrossRef] [PubMed]

403. Paur, I.; Balstad, T.R.; Blomhoff, R. Degree of roasting is the main determinant of the effects of coffee on NF-kappaB and EpRE. Free Radic. Biol. Med. 2010, 48, 1218-1227. [CrossRef] [PubMed]

404. Boettler, U.; Sommerfeld, K.; Volz, N.; Pahlke, G.; Teller, N.; Somoza, V.; Lang, R.; Hofmann, T.; Marko, D. Coffee constituents as modulators of Nrf2 nuclear translocation and ARE (EpRE)-dependent gene expression. J. Nutr. Biochem. 2011, 22, 426-440. [CrossRef]

405. Farias-Pereira, R.; Park, C.S.; Park, Y. Mechanisms of action of coffee bioactive components on lipid metabolism. Food Sci. Biotechnol. 2019, 28, 1287-1296. [CrossRef]

406. Ren, Y.; Wang, C.; Xu, J.; Wang, S. Cafestol and kahweol: A review on their bioactivities and pharmacological properties. Int. J. Mol. Sci. 2019, 20, 4238. [CrossRef]

407. De Oliveira, M.R.; de Souza, I.C.C.; Fürstenau, C.R. Mitochondrial protection promoted by the coffee diterpene kahweol in methylglyoxal-treated human neuroblastoma SH-SY5Y cells. Neurotox. Res. 2020, 37, 100-110. [CrossRef]

408. Lee, K.J.; Jeong, H.G. Protective effects of kahweol and cafestol against hydrogen peroxide-induced oxidative stress and DNA damage. Toxicol. Lett. 2007, 173, 80-87. [CrossRef]

409. Hwang, Y.P.; Jeong, H.G. The coffee diterpene kahweol induces heme oxygenase-1 via the PI3K and p38/Nrf2 pathway to protect human dopaminergic neurons from 6-hydroxydopamine-derived oxidative stress. FEBS Lett. 2008, 582, 2655-2662. [CrossRef] [PubMed] 
410. Fürstenau, C.R.; de Souza, I.C.C.; de Oliveira, M.R. The effects of kahweol, a diterpene present in coffee, on the mitochondria of the human neuroblastoma SH-SY5Y cells exposed to hydrogen peroxide. Toxicol. In Vitro 2019, 61, 104601. [CrossRef] [PubMed]

411. Lee, H.F.; Lin, J.S.; Chang, C.F. Acute kahweol treatment attenuates traumatic brain injury neuroinflammation and functional deficits. Nutrients 2019, 11, 2301. [CrossRef] [PubMed]

412. Esopenko, C.; Levine, B. Aging, neurodegenerative disease, and traumatic brain injury: The role of neuroimaging. J. Neurotrauma 2015, 32, 209-220. [CrossRef] [PubMed]

413. Trinh, K.; Andrews, L.; Krause, J.; Hanak, T.; Lee, D.; Gelb, M.; Pallanck, L. Decaffeinated coffee and nicotine-free tobacco provide neuroprotection in Drosophila models of Parkinson's disease through an NRF2-dependent mechanism. J. Neurosci. 2010, 30, 5525-5532. [CrossRef] 